\title{
MARKETING COMMUNICATION AND AUTOMATIC CONSUMER RESPONSES A CONTEXT DEPENDENCY PERSPECTIVE
}

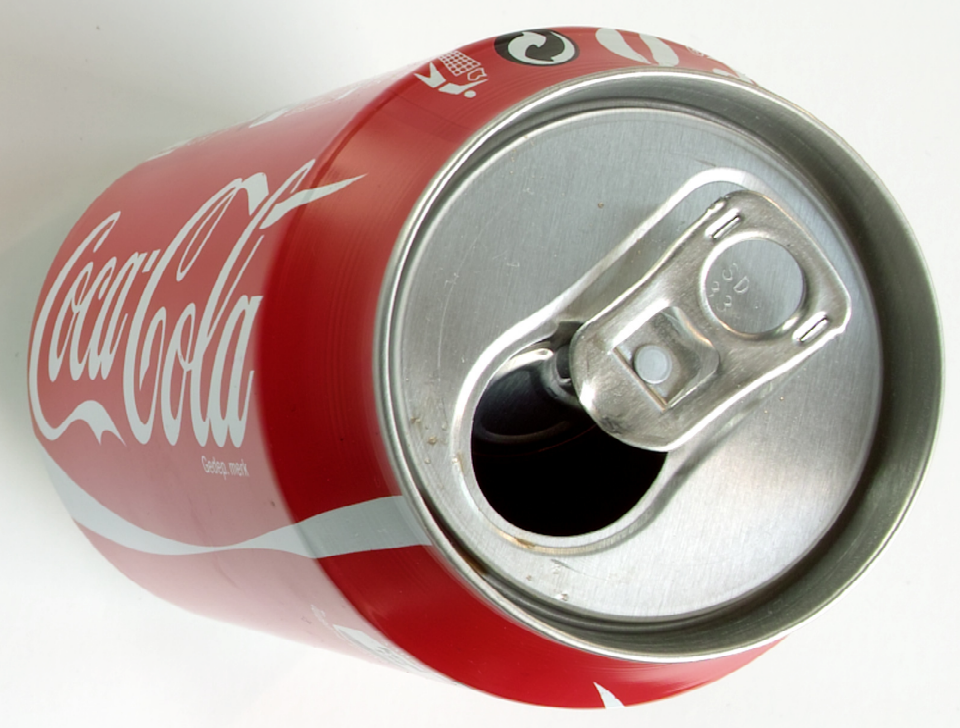

MARIEKE L. FRANSEN 
Marketing Communication and Automatic Consumer Responses:

A Context Dependency Perspective

Marieke L. Fransen 
Thesis, University of Twente, 2008

(C) Marieke L. Fransen

ISBN: 978-90-365-2741-5

Cover design: Maarten Janssen

Printed by: Print Partners Ipskamp, Enschede 


\title{
MARKETING COMMUNICATION AND AUTOMATIC CONSUMER RESPONSES:
}

\section{A CONTEXT DEPENDENCY PERSPECTIVE}

\section{PROEFSCHRIFT}

\author{
ter verkrijging van \\ de graad van doctor aan de Universiteit Twente, \\ op gezag van de rector magnificus, \\ prof.dr. W.H.M. Zijm, \\ volgens besluit van het College voor Promoties \\ in het openbaar te verdedigen \\ op vrijdag 19 december 2008 om 16.45 uur
}

door

Maria Leonora Fransen

geboren op 7 november 1977

te Helmond 
Dit proefschrift is goedgekeurd door de promotor: Prof. dr. A.Th.H. Pruyn en de assistent-promotor: dr. B.M. Fennis 


\section{Samenstelling promotiecommissie}

Promotor:

Assistent-promotor:

Leden:
Prof. dr. A.Th.H. Pruyn

Dr. B.M. Fennis

Prof. dr. P.A.E. Brey

Prof. dr. A. Dijksterhuis

Prof. dr. A. Florack

Prof. dr. P.C. Neijens

Prof. dr. W. van Rossum

Prof. dr. E.R. Seydel 


\section{Contents}

$\begin{array}{lll}\text { Chapter } 1 \text { General Introduction } & 9\end{array}$

Chapter 2 Brands and Automatic Goal Pursuit:

The Effects of Marketing-Induced Mortality Salience on Consumer Responses

Chapter 3 Matching Brand Communication Modalities:

The Effects of Marketing-Induced Congruency

on Consumer Responses

Chapter 4 Message Framing and Consumer Goals:

The Effects of Marketing-Induced Regulatory Fit on Consumer Responses

Chapter 5 General Discussion

References

Summary in Dutch (samenvatting) 

Chapter 1: General Introduction 
In modern society, it is hard to imagine life without the ubiquitous presence of marketing communications. We are surrounded by brands, advertisements, and persuasive messages almost everywhere. Daily activities such as opening our newspaper, traveling to work, reading our email, relaxing at the movies, or waiting for a bus are inextricably connected with the exposure to all kinds of marketing creations. Whether we like it or not, exposure to brands, slogans, and advertisements (i.e., marketing communications) seems inevitable. But how do these daily encounters with marketing communications affect us? Do they influence our consumer attitudes and decisions? When people are asked whether they think their daily consumer decisions are affected by exposure to marketing communications, most of them respond with a heartfelt 'no'. Although people recognize that others may be affected by external marketing communications, they generally believe that their own consumer decisions and behavior are not affected by the presence of brands and advertisements in their environment (Perloff, 1999; Wilson, Gilbert, \& Wheatley, 1998). However, most companies keep investing millions of dollars in advertising and brand management each year (Liedtke, 2007; Mulder, Poort, Marlet, \& Van Woerkens, 2006) assuming that they will eventually profit and increase sales by promoting their products and brands through marketing activities. Indeed, abundant research has shown that advertising is positively related to consumer responses such as brand recognition, brand likeability, and consumer behavior (Chandy, Tellis, Maclnnis, \& Thaivanich, 2001; see Vakratsas \& Ambler, 1999, for a review). This apparent contradiction seems to suggest that many effects of advertising and brand management are automatic and go unnoticed; consumers may simply not always be (consciously) aware of the influence that daily exposure to marketing communications might have on them.

The present dissertation aims to shed light on how consumer behavior can be automatically affected by marketing communications in the environment. It is suggested that a) marketing communications may, either solely or by interplay with consumer and situational contexts, elicit automatic goals or shape evaluation processes, which b) subsequently affect consumer attitudes, decisions, and behavior without the consumer being aware of this influence. Hence, it is argued and demonstrated that marketing communications can affect consumer responses by inducing automatic goal pursuit and affecting evaluation processes unconsciously. In light of this, we aim to address 1) the working of automaticity in the consumer behavior domain, 2) the role of marketing communications and their characteristics in unconscious consumer processes, and 3) the context dependent nature of marketing communication effects on automatic consumer responses.

In the remainder of this introductory chapter, we provide a brief overview of the evidence on the existence of unconscious behavior, including a description of research on automaticity both inside and outside the field of consumer behavior. Then, we will elaborate on the role of marketing communications in automatic consumer processes, which will be explored in the present dissertation. Finally, we will discuss how we tested our ideas by providing a brief overview of the empirical chapters. 


\section{AUTOMATIC BEHAVIOR}

Research on unconscious behavior is largely inspired by the principle of automatic construct activation. According to this principle, the subtle presence of environmental cues can influence construct accessibility (e.g., Bargh \& Pietromonaco, 1982; Higgins, Bargh, \& Lombardi, 1985; Macrae, Stangor, \& Milne, 1994; Wheeler \& Petty, 2001). The idea is that the perception of external stimuli directly causes mental activity, resulting in the activation of an internal representation of these outside stimuli. Hence, the activated constructs in our minds include representations of recently perceived objects, events, and people (Bargh \& Chartrand, 1999). For example, stereotypes of social groups are automatically activated upon the mere perception of group members' features (e.g., Bargh, 1994; 1999; Brewer, 1988; Devine, 1989). Moreover, Kay, Wheeler, Bargh, and Ross (2004) have shown that implicitly presented objects increased the cognitive accessibility of semantically related constructs.

Initial research on how unconsciously activated constructs subsequently affect behavior was based on the notion that perceptual inputs (i.e., environmental stimuli) are translated automatically into corresponding behavior because perceptual and mental representations are connected and display overlap. This process is referred to as the perception-behavior link; what we perceive is reflected in what we do. Bargh, Chen, and Burrows (1996) were the first to show evidence for the perception-behavior link by demonstrating that actual behavior may be affected by external features. They showed, for instance, that people walked slower after they were confronted (i.e., primed) with words associated with elderly people (e.g., grey, forgetful, and wrinkles). Likewise, Dijksterhuis and Van Knippenberg (1998) demonstrated that priming the stereotype of professors or the intelligence trait positively influenced performance on a general knowledge measure, while activating the stereotype of soccer hooligans or the stupidity trait negatively influenced performance. These findings have successfully been validated and extended by several researchers (e.g., Bargh \& Chartrand, 1999; Dijksterhuis \& Bargh, 2001; Macrae \& Johnston, 1998; Wheeler \& Petty, 2001). Marketing communications, such as brands, are found to have a mental network of associations stored in memory comparable to mental representations of, for instance, stereotypes. This makes it plausible that exposure to brands may result in similar automatic behavioral effects.

Research on the underlying mechanisms explaining how unconscious processes may affect behavior shows that there are two broad categories of these: 1) automatic goal pursuit and 2) automaticity in evaluations.

In the domain of automatic goal pursuit, it has been demonstrated that external stimuli can influence behavior by the activation of goals. According to the cognitive perspective, goals are mentally represented in the same way as traits, stereotypes, and schemas (Bargh, 1990). Goal-related behavior will be automatically triggered once the representation of a mental construct is activated. For example, Bargh, Gollwitzer, Lee-Chai, Barndollar, \& Trötschel (2001) found that priming participants with words related to high performance (e.g., succeed, strive, attain, achieve) 
unconsciously activated the goal to perform well. Participants in the high-performance-goal condition performed significantly better on a subsequent word-search task than participants in the control condition (for similar findings see Aarts \& Dijksterhuis, 2000; Chartrand \& Bargh, 1996; Fitzsimons \& Bargh 2003; Shah, 2003; Shah \& Kruglanski, 2003). Furthermore, Spencer, Fein, Wolfe, Fong, and Dunn (1998) revealed that an external threat to one's self-worth automatically activated the goal to restore self-esteem. In their study, they found that participants who received negative feedback about their abilities (the prime) subsequently denigrated others; denigrating others after criticism is a well-known strategy to restore self-esteem. Thus, external negative feedback unconsciously instigated the goal to restore self-esteem. Together, these studies suggest that goal pursuit can be automatically activated by external perceptual stimuli and can be guided without conscious awareness. Translating these findings to the consumer behavior domain, one could propose that exposure to marketing communications that for example, appeal to consumers' dreams, wishes, and goals may engender comparable goal pursuit strategies without consumers' awareness.

The second mechanism explaining unconscious processes is the principle of automaticity in evaluations, which has also been referred to as the perception-evaluation link (Bargh \& Chartrand, 1999). According to Zajonc (1980), we often evaluate stimuli as good or bad before we even consciously understand them; in other words, evaluations are generally activated automatically when perceiving an object, event, or person. People seem to unintentionally judge their experiences as either positive or negative instantly and without conscious awareness. This effect has been demonstrated in many studies (e.g., Bargh, Chaiken, Raymond, \& Hymes, 1996; Fazio, Sanbonmatsu, Powell, \& Kardes, 1986; Neely, 1977). These studies consistently show that people are faster in classifying a positive/negative word (e.g., beautiful/ugly) when it is preceded by an attitude object (e.g., soccer) that is evaluated as good/bad. Hence, when people unconsciously evaluate the attitude object (soccer) as 'good' it should facilitate the subsequent classification of the positive adjectives (i.e., faster response times) and slow down the classification of negative adjectives and vice versa for people who evaluate the attitude object (soccer) as 'bad'.

Moreover, research suggests that automatic processes that take place during the evaluation process often influence evaluations. Zajonc (1968) found, for example, that repeated exposure to a neutral stimulus increased liking of the stimulus. This even occurred when individuals were not aware of having been previously exposed to the concerning stimulus. Thus, repeated exposure seems to enhance evaluations. Recently, this has been explained by the concept of processing fluency, the experienced ease of processing or recalling information (e.g., Lee, 2001; Reber, Winkielman, \& Schwarz, 1998; Seamon, Brody, \& Kauff, 1983; Whittlesea, 1993; Winkielman, Schwarz, Fazeindro, \& Reber, 2003). Experiences of processing fluency are found to enhance evaluations because people misattribute the positive feelings of processing fluency to the stimulus at hand. Hence, people make an unconscious inference about the source of their experience. Likewise, studies on affective priming have revealed that subliminal exposure (i.e., perception below the threshold of conscious awareness) to happy faces increased liking of a subsequently presented stimulus and subliminal exposure to unhappy faces decreased liking of a subsequently presented stimulus. People 
apparently attributed their positive or negative feelings (induced by the happy and sad faces) automatically to the object they were evaluating afterwards (e.g., Murphy \& Zajonc, 1993; Murphy, Monahan \& Zajonc, 1995; Winkielman, Berridge, \& Wilbarger, 2005). Hence, evaluation processes seem to occur largely outside of conscious awareness, and may be affected by factors that are not recognized by the evaluator. Also in the consumer behavior field evaluation processes are of great relevance and it seems reasonable that, given their ubiquitous presence and associations, marketing communications may unconsciously affect consumer decisions through processes such as processing fluency and automatic misattribution.

These findings on automatic behavior support the notion that much of (social) behavior is guided by unconscious processes (see Bargh \& Chartrand, 1999). Moreover, the ability and resources to exercise conscious control were found to be rather limited (Baumeister, Bratslavsky, Muraven, \& Tice, 1998), and it has been argued that, even if people would want to, it is not always possible for them to base their decisions on conscious information processing strategies (e.g., Dijksterhuis, Smith, Van Baaren, \& Wigboldus, 2005). Given the frequent occurrence of automatic processes in decision making strategies and behavior, it would be interesting to further extend the research on automaticity to the domain of consumer research, which, so far, has mainly been focused on rational and conscious decision making (Simonson, 2005; Simonson, Carmon, Dhar, Drolet, \& Nowlis, 2001; Zaltman, 2000). As argued by Bargh (2002), the consumer behavior field seems a suitable context for further investigations into the automatic effects that relate to real-world situations and have consequences for actual decisions and behavior. Moreover, it seems difficult to obtain a complete understanding of consumers and their behavior without further examining the unconscious processes that pertain to the domain of consumer behavior. Hence, by focusing on automatic processes as they relate to the consumer behavior field, our aim is to add to the understanding of consumer behavior processes. In doing so, the present dissertation fits within the growing stream of research that has emphasized the cognitive and the so-called 'hot' topics in consumer behavior since the 90's (see Simonson, Carmon, Dhar, Drolet, \& Nowlis, 2001).

Above, we described two important processes in the domain of automaticity that may guide behavior, namely goal pursuit and evaluation processes. Both these processes have been found to play a profound role in examining and explaining consumer behavior. However, possible unconscious aspects that might be of significance have, to date, received little empirical attention in the consumer behavior field (Bargh, 2002). The next section will provide a short overview on how the processes of goal pursuit and evaluation are traditionally regarded in the domain of consumer behavior and how knowledge on automaticity could enlarge our understanding of these processes.

\section{GOAL PURSUIT AND EVALUATION PROCESSES IN CONSUMER BEHAVIOR}

As recognized in many studies, both consumer goal pursuit and consumer evaluation processes play an important role in consumer decision making. Goals are recognized as a key motivational construct shaping consumer decisions 
(e.g., Bagozzi \& Dholakia, 1999; Bettman, 1979; Bettman, Luce, \& Payne, 1998; Higgins, 2002). An important goal that is suggested as the primary drive for consumer decisions is to maximize utility (i.e., the goal to make beneficial decisions). From the rational economic choice approach, in particular, it has been argued that being accurate, and thereby being able to maximize benefits, is a fundamental goal for consumer decision making (e.g., Bettman, Luce, \& Payne, 1998; Deaton \& Muellbauer, 1980; Huber, Payne, \& Puto, 1982). As argued before, research in the area of consumer goal pursuit has mainly focused on the conscious aspects of goal-directed behavior (for an exception see Chartrand, Huber, Shiv, \& Tanner, 2008). Bagozzi and Dholakia (1999), for instance, provided a conceptual framework for considering the role of goal setting and goal striving in consumer behavior. However, this framework only incorporated the conscious factors of goal pursuit and disregarded the potential unconscious elements. This view of a rational and conscious consumer displays an overlap with a large part of the literature on consumer evaluation processes. Traditionally, models of consumer judgment and decision making assume that evaluations of a given product are based on product information that is present in memory or in the environment. It is hypothesized that people form judgments based on declarative information that is applicable to the target and comes to mind at the time of judgment (e.g., Higgins, 1996; Wyer \& Srull, 1989). Consumers are expected to consciously assign an expected value to every alternative option and to integrate all these (evaluative) aspects to arrive at an overall expected value (Von Neumann \& Morgenstern, 1947). Hence, consumers are assumed to engage in (more or less) conscious information processing before deciding to buy or choose a product (see also Chaiken, 1980; Petty, Cacioppo, \& Schumann, 1983).

Approaches on consumer goal pursuit and consumer evaluation processes have in common that they imply that consumers are active and conscious actors in the process of consumer decision making. In other words, the consumer is predominantly seen as a rational individual who makes sound decisions and thinks consciously about the pros and cons of any product before deciding to buy it. While there has been more attention given to aspects such as implicit memory and low involvement peripheral persuasion in recent years (see Simonson, Carmon, Dhar, Drolet, \& Nowlis, 2001), little attention has yet been paid to the automaticity that could play a role in consumer goal pursuit and consumer evaluation processes. It would be reasonable to assume that the previously discussed unconscious aspects of goal pursuit and evaluation processes may also apply to consumer evaluations, decisions, and behavior (Bargh, 2002).

Indeed, researchers have recently begun to investigate the possible influences of unconscious processes in the consumer behavior domain (see Bargh, 2002; Dijksterhuis, Aarts, Smith, 2005; Dijksterhuis, Smith, Van Baaren, \& Wigboldus, 2005). For example, Strahan, Spencer, and Zanna (2002) found that, among thirsty participants, priming the concept of 'thirst' resulted in a more favorable evaluation of a sports drink when it was accompanied by thirstquenching information than when it was accompanied by energy-restoring information. The idea is that priming the concept of 'thirst' automatically activated the goal to quench thirst, which made the thirst-quenching sports drink more attractive than the energy-restoring sports drink. Moreover, Berger and Fitzsimons (2008) found that products are 
evaluated more positively and are chosen more often when there are cues in the external environment that are conceptually or perceptually related to the product. They demonstrated, for instance, that participants who used an orange pen while filling in a survey were more likely to choose orange-related products (e.g., Fanta), and participants who used a green pen were more likely to choose green-related products (e.g., Sprite). In addition, a recent stream of research in the area of evaluation has argued that cognitive experiential information such as ease of recall or fluency of perception (e.g., Winkielman, Schwarz, Fazendeiro, \& Reber, 2003) can serve as a source of information in its own right. Next to consciously thinking about declarative information, thought processes have been hypothesized to be accompanied by cognitive experiences that unconsciously affect evaluation and decision making (for reviews see Schwarz, 2004; Schwarz \& Clore, 1996). These experiences have been found to be automatically (mis)attributed to the stimulus at hand (e.g., Lee, 2001; Seamon, Brody, \& Kauff, 1983; Winkielman, Schwarz, Fazendeiro, \& Reber, 2003; Reber, Meier, Ruch-Monachon, \& Tiberini, 2006; Whittlesea, 1993). Lee and Labroo (2004) demonstrated, for example, that people have a more positive attitude towards ketchup when they were previously exposed to mayonnaise (i.e., a closely related product) than when they were exposed to vitamins (an unrelated product). These results were explained by an attribution process of conceptual fluency. Taken together, these results offer initial empirical support for the role of automaticity in both consumer goal pursuit and consumer evaluation processes.

Moreover, when reviewing the literature on unconscious processes, it becomes apparent that most studies in this domain mainly focused on accidental environmental cues that may affect decisions and behavior. However, particularly in the domain of consumer behavior, it would be interesting to examine the role of planned marketing communications in automatic consumer responses. Are marketing communications capable of automatically influencing consumer responses? Furthermore, both the varying circumstances in which consumers might be exposed to marketing communications and the prevalence of individual differences between groups of consumers give rise to the question of whether and how these different contextual factors interact and affect unconscious consumer processes. Do marketing communications always evoke the same effects for all consumers, in all different contexts, at all times?

\section{MARKETING COMMUNICATION AND AUTOMATIC CONSUMER BEHAVIOR}

The previously described studies on unconsciousness have shown that accidental external cues can automatically influence consumer choices and preferences. However, it is unclear how marketing communications, specifically designed to influence consumer responses, can affect consumer behavior without the consumer (and maybe also the marketer) being aware of this influence. Traditionally, research on how advertising and other forms of marketing communications affect consumer decisions has primarily emphasized consumer information processing strategies. Inspired by dual information processing frameworks such as the Elaboration Likelihood Model (ELM; Petty \& Cacioppo, 1986) and the Heuristic Systematic Model (HSM; Chaiken \& Trope, 1999), much research on advertising effectiveness has focused on the conditions under which consumers engage in a specific mode of information 
processing. Although these models recognize that processing can be more or less effortful, they are both based on conscious information processing. Hence, it is assumed that consumers consciously process external marketing messages before deciding what to like, choose, or buy. Arguably, there are situations (e.g., when deciding to buy an important or expensive product) in which consumers indeed consciously weigh all available information. However, one could imagine that the processing, and the influence of marketing communications, is not always that conscious (see also Chen \& Chaiken, 1999).

The lack of attention to unconscious influences of marketing communications might be because consumer automaticity and unconscious advertising - the use of hidden, not consciously observable, messages - has a controversial history. The book 'The Hidden Persuaders' by Vance Packard (1957) and the claim of James Vicary that sales of popcorn and coca cola increased after cinema visitors were subliminally exposed to the slogans 'eat popcorn' and 'drink coca cola' - made the public very suspicious and fearful towards advertising. Even though Vicary afterwards admitted that he never found evidence for subliminal persuasion, the fear of subliminal advertising continued to exist. The concerns reached a climax when Key (1980) published his book 'The Clam-Plate Orgy: And Other Subliminals the Media Use to Manipulate Your Behavior', and posited that advertisers hide sexy figures and the word 'sex' in advertising images of ice cubes and food. Although the public feared unconscious advertising and both Key and Packard (see also Moore, 1982) warned about the dangerous effects of hidden messages in advertising, many scientific researchers were highly skeptical to the notion that subliminal messages affect our behavior (e.g., Hollender, 1986; Trappey, 1996; Vokey \& Read, 1985). Today, many consumers are still concerned about the possibility of being unconsciously influenced by marketing communications (Wilson \& Brekke, 1994; Wilson, Gilbert, \& Wheatley, 1998) and recent research implies that these concerns might not be groundless.

Indeed, a recent study by Fitzsimons, Chartrand, and Fitzsimons (2008) demonstrated initial evidence for brand priming. They found that participants were more creative after they were exposed to the brand 'Apple' than when they were exposed to the brand 'IBM'. These effects were explained by the notion that the brand 'Apple' is associated with the concepts of originality and creativity, resulting in behavior with the corresponding attributes. Although the measured outcome in this study (i.e., creative behavior) is not directly related to consumer behavior, it nicely demonstrates that marketing communications, such as brands, can instigate behavior without the actor being consciously aware of this influence. Moreover, Karremans and Stroebe (2006) found that subliminal exposure to the brand 'Lipton Ice' vs. a control brand increased the chance that thirsty participants opt for the brand 'Lipton Ice' above other brands when offered a drink. This suggests that consumer choices may depend on whether or not consumers are presented with the brand in a preceding situation.

The present dissertation will focus on unconscious processes in the consumer behavior domain by further exploring the role of marketing communications in automatic consumer responses. As stated before, most studies on automatic consumer behavior focused on the effects of accidental environmental cues (Simonson, 2005). Dijksterhuis, Smith, 
Van Baaren, \& Wigboldus (2005), for instance, used the example of a shopper automatically buying peanut butter because a young boy running trough the aisles reminded him of his little nephew who loves peanut butter. Accidentally seeing the young boy is supposed to unconsciously trigger the idea of purchasing peanut butter. Although these types of results make a substantial contribution to our understanding of automaticity in consumer decision processes, these effects seem rather incidental and are therefore hard to control and manage. Marketers cannot control the presence of other people and objects that unconsciously activate related constructs that subsequently influence consumer decisions. However, both marketers and consumers could benefit from disentangling the automaticity that is involved when confronted with marketing expressions. Integrating the unconscious aspects of marketing communications with the more established knowledge about conscious information processing would be profitable in supporting marketers in designing effective marketing strategies. On the other hand, consumers could use the information about automatic effects of marketing communications to guard themselves from buying expensive products or products that they actually do not need. Research has consistently shown that people are less vulnerable to automatic effects when they become aware of the actual source of their feelings and behavior (e.g., Higgins, 1998).

In sum, research has begun to explore unmanageable environmental factors that accidentally affect consumer evaluations and choices but the research to date has ignored the role of intentionally designed marketing strategies. The present dissertation aims to extend previous research on unconscious processes in the consumer behavior domain by investigating features of marketing communication stimuli as potential triggers of unconscious processes. In addition, we assess the extent to which the manifestation of unconscious effects of marketing communications is context dependent. It is argued that automatic processes can be evoked by the interplay between marketing communications and both situational and consumer contexts. Previous research has shown that the context in which advertisements are displayed affects appreciation and the effectiveness of the advertisement (e.g., Yi, 1990). It has been found, for example, that the emotional responses induced by a television program or commercial affected responses towards a subsequently presented advertisement (e.g., Coulter, 1998; Fennis \& Bakker, 2001). Moreover, individual differences, such as a recipients' tendency to evaluate situations positively or negatively (MacKenzie \& Lutz, 1989) and recipients' need for cognition (e.g., Haughtvedt, Petty, \& Cacioppo, 1992) have been found to influence advertising evaluation and effectiveness. While previous research studied the effects of situational and individual contexts on the evaluation of marketing communications, the present research focuses on the interplay between marketing communications and different contexts in eliciting automatic processes, which, subsequently, affect (unrelated) consumer responses. It is argued that automatic effects of marketing communications are context dependent, such that they unfold and interact with contextual variables that pertain to both the situation and the consumer. This is of importance because these various contextual factors may determine whether and in what way marketing communications affect automatic consumer responses. Contextual circumstances may change consumers' focus of attention, memory, and evaluation processes. Ferguson and Bargh (2002) demonstrated, for example, that currently activated goals affect evaluations of objects in the current environment. Hence, current contextual 
(situational or individual) circumstances may influence the way in which marketing communications guide automatic consumer processes. We propose that consumer responses to marketing communications may differ depending on consumers' individual or situational contexts. It is argued that marketing communications not always evoke the same responses for each consumer in all contexts. By incorporating such contextual factors, we extend previous research in automaticity, which, to date has mainly examined the autonomous effects of external cues without considering different situational and individual contexts (Bargh, 2006). In doing so, we take a context dependency perspective in explaining the effects of marketing communications on automatic consumer responses.

\section{FOCUS OF THIS THESIS}

In investigating the effects of marketing communications on automatic consumer responses, the present dissertation will emphasize the following aspects: First, we examine three ways through which consumer goal pursuit and evaluation processes can be unconsciously affected. We argue that these processes can be influenced by a) the mere presence of marketing communications in the environment, b) the interplay between environmental marketing communications and features of the purchase situation, and c) the interplay between external marketing communications and consumer goals. Hence, we propose that the effects of marketing communications on automatic processes may be context dependent. Marketing communications are expected to operate and have its effects through the interplay with consumer and situational differences. That is, exposure to marketing communications is suggested to result in different effects for consumers in different contexts. The same marketing stimulus may thus engender different responses depending on the situational and individual circumstances, whereas the same consumer response may be caused by different marketing communications depending on the automatic process involved. Hence, we examine the context dependent nature of marketing communication effects. Second, we focus on how different features of marketing communications such as brand associations, advertising modalities (aural or visual), and message framing can shape automatic processes. Therefore, we incorporate both conceptual and perceptual features of marketing communications that play a role in automatic consumer processes. Finally, we identify how the proposed effects of marketing communications in interplay with contextual variables, are further moderated by individual differences between consumers and features of the situation. In doing so, we aim to extend previous research in the domain of automatic consumer responses which may help marketers - who are probably not always cognizant of the automatic effects marketing communications may evoke - to improve their strategies and consumers to improve their decisions and control their actions.

The next chapters (2-4) of this dissertation consist of three different research projects that all focus on how marketing communications, in conjunction with contextual factors, influence consumers, where the consumer, and perhaps even the marketer, is not necessarily aware of this influence. Each chapter is related to the explanation of consumer choices, attitudes, and behavior as a function of marketing-induced automatic processes. All three empirical chapters should be considered as full papers that are published, or currently submitted to academic journals. As such, they 
can be read independently. Chapter 5 will provide an overview of the empirical findings described in chapters 2 to 4 , and will discuss both theoretical and practical implications. Below, we will first provide an overview of the following empirical chapters.

\section{OVERVIEW OF EMPIRICAL CHAPTERS}

In chapter 2, we examine whether the conscious or unconscious presence of brands in the environment automatically activates related brand associations instigating automatic goal pursuit. We investigate whether different brand exposure contexts activate goal pursuit in a similar way. Moreover, we investigate how automatically activated goals may affect consumer behavior. In general, consumers have the tendency to associate brands with related constructs such as product attributes, usage situations, and the brand spokespersons. When you see the brand 'Nike,' positive images of sportswear and famous tennis players will probably be activated unconsciously. However, unintended associations of, for example, 'sweatshops' in which child labor takes place may also possibly be activated upon exposure to this brand. Based on the literature on automatic behavior, we hypothesize that the subtle presence of brands is sufficient to activate such concepts in memory. With the ultimate goal to enhance product sales, marketers will try to design their strategies in such way that they create positive brand associations. However, some brands will also have 'unintentional' associations because of uncontrollable influences like negative publicity or the products attributes. We argue that insurance brands, because of their associations with disasters, accidents, and illnesses may automatically remind people of their mortality. More specifically, we propose that different exposure contexts, ranging from extensive to subtle and below the threshold of conscious perception, can automatically evoke death-related thoughts. Research on Terror Management Theory (TMT; Greenberg, Pyszczynski, \& Solomon, 1986) has shown that, when reminded of mortality, people are motivated to reduce existential anxiety. This can be achieved by enhancing self-esteem through worldview defense mechanisms. It is proposed that people who are reminded of their mortality through brand exposure will automatically adopt the goal to reduce existential anxiety. Moreover, we hypothesize that this goal would lead to worldview defense mechanisms subsequently affecting consumer intentions and evaluations. Hence, this chapter investigates how the mere presence of marketing communications in various contexts may elicit automatic goal pursuits that subsequently shape consumer responses.

While Chapter 2 emphasizes different brand exposure contexts that automatically activate consumer goals and subsequent behavior, Chapter 3 will focus on the interplay between exposure and retrieval context. In doing so, the chapter moves away from examining the effects of brand associations to examining the effects of perceptual features of brand exposure, such as communication modality. More specifically, we investigate how congruence between communication modalities (e.g., visual vs. aural) when brands are initially presented (i.e., during advertising) and communication modalities during evaluation or choice (i.e., purchase situation) automatically affects brand attitudes and choices. Hence, in this chapter, we describe how we investigated the way that perceptual features of marketing communications, in interplay with perceptual features of the situational context, automatically influence consumer 
responses. Previous research has already demonstrated that prior exposure to neutral stimuli leads to enhanced liking of these stimuli because repeated exposure improves processing fluency, which, in turn, positively affects evaluations. In line with this reasoning, it is argued in Chapter 3 that effects of prior exposure depend on the congruence between the communication modality in which brand exposure takes place and the modality in which brand evaluation and choices are made. Specifically, it is hypothesized that congruence in communication modalities has a positive effect on brand evaluation and brand choice, compared with incongruence in modalities. Processing fluency is proposed as the underlying mechanism. We argue that consumers automatically attribute the experienced positive feelings of fluency to the brand they are evaluating. Moreover, we investigate whether the effects of communication congruence are stronger when consumers are explicitly or implicitly drawn to perceptual features of the brand (i.e., data-driven processing style) compared with when consumers' attention is drawn to the meaning of the brand (i.e., conceptually-driven processing style). Thus, in this chapter we focus on how the interplay between features of marketing communications and features of the purchase situation automatically affects evaluation processes, which subsequently influence brand attitudes and choice.

The final empirical chapter (4) extends the previous chapters by addressing another type of interplay, namely the interplay between marketing communications' encoding context and consumer goals. Whereas Chapter 3 highlights the interplay between different contexts (i.e., encoding and retrieval) in which consumers are exposed to marketing communication stimuli, Chapter 4 discusses individual differences between consumers regarding their focus on the self rather than merely on the marketing stimulus. Moreover, Chapter 4 will focus on another form of consumer response, namely charitable behavior. According to the Giving USA foundation (2007) charitable giving has become a 300 billion dollar industry in the United States making it a significant part of consumer spending. Accordingly, more recently consumer researchers have extended their research interest to charitable behavior (e.g., Fisher, Vandenbosch, \& Antia, 2008; Liu \& Aaker, 2008). Based on the principle of regulatory fit (Higgins, 2000), it is argued that a persuasive message framed in such way that it matches the consumer's current regulatory goals (promotion vs. prevention) yields more positive reactions towards the objective of the message (i.e., charity) compared with a persuasive message that is mismatched to the consumer's current regulatory focus i.e., it is expected that consumers unconsciously use the fit experience to evaluate the message at hand. More specifically, it is proposed that consumers process a message that fits with their current orientation focus more easily than a message that does not match their current orientation focus. This positive experience of processing fluency is expected to subsequently be attributed to the message concerned, eliciting favorable attitudes and behavior. In addition, we propose that these regulatory fit effects are stronger for people with a high private self-focus because these people are especially affected by external information that is optionally relevant for the self (Hull, Slone, Meteyer, \& Matthews, 2002). Private self-focus is expected to increase the activation of self-knowledge, which helps to easily process information that fits with one's activated self-knowledge (i.e., regulatory focus). Hence, this chapter examines how the interplay between the framing of marketing communications and individual differences in regulatory focus automatically affects consumer responses (i.e., attitudes, behavioral intentions, and actual behavior). 


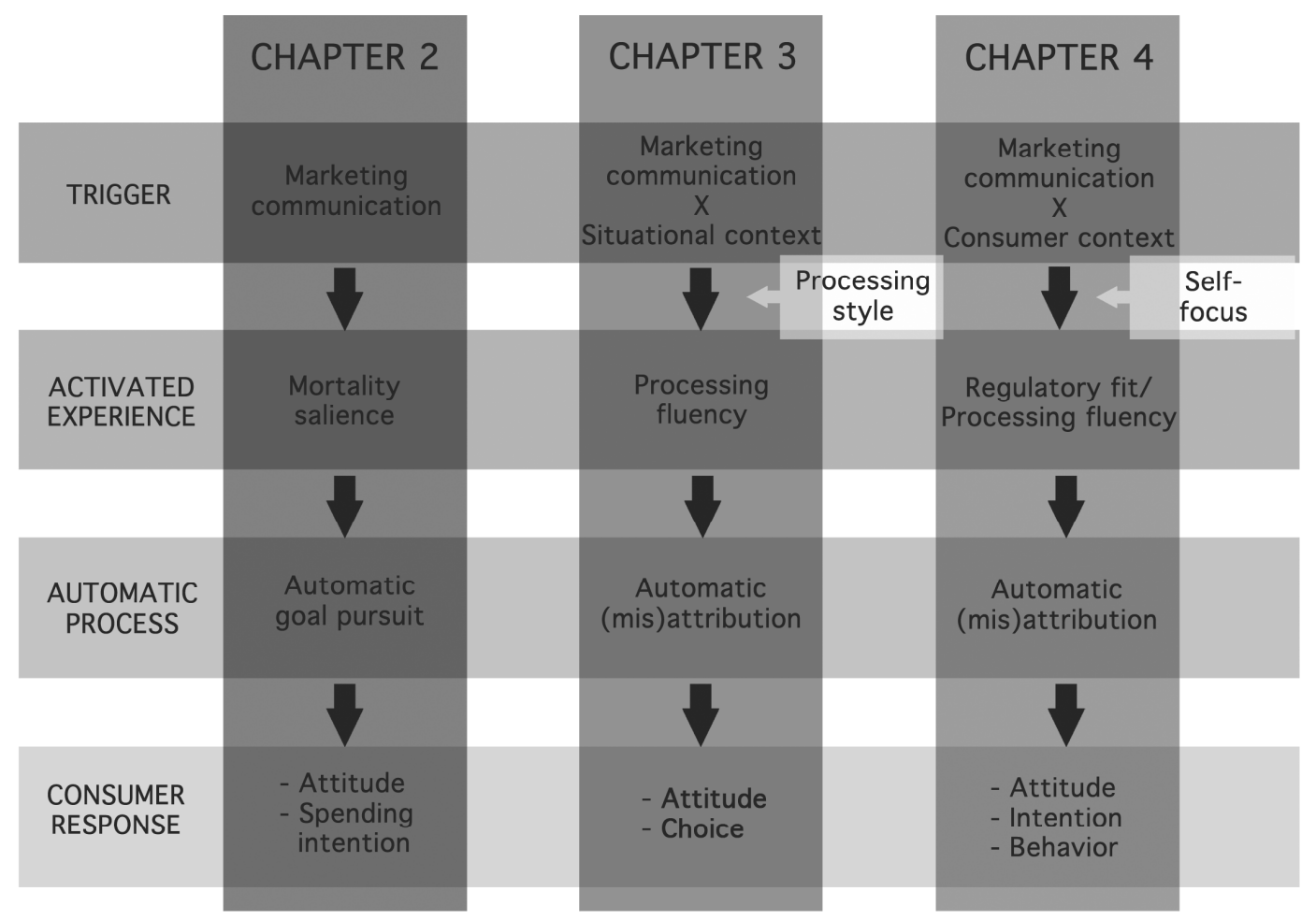

Figure 1.1. Overview of Empirical Chapters. 


\section{CONTRIBUTIONS OF THE PRESENT DISSERTATION}

While previous research has mainly emphasized rational and conscious consumer decision making, the present dissertation attests to the possible ways in which consumer behavior may be affected by unconscious processes. In doing so, we add to the consumer behavior literature in several ways. First, the findings in this dissertation contribute to the growing body of research demonstrating that much of consumer behavior is affected by unconscious processes. We show that processes such as automatic goal pursuit and automatic misattribution influence consumer responses. Second, we demonstrate that these processes can be evoked by the presence of marketing communications in the environment. Marketing communications such as brands, slogans, and persuasive messages are found to affect consumer responses without the consumer being aware of this influence. Moreover, we focus on different marketing communication features such as brand associations, communication modalities, and message framing. Third, the findings reveal that the effects of marketing communications are context dependent such that they operate in interplay with both consumer and situational contexts. We demonstrate that automatic processes are not always instigated by the mere presence of marketing stimuli but that these processes can also be instigated as a result of the interplay between marketing communications and their contexts. Different contexts seem to evoke different responses for different consumers in different situations. Hence, it seems important to take situational and consumer differences into account when examining the automatic influence of marketing communications on consumer responses.

Taken as a whole, the present dissertation offers empirical support for automaticity in consumer decision making and speaks to the importance of considering the effects of marketing communications on automatic consumer responses. Moreover, the findings demonstrate that the effects of marketing communications are often exerted when they interact with situational and consumer contexts. Understanding the contexts in which marketing communications may automatically affect consumer responses not only extends the literature on consumer behavior but also bears direct relevance to practitioners such as advertisers and marketers. 
The following chapter will examine how the mere (unconscious) presence of brands in the environment can automatically instigate consumer goal pursuit and subsequently affect consumer responses. We will investigate whether different exposure contexts result in similar goal pursuit strategies. In a series of three studies it is shown that exposure to mortality-related brands can automatically activate the goal to reduce existential anxiety. The results demonstrate that this goal can be attained through various worldview defense mechanisms that, in turn, unconsciously affect consumer behavior. The following chapter therefore provides evidence for the role of brand associations in automatic consumer responses. 
Chapter 2

Brands and Automatic Goal Pursuit: The Effects of Marketing-Induced Mortality Salience on Consumer Responses ${ }^{1}$

\footnotetext{
${ }^{1}$ This chapter is a modified version of an article that is published as Fransen, M. L., Fennis, B. M., Pruyn, A. Th. H., \& Das, E. (2008). 'Rest in peace?' Brand-induced mortality salience and consumer behavior'. Journal of Business Research, 61, 1053-1061.
} 
Imagine buying a new car. You are looking for a fast one that will augment your driving experience and impress your friends. Two brands that automatically come to mind are 'Porsche' and 'Dodge Viper', because you associate them with all the qualities you are looking for in a car. After some consideration you decide to purchase the 'Porsche'. You start looking in the yellow pages to find an insurance company that offers a car insurance that provides security and safety. Whilst scrutinizing the relevant pages and seeing the brand names and logos of all the different insurance companies, you find yourself thinking about the terrible things that could happen to you and your precious new car: theft, damage, vandalism and even a fatal accident.

This scenario shows that brands may activate a plethora of associations, which is congruent with the idea that consumers associate brands with related constructs such as a particular product attribute, usage situation, brand spokesperson, and the brand's logo. Aaker (1991) defines brand associations as 'anything linked in memory to a brand'. These associations are assumed to be organized in a network similar to associative memory models (Anderson, 1993). For example, 'Porsche' and 'Dodge Viper' may trigger associations such as the pleasure of driving, speed and impression management, just as insurance brands can evoke associations involving security and belongingness. Such positive associations are often the result of enduring marketing strategies that repeatedly stress these brand characteristics, and they are often the focus of consumer research (e.g., Kohli, Harich, \& Leuthesser, 2005; Punj \& Moon, 2002; Van Osselaer \& Janiszewski, 2001).

However, as follows from the example above, not all brand associations originate from intentional tactics by marketers. Brand associations also seem to arise unintentionally as a consequence of, for instance, negative publicity or a product's attributes. For example, insurance brands are likely to remind us of disaster, illness, and even mortality. Whereas the effects of intentionally designed marketing strategies and consciously created brand associations on brand equity and consumer behavior received much attention, (e.g., Belén del Río, Vázquez, \& Iglesias, 2001; Brown \& Dacin, 1997; Cobb-Walgren, Ruble, \& Donthu, 1995; Keller, 1993, 2003; Krishnan, 1996; Yoo, Donthu, \& Lee, 2000), one cannot say the same about the effects of brand associations that originate spontaneously and are not part of a well-designed marketing strategy. Do such unintended, and perhaps undesired, brand associations affect consumer behavior? The present paper argues that they do. More specifically, the current research shows that brands can sometimes automatically trigger unconscious, hidden motives, desires, and fears that have a significant impact on consumer behavior without the consumer and marketer being aware of this influence. The present research will focus on one very powerful hidden motive: the fear of death (Greenberg, Pyszczynski, \& Solomon, 1986). Although previous work stressed the relevance of the construct of mortality salience for the field of consumer behavior (e.g., Arndt, Solomon, Kasser, \& Sheldon, 2004; Solomon, Greenberg, \& Pyszczynski, 2004), various important questions have been left unaddressed in the literature. The present series of studies focuses on the notion that brand attributes may (unintentionally) induce the fear of death resulting in the goal to regulate experienced death-related anxiety. Moreover, the present research aims to extend earlier findings on the effects of death-related anxiety on various forms of consumer behavior. 
The next section briefly reviews previous research on the relationship between death-related anxiety and consumer behavior, and identifies several gaps in the literature. The section that follows discusses three studies that tested the notion that brands can induce mortality salience and subsequently influence consumer behavior.

\section{CONSUMER BEHAVIOR AS TERROR MANAGEMENT}

According to Terror Management Theory (TMT: Greenberg, Pyszczynski, \& Solomon, 1986), much human behavior emanates from the fear of death that becomes salient when confronted with mortality. The will to survive and the knowledge that life is transient results in an unsolvable conflict, often referred to as terror. Terror Management Theory postulates that individuals deal with this terror by endorsing a cultural worldview that gives meaning, order and permanence to the self. Living up to these standards provides high levels of self-esteem which functions as a buffer against existential anxiety. Various studies support the proposition that reminders of mortality intensify the desire to express cultural values and to engage in culturally prescribed behavior (see Greenberg, Koole, \& Pyszczynksi, 2004 for a recent overview). For example, mortality salience leads to overestimation of consensus for one's attitudes on culturally relevant issues (Pyszczynski, et al., 1996), more positive evaluations of charities (Jonas, Schimel, Greenberg, \& Pyszczynski, 2002), a higher level of emotional distress when behaving counter to cultural values and norms (Greenberg, Porteus, Simon, Pyszczynski, \& Solomon, 1995), and more favorable attitudes of those individuals who exemplify cultural values or praise the culture (e.g., Greenberg, Pyszczynski, Solomon, \& Rosenblatt, 1990; Rosenblatt, Greenberg, Solomon, Pyszczynski, \& Lyon, 1989). Moreover, research has shown that reminders of death not only intensify the desire to express and praise cultural values, but also the inclination to defend the values and norms of one's cultural worldview (in-group-bias) and, at the same time, the tendency to derogate values of other cultures (out-group derogation). For example, Germans who thought about their mortality reported less support for the European currency, the Euro, and greater support for the German Mark (Jonas, Fritsche, \& Greenberg, 2005). Expressing cultural values and defending one's cultural worldview seem to serve as mechanisms that regulate experienced existential terror.

Recent research has begun to explore TMT assumptions in the realm of consumer behavior (Arndt, Solomon, Kasser, \& Sheldon, 2004; Rindfleisch \& Burroughs, 2004; Maheswaran \& Agrawal, 2004). In the current western society, consumerism and materialism can be seen as important values intrinsic to a Western worldview. Accordingly, thoughts about death will intensify the desire to meet these values by acting in accordance with them because this will boost self-esteem. In line with these notions, research demonstrated that participants who consciously think about their mortality evaluate their financial future more positively, and expect to spend more money on luxury items in the next fifteen years than participants in the control condition (Kasser \& Sheldon, 2000). Reminders of death also increase the attraction of high status products, presumably because these kinds of possessions show that one is doing well and meeting the standards of one's society (Heine, Harihara, \& Niiya, 2002; Mandel \& Heine, 1999). 
Research on the effects of death reminders is still in its infancy, however, and little is known as yet about other worldview defense strategies that may be directly relevant to the consumer domain. For example, it remains unclear how the previously discussed impact of mortality salience on in-group bias and out-group derogation manifests itself in the consumer domain. One rather straightforward possibility would be that mortality salience leads to a general preference for national (own-country) products and a devaluation of foreign products. The present paper will address this issue.

Furthermore, most research in the domain of Terror Management activated mortality-related thoughts by confronting participants with a threatening video about death or by instructing participants to write or think about (their) mortality (for an overview see: Pyszczynski, Greenberg, Solomon, Arndt, \& Schimel, 2004). However, research left unaddressed whether marketing communications, such as brands, physical products, or advertisements can automatically activate mortality-related thoughts resulting in the goal to decrease experienced anxiety. The present series of studies focuses on one specific type of marketing stimulus and assesses the role of brands in inducing consumer mortality salience. In sum, this research aims to establish the missing causal links between three constructs: brands, mortality salience and consumer behavior.

The present research adds to the literature in two ways. First, the hypothesis that mere brand exposure can function as an (unintended) reminder of mortality by triggering associations of disaster, fatal accidents and illnesses will be tested. Research on automatic construct activation (e.g., Bargh \& Pietromonaco, 1982; Higgins, Bargh, \& Lombardi, 1985; Macrae, Stangor, \& Milne, 1994; Wheeler \& Petty, 2001) supports the idea that subtle environmental cues can influence construct accessibility. For example, Kay, Wheeler, Bargh, and Ross (2004) showed that implicitly presented material business objects, like boardroom tables and briefcases, increase the cognitive accessibility of related constructs such as competition. In addition, research on automatic goal pursuit demonstrated that presenting participants with words related to successful performance (e.g., compete, succeed, strive, and attain) automatically activated the goal to perform well (Bargh, Gollwitzer, Lee-Chai, Barndollar, \& Trötschel, 2001). Likewise, brands considering their broad scope of associations- may trigger various constructs and goals related to unconscious consumer motives, such as a fear of death or a need to belong. To validly establish the specific relationship between brands and unconscious consumer goals, the present research examines the effects of different priming procedures on the accessibility of mortality-related thoughts resulting in the goal to reduce existential anxiety. Across studies, priming procedures are varied from extensive and explicit (i.e., supraliminal priming) to subtle and below the threshold level of conscious perception (i.e., subliminal priming; Bargh \& Chartrand, 2000). These procedures offer the possibility to learn more about the different contexts in which brand associations become active and affect subsequent behavior. This approach extends previous research in the realm of terror management by providing a first test of the role of marketing communications (i.e., brands and brand logos) as inducers of mortality perceptions and automatic goal pursuit. 
Second, this research extends previous TMT research by providing explicit tests of the various ways in which mortality concerns induces goal-directed behavior subsequently affecting consumer responses. In Western countries where consumerism is deeply interwoven with cultural beliefs and money is a pervasive barometer of self-worth (Bauman, 1995), excessive spending can function as a coping-strategy for dealing with existential anxiety (see also Arndt, Solomon, Kasser, \& Sheldon, 2004). In line with these notions, the hypothesis is that increased personal spending and charity donations are a function of the goal to reduce brand-induced mortality salience. Moreover, the present studies take in-group favoritism and out-group derogation into the consumer domain by proposing that mortality salience induces a more positive perception of products and goods that are produced in one's own country and a more negative perception of products originating from abroad. In other words, individuals who (unconsciously) think about their mortality, through brand exposure, will be motivated to defend their own culture by expressing greater appreciation for their 'own' products and lower appreciation for other cultures' ('their') products.

OVERVIEW

The aim of this research is twofold; 1) to test whether priming participants with an insurance brand logo can automatically activate death-related thoughts, and 2) to replicate and extend research on consumption-related mechanisms which serve the goal to reduce existential anxiety. This paper reports three studies that use different priming procedures: Studies 2.1 and 2.2 employ an explicit and implicit supraliminal brand priming method, respectively, to make mortality salient. Study 2.3 uses a subliminal brand priming method to activate death-related thoughts. Utilizing these different priming contexts, ranging from very explicit to very implicit, offers the possibility to validly establish the effectiveness of different forms of brand exposure, while providing and extending the knowledge about the effects of unintended and unmanaged brand associations. Accordingly, the present research is one of the first to assess the effects of brands on mortality salience, goal pursuit, and subsequent consumer behavior.

The studies measure four different types of goal-directed strategies, aimed at reducing existential anxiety, which are relevant to the consumer domain: increased spending (Study 2.1), increased donation to charity (Study 2.2), increased appreciation for national products, and decreased appreciation of foreign consumer goods (Study 2.3). The expectation is that exposure to an insurance brand increases the accessibility of mortality-related thoughts, which, in turn, will increase various types of coping strategies relevant to the consumer domain. Finally, Study 2.1 employs a mediation analysis (cf. Baron \& Kenny, 1986) to establish the mediating role of mortality salience in the relation between brand exposure and consumer worldview defense strategies. 


\section{STUDY 2.1}

Study 2.1 aimed to test three hypotheses. First, this study examined the effect of explicit -supraliminal- brand priming on mortality salience. The first hypothesis was that extensive exposure to an insurance brand increases the accessibility of mortality-related thoughts resulting in the goal to manage existential anxiety. The second hypothesis was that this brand-induced mortality salience would affect personal spending on other items than the branded ones. Finally, the third hypothesis stated that mortality salience mediates the relation between brand exposure and spending intentions.

METHOD

\section{Design and participants}

The study employed a single factor between-subjects design (brand: insurance brand logo vs. no brand logo). Fortythree participants (23 males and 20 females) with a mean age of 22 years $(S D=2.69)$ took part in the experiment. Participants received $€ 2$, - for their participation.

\section{Procedure}

On arrival at the lab, the experimenter told the participants that the study consisted of a series of unrelated studies. The experimenter placed each participant in a separate room with a computer that provided all further instructions. After answering some demographic questions, participants in the experimental condition observed a brand logo, whereas control participants did not. After brand exposure, participants completed several measures assessing mortality salience, mood, and spending intentions. Finally, participants responded to the 'funneled debriefing' procedure (Bargh \& Chartrand, 2000) to ascertain that nobody identified the real purpose of the study. After completing the different parts of the study, the experimenter debriefed, paid, and thanked participants for their attendance.

\section{Independent variable}

Brand exposure. The computer program randomly assigned participants to either the brand exposure or the control condition. In the brand manipulation condition, participants saw the brand logo of a well-known insurance company, whereas participants in the control condition did not. To ascertain a thorough and extensive confrontation, the exposure lasted for five minutes and participants wrote down all the thoughts that came to mind during the brand logo exposure (Macrae, Stangor, \& Milne, 1994). 


\section{Dependent variables}

Mood. To assess whether the brand exposure would lead to unintended mood effects, participants responded to the 20-items Positive Affect Negative Affect Schedule (PANAS; Watson, Clarke, \& Tellegen, 1988), which consisted of 10 positive items $(\alpha=.79)$ and 10 negative items $(\alpha=.78)$. This questionnaire, designed to measure participants' feelings at that particular time, also served as a delay and distraction measure. This was important because previous research showed that standard mortality salience effects mainly occur after a (short) period of delay (Arndt, Greenberg, Solomon, \& Pyszczynski, 1997).

Mortality Salience. To measure the accessibility of death-related thoughts, participants responded to the word fragment completion task (Greenberg, Pyszczynski, Solomon, \& Simon, 1994) in which they completed a set of 15 incomplete words by filling in one or more syllables. Participants could complete ten of these words as either neutral or death-related words, and the remaining 5 words served as filler items. Examples included 'De...', which participants could complete as either 'Death' or 'Dean', and '... ave' which they could complete as 'Grave' or 'Wave'. The summed total of death-related words that participants completed served as an index for mortality salience $(M=$ $.79, S D=.91$, range $=0-3)$.

Spending Intentions. Participants indicated their inclination for excessive spending by reporting how much money they were planning to spend on entertainment and food in the upcoming month. Consumption and hedonism are currently seen as the most essential values in Western countries (Baumann, 1995). Therefore, the expectation was that spending money on consuming luxury food in a restaurant and entertaining oneself are adequate ways of expressing these current Western values. The summed scores on the items entertainment and food served as a measure of short-term spending intentions.

\section{RESULTS AND DISCUSSION}

The results of the debriefing procedure revealed that none of the participants recognized the real purpose of the study. This enabled us to include all participants in the analyses.

Mood. Analysis of variance on the positive items of the PANAS, $(F(1,41)=.83$, ns) and the negative items of the PANAS, $(F(1,41)=1.77, n s)$ indicated that participants' mood states were not affected by brand exposure. Hence, mood states cannot account for the difference in cognitive accessibility of death-related words and spending intentions.

Mortality salience. An ANOVA on the number of completed death-related words showed that participants in the brand manipulation condition completed more death-related words $(M=1.20, S D=1.0)$ than participants in the control 
condition $(M=.44, S D=.66 ; F(1,41)=8.9, p<.01)$. Participants who explicitly saw the insurance brand logo indeed had more mortality-related thoughts than participants in the no-brand control condition, thus confirming that explicit brand exposure increased mortality salience.

Spending Intentions. In line with the predictions, an ANOVA on the measure of spending intentions revealed that participants in the experimental condition planned to spend more money on entertainment and food in the next month $(M=204, S D=95.83)$, than participants in the control condition $(M=129.57, S D=59.96 ; F(1,41)=9.58, p<.01)$.

Mediation Analysis. A mediation analysis tested the hypothesis that mortality salience mediates the relation between brand exposure and spending (cf. Baron \& Kenny, 1986). The first regression analysis, with spending intentions as the dependent variable and brand manipulation (dummy coded) as the predictor, yielded a significant relation ( $\beta=$ $.44, p<.01$ ). A second regression analysis, with the mediator (mortality salience) as the dependent variable and brand manipulation as the predictor, showed that brand manipulation influenced mortality salience significantly $(\beta=$ $.40, p<.01)$. Subsequently, following the procedure outlined by Baron and Kenny (1986), a regression analysis with brand manipulation (dummy coded) and mortality salience (centered, see Aiken \& West, 1991) as predictors and spending intentions as the criterion revealed that the previously found relationship between brand manipulation and spending intentions became insignificant $(\beta=.22, p>.10)$, whereas the mediator retained its significance $(\beta=.50, p<$ .01), which indicates full mediation. A Sobel test (Baron \& Kenny, 1986; Preacher \& Hayes, 2004) confirmed that mortality salience mediates the relation between brand manipulation and spending intentions $(Z=2.27, p<.05)$. These results suggest that mortality salience is a significant mediator of the relation between brand manipulation and spending intentions.

These findings support the hypothesis that mortality salience can be induced by explicit priming with an insurance brand logo. Measuring the accessibility of death-related thoughts enabled the possibility to show that brand exposure indeed induces mortality salience directly. Additionally, in accordance with the second hypothesis, the results showed that participants in the experimental condition indicated to spend more money in the near future than participants in the control condition, which offers further support for the effects of mortality salience on consumption-related intentions. Hence, participants excessive spending seems to serve as a strategy to reduce brand-induced existential anxiety. Moreover, the mediation analysis revealed that the effect of brands on spending intentions is fully mediated by the accessibility of death-related thoughts. In sum, these results show that brand logos can influence spending intentions via mortality salience. Individuals confronted with an insurance brand, are unconsciously reminded of their mortality and use spending as a means to regulate their experienced terror. This is the first study to show that effects of mortality salience on consumer behavior are indeed mediated by mortality-related thoughts.

Given the fact that this study contrasted a brand exposure condition with a non-brand exposure control condition, one could argue that brand exposure as such, regardless of the specific type of brand, may have been sufficient to 
activate associations such as spending and purchasing, which could have led to increased spending intention. To rule out this alternative explanation, Study 2.2 uses a neutral brand in the control condition. To further validate the results of Study 2.1, and mimic a more 'real world' situation, Study 2.2 employs a more implicit brand exposure by presenting the brand logo as a subtle environmental cue. Finally, Study 2.2 tests whether mortality salience can have effects other than increased personal consumerism, by examining the relationship between mortality salience and donations to charity.

\section{STUDY 2.2}

Study 2.2 aimed to extend the results of Study 2.1 in a more natural setting by adopting a more implicit, subtle exposure of the insurance brand logo. Furthermore, Study 2.2 used a control brand in the control condition to rule out the alternative explanation that exposure to any brand influences spending behavior. To guarantee the implicit presence of the brands, the brand logos were printed on a mouse pad that was used during the study yet was not the focus of attention during any part of the experiment. Hence, the brand logos were only accidentally present in the experimental setting. Moreover, the present study investigated whether mortality salience affects behavior by measuring the amount of money participants were prepared to donate to charity. Donating behavior can be seen as desirable behavior in western cultures (see Jonas, Schimel, Greenberg, \& Pyszczynski, 2002), which makes it a suitable strategy for expressing cultural values. The expectation was that individuals who used the mouse pad with the printed insurance logo would donate more money to charity than participants using a mouse pad with a control brand.

METHOD

\section{Design and Participants}

This study employed a single factor between-subjects design (brand manipulation: mouse pad with printed insurance brand logo vs. mouse pad with printed control brand logo). A total of thirty-seven participants (20 males and 17 females) with a mean age of 22 years $(S D=2.39)$ took part in this study. They were paid $€ 2$, - for their participation.

\section{Procedure}

As in Study 2.1, the experimenter told participants that they would take part in a sequence of short, unrelated studies. The entire experiment took place on a computer and participants used either a mouse pad with the printed insurance logo or a mouse pad with the logo of a control brand (a brand for a cosmetic product). Subsequently, participants responded to the Positive Affect Negative Affect Schedule (PANAS) and indicated how much money they wanted to donate to charity. Finally, the experiment contained a funneled debriefing procedure, to uncover any suspicions of the study's real goal. After the study, the experimenter debriefed, paid, and thanked participants for their attendance. 


\section{Independent variable}

Brand Manipulation. The experimenter randomly assigned participants to a room in which the mouse pad with the insurance brand logo was present or to a room in which the mouse pad with the control brand was present. Hence, during the entire study, participants used the mouse pad with either the printed insurance brand logo or the mouse pad with the printed control brand logo. To ascertain the implicit character of the experimental treatment, neither the experimenter nor the instructions provided by the computer program made any reference to the mouse pad or logo during any part of the experiment.

\section{Dependent variables}

Mood. Participants responded to the 20-item PANAS questionnaire to check for design confounds $\left(\alpha_{\text {positive items }}=.77\right.$, $\left.\alpha_{\text {negative items }}=.79\right)$.

Charity Donation. At the end of the experiment, participants read some information about a charity foundation concerned with environmental protection and climate issues and indicated how much money they wanted to donate.

\section{RESULTS AND DISCUSSION}

The results of the debriefing procedure revealed that none of the participants identified the true purpose of the study.

Mood. As in Study 2.1, analysis of variance on the positive items $(F(1,35)=.22, n s)$ and the negative items $(F(1,35)$ $=1.56, n s)$ of the PANAS showed there were no significant differences in mood states between the experimental condition and the control condition. Hence, mood states cannot account for the observed results.

Charity Donation. An ANOVA revealed that participants in the experimental condition indicated to give more money to the charity foundation $(M=21.90, S D=22.45)$ than participants in the control condition $(M=8.56, S D=9.17 ; F(1$, 35) $=5.22, p<.05)$.

These findings extend the results of Study 2.1 by showing that brand-induced mortality salience leads to expressing cultural values by more generous donations to charity. This means that brands can function as subtle environmental cues that may affect consumer-related worldview defense strategies in ways that were probably unintended by the brand owner. Moreover, the use of a control brand in the control condition ruled out that general brand associations such as consumption and spending caused the effects on spending behavior.

The findings of Studies 2.1 and 2.2 imply that consumers may use spending, specifically on culturally valued items, as a coping mechanism to attain the goal to reduce experienced terror triggered by the subtle presence of brands in 
the environment. However, there may be more ways in which brand-related mortality reminders affect consumer behavior. Terror Management Theory states that another coping strategy exists of support for one's own culture and worldview and derogation of other cultures (Greenberg, Pyszczynski, \& Solomon, 1986). These mechanisms may translate to a consumer context, as they may affect the evaluation of foreign and local products. Specifically, as a consumption-related worldview defense mechanism, individuals exposed to the insurance brand may evaluate domestic products more favorably and foreign products less favorably. Study 2.3 tests this hypothesis. Additionally, Study 2.3 employs a subliminal brand priming procedure, in order to test the hypothesis that even brands presented on an unconscious level can affect mortality salience and corresponding consumer behavior.

\section{STUDY 2.3}

Study 2.3 applied a common worldview defense mechanism following a mortality salience manipulation to a consumer context: in-group bolstering and out-group derogation (Greenberg, Pyszczynski, \& Solomon, 1986). More specifically, this study tested whether mortality salience affects the evaluation of domestic and foreign products. The study used subliminal brand exposure to establish that mortality-related associations can become active even when consumers are completely unaware of being exposed to a brand stimulus.

METHOD

\section{Design and Participants}

To test the hypotheses, this study used a 2 (subliminal exposure: insurance brand vs. control brand) $x 2$ (products: domestic vs. foreign) design with repeated measures on the second factor. Seventy-seven participants (22 male and 55 female), with a mean age of 21 years $(S D=2.38)$ participated in the present study. They received $€ 2,-$ for their participation.

\section{Procedure}

As in the previous studies, the experimenter told participants they would participate in a sequence of unrelated studies. The experimenter seated the participants in a separate room at individual computer desks. After responding to demographic questions, participants performed a lexical decision task in which a subliminal priming procedure took place. Subsequently, participants evaluated typical domestic products and typical foreign products. A debriefing procedure to assess whether participants had noticed the subliminal brand manipulation concluded the experiment.

\section{Independent variable}

Brand Exposure. The study used a subliminal priming task based on a standard priming procedure (Bargh \& Pietromonaco, 1982; Strahan, Spencer, \& Zanna, 2002). Participants performed a masked lexical decision task in 
which they had to indicate as quickly and accurately as possible (by pressing the 'a' or ';' key, respectively), whether a string of letters shown to them on a computer screen constituted an existing word or not. The string of letters appeared in the middle of the computer screen. Between the presentation of forty words and non-words, brand logo primes flashed in the middle of the screen in half of the trials. The brand logos appeared on screen for a period of 10 milliseconds each. In the experimental condition, participants received a subliminal presentation of the insurance brand logo whereas participants in the control condition received a subliminal presentation of the logo of a soft drink brand. The experiment used this brand in the control condition because the colors of the brand logo matched those of the insurance brand logo, which facilitated the masking technique. Moreover, the use of another control brand than the one used in Study 2.2 ascertained that the earlier results are not attributable to the use of one particular control brand. A 'sandwich' mask, consisting of a series of X's in the same colors as the brand logo primes, appeared before and after the primes in the exact same spot as the brand logo primes. Both masks appeared on screen for 300 milliseconds each.

\section{Dependent variable}

Product Attitudes. To measure participants' attitudes towards typically domestic (i.e., Dutch) food products and typically foreign food products, participants rated -on a 5-point scale- how positive (versus negative) they evaluated each of the products concerned. A picture -on which the product's name was clearly visible- of each product was displayed on the computer screen. Participants rated a total of five typically domestic products (e.g., 'Gouda cheese' and 'Grolsch beer') and five foreign products (e.g., 'Carbonell olives' and 'Corona beer'). A summation of the five scores on the domestic products served as the attitude score towards the domestic products and a summation of the five scores on the foreign products served as the attitude score towards the foreign products.

\section{RESULTS AND DISCUSSION}

The results of the debriefing procedure confirmed that none of the participants identified that they had been exposed to a subliminal brand manipulation.

Product Attitudes. A 2 (brand: insurance brand vs. soft drink brand) x 2 (product: domestic vs. foreign) ANOVA with repeated measures on the last factor yielded a significant main effect of product $(F(1,75)=4.05, p<.05)$, indicating that the domestic products were generally evaluated more positively $(M=17.19, S D=2.83)$ than the foreign products $(M=16.23, S D=3.22)$. This main effect was qualified by a significant interaction effect between brand and product $(F(1,75)=8.76, p<.01)$. Simple main effect analyses showed that participants in the insurance brand condition rated the domestic products more positively $(M=17.92, S D=2.10)$ than participants in the control brand condition $(M=$ $16.49, S D=3.28, F(1,75)=5.20, p<.05)$. Conversely, participants in the insurance brand condition rated the foreign products less positively $(M=15.50, S D=3.34)$ than participants in the control brand condition $(M=16.95, S D=2.96$, $F(1,75)=4.05, p<.05)$. These findings suggest that participants in the insurance brand condition showed in-group 
favoritism, by expressing a more positive attitude towards domestic products, as well as out-group derogation, by expressing a more negative attitude towards foreign products (see Figure 2.1).

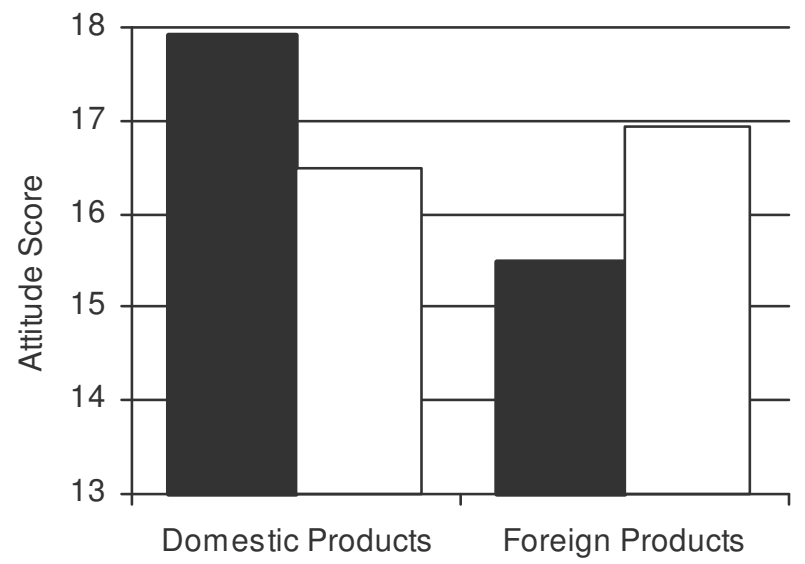

Insurance brand $\square$ Control brand

Figure 2.1. Attitude scores on domestic and foreign food products as a function of brand exposure.

These findings demonstrate that unintended brand associations can affect the evaluation of different products. The present findings may thus be the first to provide a clear demonstration of consumption-related in-group favoritism and out-group derogation as a function of brand induced mortality salience. Hence, the results attest to the various forms in which consumer behavior may function to achieve the goal to reduce existential terror that is experienced when individuals are confronted with a mortality-related brand. Furthermore, the present findings show that these effects can even be induced when the brand has been presented subliminally.

\section{GENERAL DISCUSSION}

The present research investigated whether unintended brand associations can influence consumer behavior by triggering unconscious consumer goals. The hypotheses were that exposure to an insurance brand would activate mortality-related thoughts and that mortality-related thoughts, in turn, would increase consumer spending, increase consumer preference for domestic products, and decrease consumer preference for foreign products. The present 
findings support these hypotheses. First, the current research is the first to show that exposure to marketing communications, like brands, is sufficient to induce mortality salience and the related goal to reduce existential anxiety. This is a clear extension of earlier research that has underscored the relevance of the mortality salience construct for understanding various forms of consumer behavior (e.g., Solomon, Greenberg, \& Pyszczynski, 2004; Arndt, Solomon, Kasser, \& Sheldon, 2004) but thus far has ignored the role of marketing communications as causal agents in this process. The present results align with earlier findings indicating that brand communications are capable of activating direct and indirect consumer associations. In this regard, it is noteworthy that something so subtle and perhaps trivial as a simple brand logo that is presented with (Study 2.1) or without (Studies 2.2 \& 2.3 ) any concomitant instructions and even nonconsciously (Study 2.3), can have these dramatic and far-reaching effects on man's ultimate fear: his or her death. Second, the present research shows that consumers have several response options to deal with induced existential terror. Studies 2.1 and 2.2 revealed that exposure to an insurance brand enhanced spending on items that one values positively in current western society. A mediation analysis confirmed that the relation between brand associations on the one hand, and spending on the other, was mediated by mortality salience. Hence, excessive spending on culturally valued items is a direct response to mortality salience. Study 2.3 showed that a subliminal brand prime increased preference of domestic over foreign products, thus demonstrating how worldview defense mechanisms, such as in-group favoritism and out-group derogation can pervade a consumer context. Hence, consumers seem to have several strategies to serve the goal of reducing existential anxiety.

\section{TERROR MANAGEMENT THEORY AND CONSUMER BEHAVIOR}

Effects of mortality reminders have been under frequent investigation since Greenberg, Pyszczynski, \& Solomon (1986) formulated Terror Management Theory. The main focus of this research has been on the general consequences of mortality salience, such as self-esteem striving, group affiliations, and self-serving biases (for a review see Pyszczynski, Greenberg, Solomon, Arndt, \& Schimel, 2004). More recently, mortality salience has also grasped the attention of consumer researchers, but work in this domain has remained on the conceptual level for a long time (e.g., Arndt, Solomon, Kasser, \& Sheldon, 2004; Maheswaran \& Agrawal, 2004), and has only scarcely included empirical demonstrations of mortality salience directly pertaining to consumer behavior (Ferraro, Shiv, \& Bettman, 2005; Heine, Harihara, \& Niiya, 2002; Jonas, Fritsche, \& Greenberg, 2005; Kasser \& Sheldon, 2000; Mandel \& Smeesters, 2008). The present findings offer empirical support for the notion that mortality salience can lead to 'the urge to splurge', which was suggested, but not tested by Arndt, Solomon, Kasser, and Sheldon (2004). Mortality salience not only results in overestimating one's financial position in the future (Kasser \& Sheldon, 2002), but mortality salience also influences spending intentions on culturally prescribed items in the short term. Participants anticipated spending more money in the coming month when they perceived a mortality-related brand. These results suggest that mortality salience directly activates the goal to reduce their experienced terror. Moreover, these findings empirically verify that attaining this goal is conceivable through lavish consumption. 
Additionally, the studies demonstrated that mortality-related brand-priming influences consumer behavior in more ways than one. Although other studies in this domain showed instances of in-group favoritism (e.g., Nelson, Moore, Olivetti, \& Scott, 1997), the current study presents evidence for both in-group favoritism as well as out-group derogation in a consumer context. Specifically, mortality salience influenced attitudes towards both domestic and foreign food products by boosting the evaluation of domestic products while simultaneously lowering the evaluation of foreign products. These findings demonstrate that one's daily shopping behavior may be pervaded by motives and goals that are hidden to the eye and the conscious mind. Accordingly, even subtle reminders of mortality may directly affect the amount of money one plans to spend, the extent to which one is keen to support charity, and the kinds of products one likes and dislikes. As such the present results provide empirical evidence for the notion that the fear of death can be induced and managed by entities that are commonly and even ubiquitously found in the consumerbehavior domain.

\section{BRAND ASSOCIATIONS AND CONSUMER BEHAVIOR}

From the somewhat broader perspective of unconscious activation (i.e., priming) of perceptions, goals, and behavior (see Bargh, 2002), the present study is the first that directly measures mortality salience after brand priming. The findings show that mere brand logos can serve as primes in activating constructs. This means that brand associations, even without the physical presence of the accompanying product, can become active by exposing participants explicitly to the brand as well as by implicit, incidental brand exposure. Brand confrontation not only has an effect on construct accessibility but also on preferences and the tendency to spend lots of money. This finding offers support for a full causal chain of brand exposure, inducing unintended brand associations (i.e., mortality salience) and goals (i.e., to reduce existential anxiety), which subsequently spur concomitant consumer behavior.

Marketers try to influence consumer behavior by creating positive brand associations on the assumption that this will increase both sales and brand loyalty. The results found that unintended (even unknown) associations can direct consumer decisions as well. Whether these kinds of unintended brand associations are harmful or fruitful to a certain company will depend on the kind of associations that spontaneously arise around a brand or product. The present studies used one particular brand to induce mortality salience. For future studies, it would be interesting to verify whether other types of brands can engender similar effects so that the present results can be generalized to other product categories and brands. However, for now, it seems wise for brand managers to bear in mind that brands may have a host of unknown (and possibly undesirable) associations that might facilitate or interfere unintentionally with their brand strategies, especially because these unintended brand associations can become activated by very subtle and even subliminal exposure. Stretching this point results in the provocative notion that brand advertising for product A may directly benefit sales for brand $B$ (either in or outside the product category of $A$ ) to the extent that consumers buy brand $B$ as an effective defense strategy to manage the mortality salience induced by brand $A$. 
Additionally, in the realm of consumer behavior, different priming methods have been used for influencing brand and product choices. It has been established that (supra- and subliminally) priming various concepts can affect consumer decision making and brand preference (e.g., Strahan, Spencer, \& Zanna, 2002). The present results contribute to this body of knowledge by demonstrating that brands themselves can also function as primes and indirectly affect different forms of consumer behavior. Brands seem capable of activating a host of associations and goals that can lead to consumer behavior, which is not necessarily related to the advertised product. Although the present research did not directly measure any activated goals, the underlying assumption is that the activated death-related thoughts induced the goal to regulate experienced terror. This observation opens a new reservoir of behavior, goals and needs that might be susceptible to activation by brand exposure.

In sum, marketing communications can serve as primes that trigger unconscious consumer goals automatically affecting consumer responses. In the present research, a seemingly trivial stimulus such as a brand logo activated different worldview defense strategies when participants thought about the brand very thoroughly, when the brand was an incidental part of the environment, and even when participants perceived the brand logo at a subliminal level. Brands are capable of automatically activating related constructs and presumably goals as well. This might open a new way of looking at brand marketing strategies particularly when one realizes that consumers are surrounded by brands almost continuously. Consumers are certainly not aware of all the effects that brand exposure might have on them, regardless of whether this exposure was a conscious or unconscious experience. None of the participants in our studies made any connection between the brand exposure and their spending intentions or product evaluations. Hence, the present studies contribute to our reasoning that consumer evaluation processes and behavior might be affected by marketing communications without consumers' awareness. 
The previous chapter examined the role of brand associations in automatic consumer processes. It revealed that brand associations can induce automatic goal pursuit in different exposure contexts, which, in turn, affect spending intentions and product evaluations without the consumer being aware of this influence. The results offer initial support for our notion that consumer processes may be automatic and occur outside of conscious awareness. Moreover, by focusing on mere brand exposure, Chapter 2 identified (unintended) brand associations as inducers of automatic goal pursuit. In the next chapter we will extend our focus to another characteristic of marketing communications, namely the modality (visual vs. aural) in which a brand can be communicated. We argue that the effects of brand communication modality depend on the context in which consumers are presented with the brand in a subsequent situation. Rather than solely focusing on the exposure context, the following chapter will therefore examine the interplay between exposure and retrieval context. More specifically, it is proposed that matching communication modalities between the initial exposure (i.e., during advertising) and during brand evaluation (i.e., when deciding whether or not to buy a particular brand) enhances brand evaluation and brand choice. Based on the principle of processing fluency, we argue that congruence in communication modality positively affects the ease with which brands are processed. The experience of processing fluency is expected to subsequently enhance brand attitudes and actual brand choice through the process of misattribution. The following chapter will also investigate whether the effects of modality congruence are stronger when consumers adopt a processing style that is particularly focused on the perceptual (i.e., data-driven processing) rather than the conceptual features (i.e., conceptually-driven processing) of the brands. The findings of a series of four studies offer support for our hypotheses by demonstrating 1) the positive effects of modality congruence on brand evaluation and choice, and 2) the moderating role of processing style. 
Chapter 3

Matching Brand Communication Modalities: The Effects of Marketing-Induced Congruency on Consumer Responses ${ }^{2}$

${ }^{2}$ This chapter is a modified version of the manuscript Fransen, M. L., Fennis, B. M., \& Pruyn, A. Th. H. Matching communication modalities: The effects of modality congruence and processing style on brand evaluation and brand choice. Under Review. 
On average people are exposed to more than 1000 commercial messages each day (Kotler \& Keller, 2005). Not only are we being exposed to brands in visual advertisements on billboards and websites, in magazines and emails, but also to brands in aural commercial messages on the radio and through personal selling. Many studies have focused on the content, framing, and design of these messages on consumers' attitudes, preferences, and intentions (e.g., Chang, 2002; McMillan, Hwang, \& Lee, 2003; Shen \& Dillard, 2007; Yates \& Noyes, 2007). The present research extends this work by focusing on the medium through which commercial messages reach the audience. How do differences in communication modality (i.e., visual or aural presentation) affect brand evaluations and brand choices? Do visual and aural brand exposures result in similar effects? Previous research has shown that prior brand exposure (e.g., during advertising) enhances brand consideration and brand choice (e.g., Coates, Butler, \& Berry, 2006; Karremans \& Stroebe, 2006). In the present studies we argue that effects of prior brand exposure on brand evaluation and brand choice depend on the interplay between the communication modality in which brand exposure takes place and the communication modality in which evaluations are formed and choices are made. More specifically, we propose that the effects of prior brand exposure increase when consumers use the same sensory process (seeing or hearing) during exposure to the brand advertisement and during evaluation and choice (i.e., when deciding whether or not to buy a particular brand). It is expected that processing fluency is the underlying mechanism explaining the relation between modality congruence and brand evaluation and brand choice in such a way that modality congruence enhances processing fluency, which, in turn, positively affects evaluation and choice. Moreover, we argue that the effects of modality congruence on brand evaluation and brand choice will not be equally strong in all situations. We propose that these effects will be stronger when recipients' attention, during exposure, is explicitly drawn to the physical characteristics of the brand name.

\section{PROCESSING FLUENCY AND EVALUATION}

Zajonc (1968) demonstrated that repeated exposure to a neutral stimulus leads to increased liking of the stimulus even when individuals are not aware of having been previously exposed to the stimulus. For instance, he found a positive relation between number of exposures to Chinese ideographs and ratings of positive affect towards these ideographs (Zajonc, 1968: Study 2). Hence, he argued that familiarity leads to liking. This effect has proven to be robust for various types of stimuli and various evaluation procedures (see Bornstein, 1989 for a review). One explanation for this mere exposure effect is 'processing fluency': the experienced ease of processing or recalling information (e.g., Lee, 2001; Reber, Winkielman, \& Schwarz, 1998; Seamon, Brody, \& Kauff, 1983; Whittlesea, 1993; Winkielman, Schwarz, Fazeindro, \& Reber, 2003). High fluency is generally experienced as hedonically positive, as reflected in psychophysiological measures (Winkielman \& Cacioppo, 2001). Research on processing fluency has shown that fluent processing (which can originate from prior exposure) leads to more positive evaluations of the stimulus (e.g., Reber, Winkielman, \& Schwarz, 1998; Lee \& Labroo, 2004), because people automatically (mis)attribute the positive feelings of processing fluency to the stimulus at hand. Hence, people make an unconscious inference about the source of their experience. 
These findings suggest that repeated brand exposure (e.g., through advertising) could lead to more favorable brand evaluations as a function of the automatic misattribution of perceptual fluency. Brands encountered previously become (temporarily) more accessible which enhances processing fluency. Studies about the effectiveness of prior brand exposure (i.e., priming) on brand name recall, brand recognition, brand judgment, and brand choice have indeed demonstrated positive effects of repeated brand exposure (e.g., Baker, 1999; Bemmaor \& Mouchoux, 1991; Butler \& Berry, 2001; Chung \& Szymanski, 1997; Janiszewski, 1993; Janiszewski \& Meyvis, 2001; Nebenzahl \& Hornik, 1985; Pham, 1992), at least up to a certain number of exposures, beyond which positive effects start to diminish (Batra \& Ray, 1986; Calder \& Sternthal, 1980; Pieters, Wedel, \& Rosbergen, 1999). In extension to these findings, we propose that an important qualifier for the process of ad-induced processing fluency is the interplay between presentation (i.e., encoding) and evaluation (i.e., retrieval) modalities. Based on the notion that perceptual similarities(differences) between exposure and retrieval enhance(decrease) priming effects on memory tasks (see Roediger \& McDermott, 1993 for a review), we expect that a brand is processed more easily - and subsequently evaluated more positively - in a situation of modality congruence than in a situation in which modality differs between exposure and evaluation phase. Hence, it is argued in the next section that a visual(aural) brand advertisement is more effective in influencing brand evaluation and brand choice when brands are visually(aurally) perceived during the evaluation or purchase situation (i.e., same-modality) than when the modality differs during exposure and evaluation context (i.e., cross-modality).

\section{MODALITY CONGRUENCE AND EVALUATION}

Research on implicit memory has shown that surface alterations between the exposure and the retrieval context can diminish priming effects on various implicit memory tasks and consequently on processing fluency (Franks, Bilbrey, Lien, \& McNamara, 2000; Roediger \& McDermott, 1993). Changes in surface features may involve alterations as in typography (e.g., font or case), physical characteristics of the stimulus (e.g., size), and modality (aural vs. visual). Jacoby and Hayman (1987) found, for instance, that changing typography at exposure and retrieval decreased performance on a word identification task compared to a match in typography (Madigan, McDowd, \& Murphy, 1991; see Roediger \& Blaxton, 1987 for similar effects). In addition, Weldon and Roediger (1987) demonstrated that prior exposure to a series of pictures resulted in greater priming effects when measured with a picture-naming task than with a word-fragment completion task, whereas the opposite was true for participants previously exposed to a series of words. Studies on the effects of modality changes on memory tasks have mainly used both aural and visual presentations during the exposure phase but only visual implicit memory tasks. Results showed greater priming effects on visual implicit memory tasks when the stimuli were visually presented in the exposure phase, which indicates a same-modality effect on implicit memory tasks (e.g., Kelley, Jacoby, \& Hollingshead, 1989; Rajaram \& Roediger, 1993). Moreover, in their studies, Bassili, Smith, and MacLeod (1989) incorporated both visual and aural presentations of stimuli, and a visual and aural word-stem completion task as a measure of implicit memory. It was 
demonstrated that using the same modality during exposure and memory contexts led to better performance on memory tasks than when modalities were altered.

Most research on modality congruence effects focused on implicit memory tasks measuring retention and recognition. To extend these findings, and using brands as stimulus material, the present studies focus on brand evaluations and choices after prior exposure. It is proposed that easier retention and recognition of a stimulus will lead to the experience of processing fluency resulting in more positive evaluations of the stimuli through the process of automatic misattribution (e.g., Winkielman, Schwarz, Fazeindro, \& Reber, 2003). It is argued that the overlap in stimuli, situation and cognitive processes (in the current studies: modality congruence), used during initial exposure to a brand name and the later evaluation of the brand name, will enhance processing fluency and therefore brand evaluations and brand choice (see Butler \& Berry, 2001 for a related view). More specifically, it is hypothesized that modality congruence enhances processing fluency (Study 3.1), and subsequently has a positive influence on brand evaluation (Studies 3.2 and 3.3) and actual brand choice (Study 3.4) because of an automatic misattribution process.

PROCESSING STYLE

As stated before, implicit memory tasks are strongly influenced by changes in physical features like modality (e.g., Vaidya et al., 1997). There are reasons to assume that the effects of modality congruence are not equally strong for all individuals in any given situation. The way in which stimuli are processed in the initial exposure phase seems to influence performance on implicit and explicit memory tasks (e.g., Craik, Moscovitch, \& McDowd, 1994). In the present context it would be plausible to expect greater effects of modality congruence when a person's attention in the exposure phase is explicitly drawn to the physical characteristics (e.g., modality) of the brand, rather than the semantic meaning of the brand. In this context, two distinct but related processing styles are of relevance: data-driven processing and conceptually-driven processing. Data-driven processing (also known as bottom-up processing) refers to detailed processing of mainly surface features of the stimulus. Moreover, data-driven processing is primarily concerned with recognizing and decoding the stimulus at hand without attributing meaning to it. Conversely, conceptually-driven processing (also known as top-down processing) entails generating and elaborating information and knowledge related to the stimulus (Jacoby, 1983). This mode of processing relies heavily on existing schemata to form expectations of incoming information. We argue that the effects of modality congruence on brand evaluations are moderated by receivers' processing style (data-driven vs. conceptually driven) in the exposure phase. More specifically, the effect of modality congruence is expected to be stronger when a person's attention in the exposure phase is explicitly drawn to the physical characteristics of the stimulus without attributing meaning to it. It is expected that the processing of physical features of the stimulus enhances processing fluency experienced when the modality at exposure and test are congruent. Conceptually-driven processing will attract attention to information and knowledge that can be inferred from the stimuli, rather than the characteristics of the stimuli themselves, and is therefore expected to reduce the effect of modality congruence. 


\section{OVERVIEW OF STUDIES}

In a series of four studies we focus on the interplay between advertising and evaluation contexts by examining the effects of modality congruence on processing fluency, brand evaluation and brand choice. In Study 3.1 we show that brands are processed more easily when modalities between initial brand exposure and a subsequent brand recognition task either match or mismatch. Studies 3.2 and 3.3 focus on brand evaluation and the role of consumer processing style in the effects of modality congruence. These studies demonstrate that same-modality priming leads to more positive brand evaluations than cross-modality priming, and that this effect is more pronounced when the brands are processed in a data-driven as opposed to a conceptually-driven manner. Finally, Study 3.4 extends the findings to actual advertising slogans and brand choice and shows that a brand is chosen more often when communication modalities between prior brand exposure (advertisement) and actual brand choice match.

\section{STUDY 3.1}

The first study of this chapter was designed to examine the effects of modality congruence on processing fluency. It was hypothesized that brands are recognized more easily, and therefore processed more fluently, when there is congruence (vs. incongruence) between modalities during prior exposure and during the recognition task.

METHOD

\section{Design and participants}

Study 3.1 used a single factor between-subjects design (modality: same-modality vs. cross-modality). A total of 77 undergraduate students ( 29 male and 48 female) were randomly assigned to the same-modality or cross-modality condition. Their mean age was 21.49 years $(S D=2.20)$. Participants received $€ 6$,- or course credit for their participation.

\section{Procedure}

The experimenter led participants to individual cubicles with a computer where they were told that they would participate in a sequence of unrelated studies. First, participants responded to some demographic questions after which they were aurally or visually exposed to a series of words and brand names. After an extensive filler task, participants performed a visual or aural version of a brand decision task serving as a measure of processing fluency. 


\section{Independent variable}

Modality. Participants in the same-modality condition were assigned to the brand decision task that matched the modality of the exposure phase. More specifically, in this condition, participants who were visually exposed to the words and brands completed the visual version of the brand decision task, and the participants who were aurally exposed to the words and brands completed the aural version of the brand decision task. In contrast, participants in the cross-modality condition who were visually exposed to the words and brands completed the aural version of the brand decision task, and participants who were aurally exposed to the words and brands completed the visual brand decision task.

Brand exposure phase. In the brand exposure phase, participants were exposed to a total of 40 words. They were informed that the researchers were interested in how individuals process different types of words. Ten of the 40 words were the target brands and were familiar brand names (e.g., Prada, Mars, Dove). Fifteen filler brand names (e.g., Fristi, Adidas, and Vogue), and 15 randomly chosen words (e.g., beach, tree, and windowsill) served to distract participants from the actual goal of the experiment. Participants in the aural brand exposure condition heard each word once through a headphone. On average this took three seconds. The words in the visual brand exposure condition were each displayed on the computer screen for 3 seconds to keep the duration of exposure constant over the different conditions.

\section{Dependent variable}

Brand decision task. To measure processing fluency, we created a brand decision task based on a standard lexical decision task (Meyer \& Schvaneveldt, 1971) which has been used extensively to measure concept activation and fluency. In this task, participants had to indicate as quickly and as accurately as possible (by pressing the 'a' or ';' key, respectively) whether the word presented was an existing brand name or not. Participants were presented with a total of 40 words of which 10 were the target brands from the exposure phase, 10 were filler brand names (other filler brands than in the exposure phase), and 20 strings of letters were non-existing words. In the visual brand decision task, all words were preceded by a series of Xs that remained on screen for a period of 3 seconds. Each word remained on screen until participants had decided whether the word was an actual brand name or not. In the aural version of the brand decision task, participants heard each word once and then had to indicate whether or not the brand was an existing one. All aural exposures were preceded by a pause of 3 seconds. The mean standardized response time on the ten target brands served as a measure of processing fluency.

\section{RESULTS AND DISCUSSION}

Response times below 300 ms or above 3000 ms were removed, as well as the response times on trials in which an incorrect answer was given (5\%). To control for any differences in the type of brand decision task (visual vs. aural), all response times were transformed to z-scores. In order to test the hypothesis that same-modality priming leads to 
more processing fluency than cross-modality priming, we performed an ANOVA on the mean response time on the target brands. The results demonstrated that participants in the same-modality condition responded faster to the target brands $(M=-.20, S D=.67)$ than participants in the cross-modality condition $(M=.19, S D=.94 ; F(1,75)=4.56$, $p<.05)$. This indicates that brands are processed more fluently when modalities are congruent. These results are in line with findings by Bassili, Smith, and MacLeod (1993). Hence, the extent to which brands are easily processed depends on the interplay between encoding and retrieval contexts. It can be concluded that individuals process a brand name more easily when the modality of the brand exposure matches (vs. mismatches) the modality of the recognition task. The next experiment extends this finding to brand evaluation, whereby it is argued that modality congruence positively affects brand evaluations. Furthermore, it is expected that the effect of modality congruence is stronger when participants adopt a data-driven processing style (vs. a conceptually-driven processing style) because this style is primarily concerned with processing surface features (such as modality) of the stimulus without generating additional knowledge related to the stimulus.

\section{STUDY 3.2}

The present study was designed to further examine the interplay between marketing communication and evaluation context. We tested the proposition that same-modality brand priming leads to more positive brand evaluations than cross-modality brand priming. In addition, it was expected that this effect is more pronounced when participants adopt a data-driven processing style, as opposed to a conceptually-driven processing style.

METHOD

\section{Design and participants}

To test the hypotheses we used a 2 (modality: same-modality vs. cross-modality) x 2 (processing style: data-driven vs. conceptually-driven) between-subjects design. One hundred and fifty-four undergraduate students (58 male and 96 female), with a mean age of 20.2 years $(S D=2.1)$, participated in this experiment. Participants either received course credit or $€ 6$, - for their attendance.

\section{Procedure}

On arrival at the lab, the experimenter informed the participants that the study would consist of several unrelated studies, and subsequently led them to a room with a computer that provided all further instructions. After responding to a number of demographic questions, participants were visually or aurally exposed to a series of brand names and were randomly assigned to the conceptually-driven condition or the data-driven condition. A visual versus aural brand evaluation scale was used to measure participants' attitudes towards the previously exposed brands. An awareness 
check was used to ascertain that nobody had identified the true goal of the experiment. Finally, participants were paid and thanked for their participation.

\section{Independent variables}

Modality. Similar to Study 3.1, participants in the same-modality condition were assigned to the brand evaluation task that matched the modality of the brand exposure phase, and participants in the cross-modality condition responded to the brand evaluation task that mismatched the modality of the brand exposure phase.

Processing style. Data-driven processing was induced using a procedure designed by Chung and Szymanski (1997). In more detail, we asked participants to count the number of syllables of each of the brand names they were exposed to. This task directs participants' attention to the physical and surface features of the stimuli. In contrast, conceptuallydriven processing was induced by having participants indicate at which time of the day (morning-afternoon-eveningnight) they were most likely to use each brand. This instruction directs participants towards processing the brand names at a conceptual level by elaborating on brand knowledge and features of the product usage situation (see also Leshner \& Coyle, 2000 for a similar procedure).

Brand exposure. In the brand exposure phase, participants were either visually or aurally exposed to a total of 40 brand names. Ten of these brand names were target brands and the remaining 30 were filler brands to distract participants from the real objective of the experiment. All of the target brands were real and familiar (e.g., Extran, Puma, and Armani) and covered different product categories. In the aural exposure condition, participants heard each brand name twice with a pause of 0.5 seconds in between (a procedure adopted from Butler \& Berry, 2001). After participants counted the number of syllables or indicated what time of the day they were most likely to use the presented brand, the next one was presented. In the visual exposure condition, the brand name remained on screen until participants had either indicated how many syllables it consisted of or had answered when they were most likely to use the brand. After responding to this question, the next brand automatically emerged on the screen.

\section{Dependent variables}

Mood. As a confound check to measure whether the brand exposure phase, the processing style induction or the interaction between these variables would lead to unintended mood effects, participants completed the Positive and Negative Affect Schedule (PANAS: Watson, Clarke, \& Tellegen, 1988). This questionnaire is designed to measure participants' mood state at a particular point in time and consists of 10 positive $(\alpha=.86)$ and 10 negative items $(\alpha=$ .79). This questionnaire, together with an extended irrelevant personality questionnaire, also functioned as a filler task to blur the relation between the brand exposure phase and the brand evaluation task. 
Brand evaluation task. Participants were either exposed to the visual or the aural version of a brand evaluation task. In both versions, participants saw or heard 28 brands of different product categories. Ten of these brands were the target brands from the brand exposure phase; the remaining 18 brands served as filler-items and differed from the filler brands used in the brand exposure phase. In the visual version of the task, participants saw the brand names (one at a time) and rated on a five-point semantic differential scale how positively versus negatively they rated each of the brands. The next brand emerged after participants had given their opinion of the brand on the screen. Participants who received the aural version of the task completed the same task with the difference that they heard each brand twice (with a pause of 0.5 seconds in between). The response options appeared on the screen after the aural exposure of the brand, and the next brand was presented after participants had responded. The responses on the 10 target brands were summed up and served as a measure of brand evaluation.

\section{RESULTS AND DISCUSSION}

Mood. An ANOVA on the positive items and the negative items of the PANAS indicated that mood states were not affected by the brand exposure phase, processing style manipulation, nor the interaction between brand exposure and processing style (all Fs $<1$ ). Thus, mood states cannot account for any effects on brand evaluation.

Brand evaluation. To test the hypothesis that same-modality priming leads to more positive brand evaluations than cross-modality priming, particularly for participants in the data-driven processing condition, a full factorial ANOVA was conducted on the brand evaluation scale. This analysis yielded a main effect of modality $(F(1,150)=4.11, p<.05)$, indicating that when the modalities in the exposure phase and the evaluation task match (same-modality), participants evaluated the brands more positively $(M=34.66, S D=3.76)$ than when there was no such match (crossmodality), $M=33.64, S D=3.18$. Moreover, we found a main effect of processing style $(F(1,150)=11.3, p<.01)$, showing that participants in the data-driven condition rated the brands more positively $(M=34.97, S D=3.21)$ than participants in the conceptually-driven condition $(M=33.27, S D=3.57)$. More importantly, the results yielded a significant interaction effect between modality and processing style $(F(1,150)=4.67, p<.05)$. The interaction effect indicated that the modality manipulation particularly affected brand evaluations among participants in the data-driven condition, rather than among participants in the conceptually-driven condition. Simple main effect analyses revealed that participants in the data-driven condition evaluated the brands more positively in the same-modality condition $(M$ $=36.2, S D=3.09)$, than in the cross-modality condition $(M=33.95, S D=2.96 ; F(1,150)=8.73, p<.01)$. Participants in the conceptually-driven condition did not show such an effect $(M=33.24, S D=3.79$ vs. $M=33.31, S D=3.4 ; F<$ 1, see Figure 3.1). 


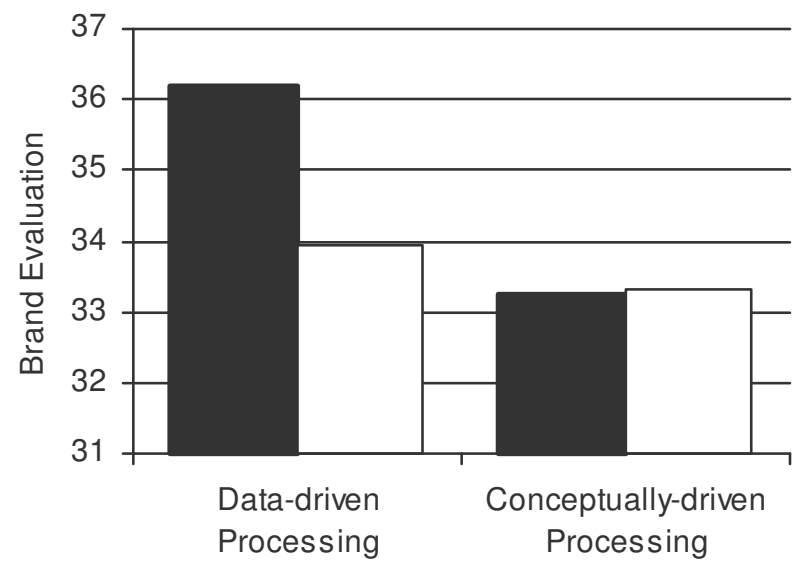

Same-modality $\square$ Cross-modality

Figure 3.1. Brand evaluation as a function of communication congruence and processing style.

These results support our hypotheses by demonstrating that same-modality priming affects brand evaluations positively but primarily under conditions of data-driven processing. As opposed to cross-modality priming, samemodality priming seems to enhance processing fluency through easier retention of the brand. The positive feelings associated with the subjective ease of processing subsequently led to more favorable evaluations through the automatic process of misattribution. Hence, brand evaluations seem to depend on the interplay between the modality in which brands are communicated during the exposure phase and the modality in which brands are communicated during the evaluation phase. Moreover, the results suggest that the effects of modality congruence are stronger when participants are instructed to pay attention to physical features by inducing a data-driven processing style than when participants adopt a conceptually-driven processing style. Hence, attention to physical features of the stimuli seems to be required to obtain benefits from modality congruence. Altogether, the findings provide supporting evidence for the notion that brand evaluations depend on the interplay between communication modalities used for advertising and communication modalities in the brand evaluation context. In the present study, we used an explicit processing style manipulation; participants were explicitly asked to count the number of syllables a brand entails (data-driven processing) or to think about the time of day they regularly use the particular brand (conceptually-driven processing). In addition, to enhance the generalizability of our findings, it is of interest to unravel more ecologically valid situations 
in which consumers generally and automatically adopt a particular processing style when seeing or hearing a persuasive message. It would be reasonable to expect that new information, as opposed to familiar information, is processed to a higher extent in a data-driven manner because new information has no related associations and knowledge stored in memory that could enhance a conceptually-driven processing style. For the present context, this could mean that new brands are automatically processed in a data-driven manner because there are no schemata concerning these brands available in memory. Therefore, it is argued that the effects of modality congruence are especially important when consumers encounter a new as opposed to a familiar brand because these brands are more likely to induce a data-driven processing style. Accordingly, Study 3.3 will test the hypothesis that the effects of modality congruence are stronger for new brands than for familiar ones.

\section{STUDY 3.3}

The aim of the present study was to examine the effects of modality congruence for new versus familiar brands. It was hypothesized that the effects of modality congruence on brand evaluation are stronger for new as opposed to familiar brands because new brands are expected to induce a data-driven processing style. As became apparent in the second study, a data-driven processing style was shown to increase the effects of modality congruence. Based on the processing fluency account (i.e., familiar stimuli induce positive evaluations) we expected an overall main effect of brands such that familiar brands are rated more positively than unfamiliar new ones because familiar information is generally processed more easily than new information (Jacoby \& Dallas, 1981). However, we argued that the processing of new information (vs. familiar information) could benefit from modality congruence because new information is proposed to induce a data-driven processing style. Hence, it was expected that new brands are rated more positively when modality is congruent versus incongruent, because the congruence in modality at exposure and evaluation will induce more processing fluency than a situation of incongruence.

METHOD

\section{Design and participants}

We used a 2 (modality: same-modality vs. cross-modality) x 2 (brands: new brands vs. familiar brands) design with modality as between-subjects factor, and brands as within subjects factor. Participants comprised 76 undergraduate students (28 male and 48 female), with a mean age of 21.22 years $(S D=2.23)$. They received course credit or $€ 6$, for their participation.

\section{Procedure}

When participants arrived at the lab, they were seated in individual cubicles equipped with a computer providing further instructions. First participants had to respond to demographic questions before being visually or aurally 
exposed to a series of familiar and new brands. Next, participants completed a filler questionnaire to obscure the real goal of the study. After this filler task, participants responded to either a visual version or an aural version of a brand evaluation task. At the end of the experiment, participants were rewarded, debriefed, and thanked for their attendance.

\section{Independent variable}

Modality. As in the previous studies, participants in the same-modality condition were assigned to the brand evaluation task that matched the modality of the exposure phase, and participants in the cross-modality condition were assigned to the brand evaluation task that mismatched the modality of the exposure phase.

Brand exposure phase. Participants were either visually or aurally exposed, on a random basis, to 30 brand names. In total, there were six target brands of which three were real and familiar and the other three were fictitious (and hence new and unfamiliar). Participants were told that they would be exposed to 30 brand names and that some of them might seem more familiar than others because a number of the brands were new or foreign. The remaining 24 brands (12 familiar and 12 new) served as filler items. In the aural exposure condition, participants heard each brand once, which took on average three seconds. To keep the duration constant, the brands in the visual exposure condition were also displayed for a period of three seconds each.

\section{Dependent variables}

Brand evaluation task. Participants completed either the visual or the aural version of the brand evaluation task. In both conditions participants rated a total of 30 brands. Six of these brands were the target brands from the exposure phase (three familiar and three new brands). The remaining 24 brands served as filler items and differed from the filler brands that had been used in the exposure phase. Participants rated on five-point scales how positively versus negatively they evaluated each of the brands. The procedure of the visual and the aural brand evaluation task was exactly the same as the one used in Study 3.2. The scores on the three familiar brands were summed up and served as a measure of familiar brand evaluation, whereas the summed scores on the new brands served as a measure of new brand evaluation.

\section{RESULTS AND DISCUSSION}

Brand evaluation. To test the hypothesis that modality congruence effects are stronger for new brands than for familiar ones, we conducted a 2 (modality: same-modality vs. cross-modality) x 2 (brands: new brands vs. familiar brands) ANOVA with repeated measures on the last factor. First, we found a main effect of brands $(F(1,74)=108.98$, $p<.001)$, indicating that the familiar brands were rated more positively $(M=10.46, S D=1.82)$ than the new brands $(M=7.86, S D=1.55)$. This result is in line with the processing fluency account stating that familiar stimuli are processed easily and are therefore rated positively. More important for the current hypothesis, the results yielded a 
significant interaction between modality and brands $(F(1,74)=4.68, p<.05)$. Analysis of the simple main effects revealed that the new brands are rated more positively by participants in the same-modality condition $(M=8.22, S D=$ 1.44), than by participants in the cross-modality condition $(M=7.51, S D=1.59 ; F(1,74)=4.09, p<.05)$. This pattern of results was not found for the familiar brands $(M=10.27, S D=1.63$ vs. $M=10.64, S D 1.99 ; F<1$, see Figure 3.2$)$.

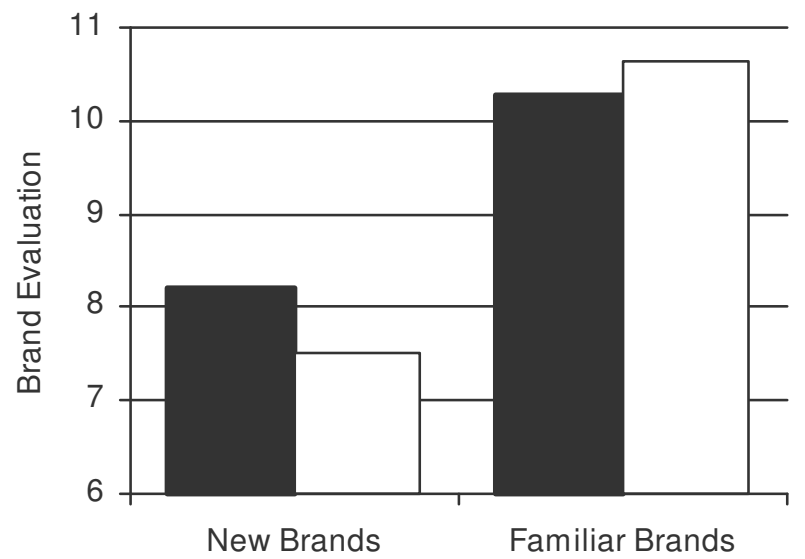

Same-modality $\square$ Cross-modality

Figure 3.2. Brand evaluation as a function of communication congruence and brand type.

The results of the present study provide additional support for our hypotheses that modality congruence leads to more favorable brand evaluations when the brands are processed in a data-driven manner. It was found that modality congruence enhances processing fluency for new brands but not for familiar brands; this defines a condition under which individuals automatically adopt a data-driven processing style leading to a greater effect of modality congruence. Study 3.4 will examine whether the effects of modality congruence can be upheld in a situation in which actual advertising slogans, rather than mere brand names, are used. Moreover, the next study will include an actual brand choice situation. 


\section{STUDY 3.4}

The present study aimed to extend the previous findings in three different ways. First, we added a control condition to the design in which participants were not exposed to the target brand. This enabled us to compare the effects of same- and cross-modality priming with a situation where there was no priming at all. Second, to externally validate the foregoing results, we used actual, real-life advertising slogans to mimic a more 'real world' situation. Finally, by using actual brand choice as the dependent variable, we tested whether the previously found modality effects carry over to affect overt consumer behavior. As the results of the previous studies indicated that modality effects are stronger when the stimuli are processed in a data-driven manner, we only applied a data-driven processing induction in this study.

METHOD

\section{Design and participants}

This experiment employed a single factor between-subjects design (modality: same-modality vs. cross-modality vs. control). One hundred and twenty eight undergraduate students (41 male and 87 female) with a mean age of 20.83 years $(S D=3.15)$ participated in the experiment. Participants were randomly assigned to either the same-modality, cross-modality or control condition and received course credit or $€ 6$, - for their attendance.

\section{Procedure}

As in the preceding studies, participants were told that the study consisted of several unrelated parts. Participants first responded to some demographic questions and were subsequently presented, either visually or aurally, with a series of advertising slogans. Similar to Study 3.2, all participants were instructed to count and report the total number of words used in each slogan. Only one brand served as the target brand (in the control condition, participants were not exposed to this brand). The brand exposure phase was followed by a mood questionnaire. At the ostensible end of the experiment participants were either visually or aurally confronted with an actual brand choice situation.

\section{Independent variable}

Modality. Participants in the same-modality condition who were visually exposed to the advertising slogans were confronted with the visual choice option, and participants who were aurally exposed to the advertising slogans were presented with the aural choice option. In contrast, participants in the cross-modality condition were presented with the brand choice in a way that was incongruent with the modality in which they were previously exposed to the advertising slogans. In the control condition, half of the participants were aurally and half were visually exposed to the 
advertising slogans and were approached either with the visual or the aural brand choice. Note that participants in the control condition were previously not exposed to the target brand.

Brand exposure phase. Participants were presented with a total of 30 different existing advertising slogans. Only advertising slogans that had both a visual (in magazines and billboards) and an aural version (on the radio) were chosen as stimulus material. The aural advertising commercials were edited in such way that the content of the slogan was exactly the same as in the visual advertisement. In each of the slogans a different brand name was present. Only one of the brands (a candy bar) served as the target brand; all other brands were used as fillers to disguise the real purpose of the experiment. In the control condition, participants were not exposed to the slogan that contained the target brand. As in Study 3.2, in the aural condition, participants heard each slogan twice (with a pause of 0.5 seconds in between). After participants had reported the number of words in the slogan (inducing data-driven processing), the next brand emerged. In the visual exposure condition, the advertising slogan remained on screen until participants had indicated how many words the slogan contained. The next brand appeared after responding to this question. In the control condition, half of the participants were visually exposed to the advertising slogans and half were aurally exposed.

\section{Dependent variables}

Mood. To measure whether the advertising slogan manipulation would lead to unintended mood effects, participants responded to the Positive and Negative Affect Schedule (PANAS: Watson, Clarke, \& Tellegen, 1988). This questionnaire measures participants' current mood state and entails 10 positive items $(\alpha=.84)$ and 10 negative items $(\alpha=.82)$.

Brand Choice. Actual brand choice was measured when participants were asked, after the ostensible end of the experiment, whether they would like a candy bar (as an expression of gratitude for participating in the study). Participants had a choice of three different bars, one of which corresponded with the target brand. In the visual condition, the candy bars were displayed on the experimenter's table and participants were told to take one of the candy bars if they wanted. Participants in the aural condition were asked whether they would like a candy bar and the available candy bars were listed (in a random order) by the experimenter. Subsequently, the experimenter took the chosen candy bar out of a closed box and gave it to the participant. The percentage of participants choosing the target brand served as the dependent variable.

\section{RESULTS AND DISCUSSION}

Fifteen participants refused a candy bar and were thus excluded from the data-analyses. A total of 113 participants (41 males and 72 females), with a mean age of 20.83 years $(S D=3.15)$, remained in the analysis. 
Mood. An ANOVA on the positive items of the PANAS indicated that the brand exposure phase had no effect on positive mood states $(F(1,110)=2.7, n s)$. Likewise, an ANOVA on the negative items of the PANAS showed no effect for negative mood $(F<1)$. Hence, mood states cannot account for the difference in brand choice.

Brand Choice. To examine the effects of modality congruence on brand choice, we performed a logistic regression with brand choice (target brand $=1$, other brands $=0$ ) as the dependent variable, and modality as our independent variable. The results showed a significant difference between the different modality conditions (Wald $(1)=7.69, p<$ $\left..01, R^{2}=.10\right)$. In the same-modality condition, $48.8 \%$ of all participants chose the target brand, in the cross-modality condition $36.6 \%$ chose the target brand and in the control condition only $16.6 \%$ of the participants chose the target brand (Pearson's chi-square $=8.27, p<.05$; see Figure 3.3).

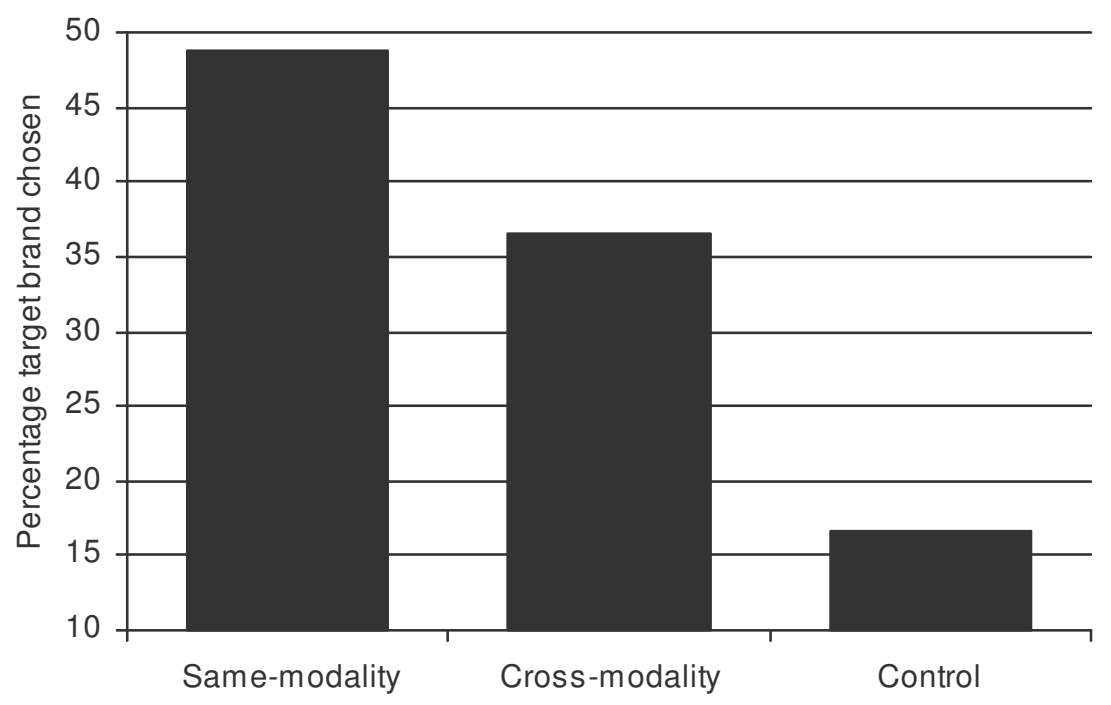

Figure 3.3. Target brand chosen as a function of communication congruence.

These results corroborate and extend the findings found in the previous studies by showing that modality congruence not only has an effect on brand evaluations but also on actual brand choice. Moreover, these results were obtained by using actual advertising slogans instead of mere brand names. 


\section{GENERAL DISCUSSION}

Across four studies we examined the interplay between brand communication modalities during brand exposure and during brand evaluation on processing fluency and subsequent appraisals and choice. Evidence was obtained for the notion that processing fluency effects (e.g., Seamon, Brody, \& Kauff, 1983) on brand evaluation and choice are stronger under conditions of same-modality priming as opposed to cross-modality or no priming. Study 3.1 showed that modality congruence has an effect on processing fluency in such a way that individuals respond faster to a brand name in a situation of same-modality versus cross-modality priming. Studies 3.2 and 3.3 revealed that same-modality priming, compared to cross-modality priming, has a positive influence on brand evaluations. Moreover, these studies showed that these effects are stronger under conditions of data-driven processing as opposed to conceptually-driven processing. In accordance with these findings, Study 3.4 demonstrated that the effects of modality congruence can be upheld in a situation in which actual brand choices are made and actual advertising slogans served as primes. Together, these results indicate that consumer responses are influenced by the interplay between advertising modality and the modality in which consumers encounter the brand again while forming their evaluations and making their decisions.

According to the processing fluency account, the fluency of a stimulus can be enhanced by prior exposure, which in turn leads to more favorable evaluations towards the stimulus. Thus, (repeated) advertising exposure decreases processing demands during the recognition and identification of the advertised brand in an (un)related situation. This experienced fluency subsequently positively affects brand evaluations and enhances the chance of being chosen through the processes of misattribution. Consumers were expected to automatically attribute the positive feelings of processing fluency to the brand at hand. We proposed that matching communication modalities between encoding (i.e., advertising) and retrieval (evaluation situation) can enhance processing fluency, which consequently positively influences brand evaluations and brand choices. The present results are consistent with this hypothesis: brands are rated more positively and have a greater chance of being chosen when they are advertised and evaluated in the same modality than when modality differs across both contexts. These results are compatible with the Encoding Specificity Principle (Tulving \& Osler, 1968, see also Kardes, 2001) and the Transfer Appropriate Processing model (TAP; see Bransford, Franks, Morris, \& Stein, 1979; Blaxton, 1989). The Encoding Specificity Principle states that stimuli are best remembered and recalled when the physical features at the exposure phase (during encoding) are similar to the features at retrieval. In addition, the TAP-model emphasizes that matching cognitive demands during exposure (i.e., learning) and retrieval leads to better performances on implicit memory tasks than a mismatch. Together, these implicit memory models indicate that a stimulus is more easily retrieved when there are no differences in stimulus-features, situation, and cognitive processes (e.g., seeing or hearing) involved in the exposure and retrieval phase. Research on the preceding implicit memory models has frequently focused on retrieval and recognition (e.g., Fisher \& Craik, 1977; Tulving \& Thomson, 1973). The current research extends these findings to 
evaluation and choice (see also Janiszewski \& Chandon, 2007). Accordingly, the present results show that evaluations were positively affected when the stimuli and situation during exposure and task had exactly the same features. Moreover, when the cognitive process required at exposure (hearing or seeing) matched the process required in the evaluation phase (hearing or seeing), brands were processed more fluently (Study 3.1 ), rated more favorably (Studies 3.2 and 3.3), and chosen more often (Study 3.4).

Studies 3.2 and 3.3, in particular, showed that processing style is an important factor in the relation between modality congruence and brand evaluations. It appears that data-driven processing, as compared to conceptually-driven processing, enhances the relationship between modality congruence and evaluations. This result was obtained by using an explicit processing style manipulation (Study 3.2), and by using new versus familiar brand names (Study 3.3). The modality congruence effect appeared more pronounced when participants' attention was explicitly drawn to physical features (by counting the syllables) and by exposure to new as opposed to familiar brands. New brands seem to automatically induce a data-driven processing style because no schema-based expectations are activated when processing new information. Hence, we uncovered a stimulus feature that intensifies the effects of modality congruence. The kind of information one is exposed to (in these studies new or familiar), seems to qualify the effects of modality congruence. Given this finding, it would also be interesting to reveal which personality traits and situational characteristics (automatically) facilitate data-driven processing. From the literature we know, for instance, that a person's mood can lead to different processing styles (e.g., Bless, Bohner, Schwarz, \& Strack, 1990; Hullett, 2005). A positive mood can be associated with conceptually-driven processing, whereas a negative mood is associated with data-driven processing. Consequently, this could mean that the effects of modality congruence are stronger under negative mood conditions.

Given the notion that consumer preferences and choices are generally not well defined but formed during the process of making a choice (i.e., 'constructed preferences'; see Novemsky, Dhar, Schwarz, Simonson, 2007), the present findings have important implications for the advertising domain. The idea of constructed preferences implies that different contexts and tasks can affect which aspects of an object or option are highlighted during evaluation and choice. The experience of processing fluency (enhanced by modality congruence) seems to influence brand evaluations and choices in a similar manner. The fluency that is experienced during brand evaluation and brand choice (i.e., during preference construction) appears to positively influence evaluations and choice through the automatic misattribution of fluency. Therefore, when developing advertising strategies, it seems beneficial to bear in mind the contexts and circumstances in which consumers make their decisions. More central to the current findings, when choosing advertising strategies (for instance, between an aural or visual advertisement), it would seem profitable to consider in what modality consumers are most likely to encounter the advertised brand again. Based on the present results, the most advantageous would seem to use visual advertisements for products sold in, for example, a supermarket where products are generally displayed visually. Aural commercial messages, on the other hand, seem best suited for products that are sold in interpersonal selling situations in which it is most likely for 
consumers to hear the brand name again. Processing style also appears to be an important factor in predicting the effects of communication modality. Particularly the evaluation of new brands seems to be influenced by modality congruence, which makes modality considerations especially relevant when launching a new brand. Moreover, it would be advisable to take product type into account. One could argue that different product types are processed in distinct ways. In general, decisions about more expensive, high-risk, and complex products induce a data-drivenprocessing style, whereas decisions about more common, low-risk, less complex products induce a more conceptually-driven processing style. Therefore, advertisements on complex, high-risk products are particularly likely to benefit from modality deliberations.

Additionally, from both a practical and a theoretical perspective, it would be interesting to examine the effects of multimodality commercial messages, i.e. a message with both visual and aural features. Research on memory for television messages, for instance, has mainly focused on audio/video redundancy effects. In these studies it is typically found that memory for messages is better when the audio and video messages are redundant as compared to dissonant (Brosius, Donsbach, \& Birk, 1996; Fox, 2004; Lang, 1995). From a modality congruence perspective, it is important to investigate whether brands presented in multi-modality messages thrive best in an evaluation or choice situation in which both features are present. We expect that they would (e.g., a store with ample display facilities and active sales representatives). Hence, these findings might be profitable for 'point-of-purchase' (POP) communications, which entail such aspects as packaging, product presentation and different dimensions of store atmosphere (e.g., visual, aural, olfactory, and tactile). Matching these POP-communication strategies with the communications strategies in advertisements appears to be beneficial to brand evaluations and choices.

Altogether, the present research provides promising evidence for the notion that processing fluency profits from congruence in communication modality. Moreover it offers new insights into the interplay between advertising and purchase contexts in automatic consumer responses. 
In the previous chapters, it was shown that marketing communications can guide consumer evaluation and choice processes without the consumer being aware of this influence. Chapter 2 focused on brand associations automatically inducing consumer goals, while Chapter 3 emphasized the role of modality congruence in processing fluency effects. Both chapters provided evidence for automaticity in consumer behavior processes and highlighted the role of brand associations and communication modalities. By showing that the interplay between encoding and retrieval contexts accounted for the observed effects, the findings in Chapter 3 also supported our notion that the automatic effects of marketing communications may be context dependent. Hence, different situational contexts resulted in different effects. The following chapter will investigate another feature of marketing communications by incorporating the role of message framing. In doing so, we will focus on another type of interplay by examining the interplay between message framing and consumer goals. It is hypothesized that framing a persuasive message in congruence with recipients' regulatory focus (i.e., regulatory fit) enhances consumers' reactions (i.e., attitudes, behavioral intentions, and actual behavior) towards the message objective (i.e., charity). Moreover, it is expected that the effects of regulatory fit are stronger for consumers with a high versus low private self-focus, because these consumers are proposed to process information that fits with their regulatory focus more easily. This positive experience of processing fluency is subsequently expected to be automatically misattributed to the message objective. The moderating role of private self-focus in regulatory fit effects is demonstrated in four studies. The misattribution process of fluency is revealed as the underlying mechanism that explains the observed moderating role of private self-focus. 
Chapter 4:

Message-Framing and Consumer Goals: The Effects of Marketing-Induced Regulatory Fit on Consumer Responses ${ }^{3}$

${ }^{3}$ This Chapter is a modified version of the manuscript Fransen, M. L., Fennis, B. M., Vohs, K. D., \& Pruyn, A. Th. H. 'Fit for charity': The role of private self-focus in the effectiveness of regulatory fit. Invited for Revision. 
In a world full of societal problems such as hunger, homelessness, illiteracy, and diseases the need for charity support cannot be exaggerated. Despite the fact that many people already engage in volunteering (National and Community Service, 2007) and donate money to charity (Giving USA foundation, 2007), fundraisers must keep continue advocating for more attention, effort, and donations to support their cause. Previous research on the determinants of charitable behavior has focused primarily on demographic and individual characteristics of volunteers and donators (e.g., Matsuba, Hart, \& Atkins, 2007), or on the techniques used by charities to convince people to help. For instance, studies on demographic variables have revealed that charitable behavior is predicted by such factors as social capital (Brooks, 2005), income (James \& Sharpe, 2007), and household structure (Burgoyne, Young, \& Walker, 2005). Moreover, individual differences such as gender (Walker et al., 2002), altruism, (Khalil, 2004; Walker, 2004), and empathy (Warren \& Walker, 1991; Basil, Ridgway, \& Basil, 2008) also influence volunteering behavior.

In another vein, there is considerable research on how to persuade consumers to comply with a request for help or money. Work on social influence (e.g., Cialdini \& Goldstein, 2004) has elucidated techniques that enhance compliance with a request. For instance, Davis and Knowles (1999) showed that small changes in a request script can produce big differences in compliance with the request. Research on advertising appeals aimed at gaining contributions to charity has shown that message elements such as pictures (Perrine, 2000), guilt appeals (Hibbert, Smith, \& Davies, 2007), as well as focusing on egoistic and altruistic motives (Nelson, Brunel, Supphellen, \& Manchande, 2006) can increase the effectiveness of these appeals. In sum, previous research highlighted either the characteristics of the donators or the features of the charity messages in explaining charitable behavior.

Yet naturalistic settings involve both people and messages, and research is heretofore mute on what happens when these two components meet. Is a charity appeal more persuasive when its motives and values are framed in congruence (vs. incongruence) with the potential donator's motivational strategies? Hence, how does the interplay between message framing and consumer goals affect subsequent consumer responses? The present research proposes that a message to convince consumers to donate to charity is more likely to be successful when it focuses on goal pursuit strategies that fit with consumers' individual goal pursuit strategies than when there is a mismatch. Hence, we argue that the interplay between individual differences in self-regulation mechanisms and the persuasion technique used by charities accounts for charity support.

Specifically, we propose that the interplay between either individual or situational differences in regulatory focus (Higgins, 1997) and the framing of a persuasive message influences whether and to what extent people are willing to be involved in charitable behavior. In addition, we argue that these regulatory fit effects on charitable behavior are stronger for people with high private self-focus because these people are especially affected by external information that is optionally relevant for the self (Hull, Slone, Meteyer, \& Matthews, 2002). Private self-focus increases the activation of self-knowledge, which renders information that fits with one's activated self-knowledge (i.e., regulatory focus) easily processed. The positive experience of processing fluency is subsequently expected to be misattributed to the message objective. In the next section we introduce the concepts of regulatory fit and private self-focus, 
followed by a discussion on how private self-focus moderates the effects of regulatory fit on charitable giving. We then present four studies showing that regulatory fit enhances charitable behavior, especially under conditions of high private self-focus.

\section{REGULATORY FIT}

Regulatory Focus Theory (Higgins, 1997) states there are two distinct mechanisms to regulate judgments and behavior, which are labeled promotion and prevention focus. When people are concerned with their ideal self, they adopt a promotion focus. This focus involves an eager strategy in the pursuit of hopes, wishes, and aspirations. Moreover, people with a promotion focus are especially sensitive to the presence or absence of positive outcomes. In contrast, when people are concerned with their ought self, they adopt a prevention focus that entails vigilant strategies to fulfill duties, obligations, and responsibilities. A prevention focus is concerned with the presence or absence of negative outcomes. Both self-regulatory strategies are independent of each other and assumed to coexist in every individual. Nonetheless, people tend to have a chronic predominant orientation focus (e.g., Higgins, 2001). In addition, regulatory foci can be made temporarily more accessible by situational features (Idson, Liberman, \& Higgins, 2000).

Past research suggests that people in a promotion orientation state are especially focused on information relating to the achievement of success, whereas those in a prevention orientation state are focused on avoiding failure (Higgins \& Tykocinski, 1992). This notion bears relevance to the domain of fundraising because charities are in constant need of resources, thereby making it possible to either encourage positive outcomes (e.g., promoting health or education) or to prevent negative outcomes (e.g., stopping starvation or diseases). Emphasizing the negative outcomes that may be averted with charity donation fits with a prevention oriented state whereas stressing the positive outcomes that may be achieved with charity fits a promotion focus. Hence, incorporating different regulatory orientation strategies may result in a better understanding of the underlying motivations to engage in charitable behavior.

Furthermore, people are not only more sensitive to information that corresponds with their own orientation state, they are also more motivated (e.g., Forster, Higgins, \& Idson, 1998) and perform better (e.g., Shah, Higgins, \& Friedman, 1998) when they use goal pursuit strategies that match their orientation state than when they use goal pursuit strategies that mismatch their orientation state. These results are in line with the principle that Higgins (2000) has termed 'value from fit' (see also Avnet \& Higgins, 2006; Higgins, 2002, 2005). This principle holds that people experience regulatory fit when they use goal pursuit strategies that match their (current) focus orientation, which in turn will increase the perceived value of their behavior. In accordance with this notion, research showed that people are more motivated by role models who fit their regulatory concerns than by role models who emphasize strategies that do not fit their orientation state (Lockwood, Jordan, \& Kunda, 2002). 
Of importance to the present research, Aaker and Lee (2006) recently distinguished two types of regulatory fit. People can experience regulatory fit (versus nonfit) when they use decision strategies that match (versus mismatch) their current focus orientation (i.e., process-based fit), and regulatory fit can be experienced when outcomes are framed in such a way that they fit with one's regulatory focus (i.e., outcome-based fit). Outcome-based fit is of particular relevance to the current research because we are interested in the interplay between message framing and individual differences in regulatory focus on charitable behavior. Hence, we focus on how charity goals are framed in persuasive messages rather than on the process that may be involved in attaining these goals.

Previous research on outcome-based fit in the domain of advertising has demonstrated that individuals are more persuaded when an advertisement is framed in line with their current orientation focus than when an advertisement mismatches their regulatory focus (e.g., Lee \& Aaker, 2004; Cesario, Grant, \& Higgins, 2004, Study 2). Moreover, Florack and Scarabis (2006) found that consumers preferred products in an advertisement that were promoted with a claim that matched rather than mismatched consumers' current orientation focus. Based on the foregoing research, then, we expect that consumers will show a stronger tendency to help and donate to a charitable cause when outcomes are framed in terms of their current regulatory focus as compared to when the outcomes are not framed in terms of their regulatory focus.

\section{RELATING REGULATORY FIT AND PRIVATE SELF-FOCUS}

In recent studies, the effects of outcome-based fit on product evaluations and other types of outcome measures have been explained by processing fluency, which is the experienced ease of processing or recalling information (e.g., Labroo \& Lee, 2006; Lee \& Aaker, 2004). These studies show that information that fits with one's regulatory focus is processed more easily than information that does not fit, and is therefore evaluated more positively. It is assumed that people automatically misattribute the positive feelings of processing fluency to the stimulus at hand. Hence, processing fluency is thought to mediate the effects of regulatory fit on evaluations. Such results are in line with previous research demonstrating that processing ease in general engenders positive evaluations (Whittlesea, 1993; Winkielman, Schwarz, Fazendeiro, \& Reber, 2003).

There are reasons to assume that private self-focus will boost the mediating role of processing fluency in the relationship between regulatory fit and charitable behavior in such a way that regulatory fit effects are stronger when consumers have a high private self-focus. Before explaining this relationship in detail we first elaborate on the concept of private self-focus.

Objective self-awareness theory (Duval \& Wicklund, 1972) states that people have the ability to focus their attention on objects and events in the external environment or on themselves, and that people can and do switch between these domains of focus. It is generally agreed that the focus on one's self has a public and a private dimension (e.g., 
Fenigstein, Scheier, \& Buss, 1975; Franzoi \& Brewer, 1984). Public self-focus is characterized by the awareness of oneself from the imagined perspective of others whereas private self-focus is characterized by attentiveness to one's inner state, personal history, or any other aspect of oneself. People with a high private self-focus tend to think frequently about themselves, scrutinize their behavior, and reflect on their thoughts. Moreover, people high in private self-focus are quick to make self-descriptive statements and are sensitive to changes in their internal state (Mueller, 1982; Scheier, Carver, \& Gibbons, 1979). In contrast, individuals with a low private self-focus show a lesser tendency to scrutinize their personal motives and states or be sensitive to them.

Private self-focus can be both situational and dispositional. In the literature, situational private self-focus is often referred to as private self-awareness and is often times manipulated by instructing individuals to focus on personal thoughts and feelings (e.g., Webb, Marsh, Schneiderman, \& Davis, 1989) or by placing them in front of a small mirror that reflects only their shoulders and head (e.g., Govern \& Marsch, 1997). Dispositional private self-focus, on the other hand, is often referred to as private self-consciousness and is assumed to be a relatively stable trait (Fenigstein, Scheier, \& Buss, 1975). In the current chapter we will use the term situational private self-focus when discussing manipulated states of private self-focus (i.e., private self-awareness), whereas the term dispositional private self-focus will be used to describe stable individual differences in private self-focus (i.e., private selfconsciousness). When discussing both, the more general term of private self-focus will be used.

Theories on private self-focus generally define private self-focus as a state that involves attentiveness to the internal, personal aspect of one's self, which results in self-evaluation. Such self-evaluation is expected to instigate a selfregulatory process aimed at reducing discrepancies between the current state and an internal norm or standard. However, Hull and colleagues (Hull \& Levy, 1979; Hull, Treuren, Ashford, Propsom, \& Andrus, 1988; Hull, Slone, Meteyer, \& Matthews, 2002) have forwarded a different perspective by emphasizing the role of information processing under conditions of high private self-focus. These authors propose that private self-focus relates to the encoding of information in terms of its self-relevance. According to their theorizing, private self-focus has an effect on behavior by enhancing sensitivity and responsiveness to aspects of the environment that are potentially relevant to the self. High private self-focus is proposed to facilitate the processing of external information in self-relevant terms. Specifically, a state of high private self-focus enhances the processing of self-relevant stimuli by activating knowledge about the self (Geller \& Shaver, 1976).

Particularly germane to the current studies, Hull, Slone, Meteyer, and Matthews (2002) found that the behavior of people high in private self-focus is more influenced by external primes than the behavior of people low in private selffocus. That is, Hull et al. (2002; Experiment 3) found that high private self-focused participants performed better on a cognitive task after an implicit success prime but worse on the same task when given a failure prime, whereas the performance of people low in private self-focus was unaffected by the primes. These effects suggest that people high in private self-focus are prone to encode external information as self-relevant. 
In accordance with these findings, we propose that high private self-focus renders consumers susceptible to external information involving a charitable request. Yet it would not be adaptive for people to walk around open, porous, and readily influenced by any and all environmental information; hence, we argue that not all information is considered self-relevant for people high in private self-focus. Rather, we propose that consumers high in private self-focus will easily relate external information that already fits with stored self-knowledge to the self. Translated into the current studies this would imply that charity appeals framed in promotion terms will be readily perceived as self-relevant to high self-focused people with a promotion focus and charity appeals framed in prevention terms will be readily perceived as self-relevant to high self-focused people with a prevention focus. Appeals framed in congruent terms are proposed to be processed easily because a state of private self-focus activates a well-organized self-schema (Geller \& Shaver, 1976). Therefore, we expect that people high in private self-focus (as opposed to low in private self-focus) will experience greater processing fluency when they encounter information that fits with stored or activated selfknowledge. Ease of processing is subsequently expected to positively influence attitudes, behavioral intentions, and actual behavior through the process of misattribution.

\section{OVERVIEW OF STUDIES}

In four studies we examine the interplay between message framing and consumers' regulatory goals. We hypothesize that consumers will show more charitable support when the charity's description fits their regulatory focus orientation (dispositional and situational) as compared with a situation in which there is no such fit. More importantly, we examine whether the effects of regulatory fit on charitable behavior are stronger for consumers with a high private self-focus (dispositional and situational) than for consumers with a low private self-focus. In Study 4.1 we demonstrate that consumers are more willing to help a charity when it is framed in terms that are congruent with one's regulatory focus than when it is framed in incongruent terms, and that this effect is more pronounced for consumers high as opposed to low in private self-focus. Studies $4.2 \mathrm{a}$ and $4.2 \mathrm{~b}$ extend these findings to actual charity donations and show that people donate more money to charity when their regulatory focus matches versus mismatches with the charity's description, especially for individuals with a high as opposed to low private self-focus. Study 4.3 reveals that the misattribution of processing fluency is the underlying mechanism accounting for the role of private self-focus in regulatory fit effects on charity support. People high in private self-focus process charityinformation that fits with their regulatory focus more easily and therefore have a more positive attitude towards the charity than participants low in private self-focus.

The current studies extend the literature on both charitable behavior and regulatory focus theory by concentrating on behavioral intentions and actual charity donations as a consequence of regulatory fit. Moreover this work highlights the role of private self-focus as a boundary condition for regulatory fit effects on charitable behavior to occur. The moderating role of private self-focus is explained by the misattribution of processing fluency. 


\section{STUDY 4.1}

Study 4.1 was designed to test whether people are more inclined to help a charity when the charity is framed in line with their regulatory focus than when the framing of the charity is not in line with their regulatory focus. It was expected that participants with an induced promotion focus would offer more aid to a charity when the charity is framed in terms of gains (attaining positive outcomes) than when the charity is framed in terms of losses (preventing negative outcomes). In contrast, participants with an induced prevention focus were expected to offer more aid to a charity that was framed in terms of losses than to a charity framed in terms of gains. Moreover, we hypothesized that these effects would be stronger for participants with a dispositional high (versus low) private self-focus because these participants are expected to be highly affected by external self-relevant information (i.e., information that fits with their current orientation focus).

\section{Design and Participants}

The experiment used a 2 (focus: promotion vs. prevention) x 2 (charity framing: promotion-framed vs. preventionframed) $\times 2$ (private self-focus: high vs. low) between-subjects design. One hundred thirty-one college students (90 male and 41 female) with a mean age of 22 years $(S D=3.08)$ took part in the experiment. Participants received $€ 6$,or course credit for participating.

\section{Procedure}

Participants were told that the experiment consisted of various unrelated parts. After responding to some demographic questions, their dispositional private self-focus was measured and either a promotion or prevention focus was induced by exposing them to promotion-based advertising slogans or prevention-based advertising slogans respectively. Subsequently, participants were asked whether they would be willing to help a charity that expressed either prevention-related or promotion-related values.

\section{Independent Variables}

Private self-focus. Private self-focus was measured using the Private Self-Consciousness scale originally developed by Fenigstein, Scheier, and Buss (1975; Vleeming \& Engelse, 1981). This scale measures stable individual differences in private self-focus $(\alpha=.74)$. Participants rated a total of 10 statements (e.g., 'I reflect on myself a lot' and 'I'm generally attentive to my inner feelings') on a five-point Likert scale ( 1 = extremely uncharacteristic, $5=$ extremely characteristic). To obtain an index of dispositional private self-focus, we calculated the mean score of the responses on the ten statements. Based on a median split (median $=3.4$ ), participants were classified as either high or low in private self-focus. 
Focus manipulation. Situational regulatory focus was activated by exposing participants to four brand logos of different product categories (i.e., cars, clothing, facial cosmetics, and airlines). These four logos were accompanied by either promotion-based (i.e., 'Its Your Goal!', 'Fits Your Ambition', 'Retains Your Youth', 'Straight to your Dreams') or prevention-based (e.g., 'Your Safety is Our Priority', 'Fits your Responsibility' 'Prevents Aging', 'Smooth \& Save') slogans (for a similar procedure see Aaker \& Lee, 2001; Fransen, Fennis, \& Pruyn, 2007). During exposure, participants were asked to provide their opinion on three statements regarding the brand logos and the slogans (e.g., 'the slogan is well formulated') in order to keep their attention on the brands. No time limit was given.

A pretest was conducted to test whether the slogans activated the corresponding orientation focus. Participants ( $\mathrm{N}=$ 36) were exposed to the advertising slogans, as described above, and subsequently responded to three different items, which were labeled as 'personal choices' (Pham \& Avnet, 2004). Participants were asked to choose one of two statements that anchored opposite ends of seven-point scales ( $1=$ ideal; 7 = ought). The three items all started with 'I would prefer to.... Participants could indicate which statement they would prefer at this moment in time (e.g., 'take a trip around the world' vs. 'pay back my loans'). Participants' ratings were added and then divided by the number of items (three) to arrive at an index of orientation focus ranging from 1 (emphasis on ideals) to 7 (emphasis on oughts). As expected, participants who were exposed to the prevention-based advertising slogans scored higher on this measure $(M=3.06, S D=0.84)$, indicating a relatively greater emphasis on oughts compared to participants who saw the promotion-based slogans $(M=2.44, S D=.34),(F(1,34)=8.0, p<.01)$.

Charity framing. Participants were instructed to read the description of an existing but unfamiliar charitable organization (G.S.A.P.; General Society for African Projects) that expressed their goals either in eager terms aimed at realizing desirable outcomes (e.g., 'Our main aim is to make sure that children can go to school so they can learn how to read and thus realize their ambition and dreams') or in vigilant terms, aimed at avoiding failure (e.g., 'Our main aim is to make sure that children can go to school so we can prevent illiteracy and a lack of education and thus forestall unemployment'). Participants were randomly assigned to the promotion-framed or prevention-framed charity information.

\section{Dependent Variable}

Charity support. To measure inclination to support the charity, participants were asked whether 1) they would like to receive more information about the charity, 2) they would be willing to help the charity by distributing flyers, 3) they would donate money, and 4) they would leave their email address so they could be contacted when the charity needed help and support in the future $(\alpha=.76)$. The number of times participants responded positively (i.e., with a 'yes') were summed up and served as our dependent variable (range 0-3). 


\section{RESULTS AND DISCUSSION}

Charity support. We conducted a 2 (focus: promotion vs. prevention) $\times 2$ (charity framing: promotion-framed vs. prevention-framed) $\times 2$ (private self-focus: high vs. low) analysis of variance (ANOVA) to test two of our hypotheses: that participants would offer more help to a charity whose values correspond with their current orientation state and that this interaction effect would be moderated by participants' private self-focus. As expected, a significant interaction effect between regulatory focus and charity framing was found $(F(1,123)=7.84, p<.01)$. The means showed that participants in the promotion focus condition were more willing to help a charity framed in promotionrelated values $(M=.55, S D=1.06)$ than a charity framed in prevention-related values $(M=.15, S D=.62)$, whereas participants in the prevention focus condition were more inclined to help a charity expressing prevention-related values $(M=.32, S D=.84)$ than a charity expressing promotion-related values $(M=.06, S D=.35)$.

Moreover, the results yielded the predicted three-way interaction between regulatory focus, charity framing and private self-focus $(F(1,123)=5.27, p<.05)$, indicating that the interaction between regulatory focus and charity framing is more pronounced for participants with a high private self-focus than for participants low in private selffocus. Simple main effect analyses revealed that among participants high in private self-focus, a situationallyactivated promotion focus led to more help to the promotion-framed charity $(M=.65, S D=1.18)$ than to the prevention-framed charity $(M=.10, S D=45), \quad(F(1,123)=5.65, p<.05)$. Conversely, participants high in private self-focus with a situational prevention focus offered more help to a prevention-framed charity $(M=.92, S D=1.24)$ than to a promotion-framed charity $(M=.13, S D=.50),(F(1,123)=8.03, p<.01)$. For participants with a low private self-focus this pattern was not found (both $F_{S}<1$, see figure 4.1). 
Private Self-Focus: High

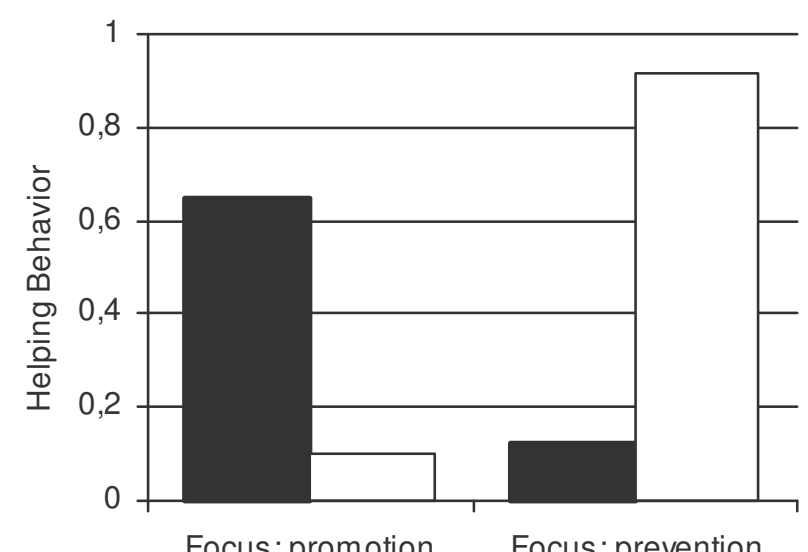

Charity: promotion $\square$ Charity: prevention
Private Self-Focus: Low

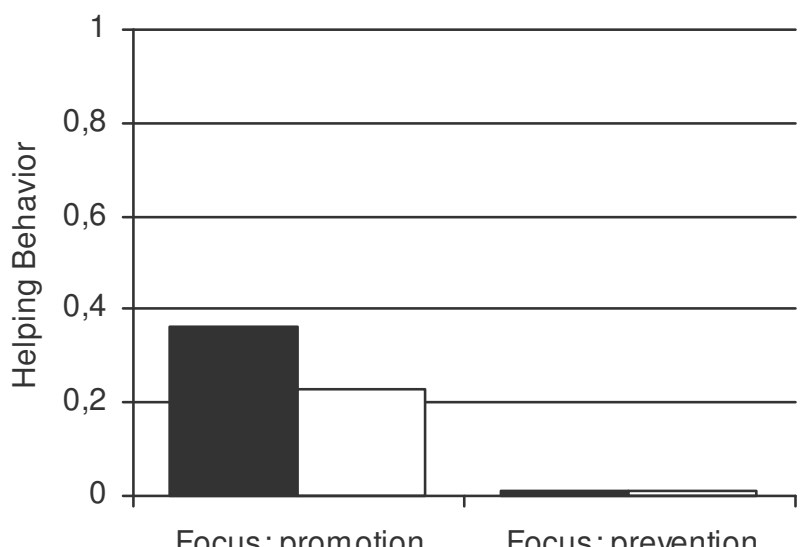

Charity: promotion $\square$ Charity: prevention

Figure 4.1. Helping Behavior as a function of regulatory focus, charity framing, and private self-focus.

The results of study 4.1 provided a first empirical demonstration of our hypothesis that the interplay between message framing and consumers' current regulatory goals determines charity support. The findings showed that people are more willing to contribute to charity when the charity expresses its objectives in such a way that they fit with people's currently activated regulatory focus than when there is no such fit. Moreover, the present findings are the first to show that private self-focus moderates the effects of outcome-based regulatory fit. High private selffocused individuals were more affected by external information that fit with their regulatory focus than were low private self-focused individuals. These results offer initial support for the notion that the focus on one's private self activates self-knowledge (i.e., one's regulatory orientation) making information that matches with this knowledge highly influential. To extend these findings to actual behavior, rather than behavioral intentions, the next two studies focus on actual charity donations. 


\section{STUDY 4.2A}

The aim of this study was to extend the findings of the first study in several ways. First, we switched to focusing on actual monetary donations as the dependent variable, rather than behavioral intentions. The study of actual behavior is lacking in much of the so-called behavioral sciences - in part because such data are difficult to collect and perhaps find significant results within them (Baumeister, Vohs, \& Funder, 2007). Therefore a move to gathering behavioral data represents a significant advance beyond stated intentions. Second, the present study measured participants' trait regulatory focus rather than the state manipulation of regulatory focus employed in the first study. This change goes toward construct validity by attempting to find converging evidence using state manipulations as well as trait assessments. Third, a private self-focus manipulation was used to establish that the previously found results also hold when private self-focus is momentarily induced. We expected that people would donate more money to a charity whose message is framed in terms that fit with their predominant regulatory focus than when there was no such fit. Furthermore, this effect was expected to be stronger under conditions of situational high (versus low) private self-focus.

METHOD

\section{Design and Participants}

Our predictions were tested in a 2 (regulatory focus: promotion vs. prevention) $\times 2$ (charity framing: promotion vs. prevention) $\times 2$ (private self-focus: high vs. low) design with regulatory focus and private self-focus as between subjects variables and charity framing as a within subjects variable. Fifty-three undergraduate students (27 males and 26 females) participated in the experiment $\left(M_{\text {age }}=20.94, S D_{\text {age }}=2.80\right)$. Participants were provided with course credit and $€ 6$, -

\section{Procedure}

Upon arrival in the lab participants were told that the experiment consisted of several unrelated parts. First, they responded to some demographic questions after which their predominant regulatory focus was measured. Subsequently, private self-focus was manipulated and participants read information about two charities. One of the charities was framed in promotion-related terms whereas the other was framed in prevention-related terms. Finally, participants were asked if they would like to donate money to either one or both charities. After data collection was done, the amount of money raised during the experiment was indeed donated to the two charities.

\section{Independent Variables}

Private self-focus. To activate situational private self-focus we used a procedure developed and validated by Fenigstein and Levine (1984). In this task participants in the high private self-focus condition were instructed to write 
a story using the following words (target words italicized): ' 'forgetting', 'me', 'throwing', 'solve', 'glove', 'case', 'shampoo', 'my', 'never', 'face', 'alarm clock', 'alone', 'bike'. In the low private self focus condition the target words were replaced by the words 'he', 'himself', 'his', 'him', and 'together'.

Regulatory focus. We used the Regulatory Focus Questionnaire (Higgins et al., 2001), comprising six promotionitems $(\alpha=.66)$ and five prevention items $(\alpha=.55)$ to establish whether participants had a predominant promotion or prevention focus. A procedure developed by Cesario, Grant, \& Higgins (2004) was used to assess whether participants were predominantly promotion or prevention focused. To this end, difference scores were calculated between the mean scores on the promotion items and the mean scores on the prevention items. A median split (median $=.23$ ) was then performed to classify participants as either promotion or prevention focused.

Charity framing. Participants were informed that a group of researchers in the faculty had decided to start supporting two different charities, G.S.A.P and Nepal Pariwar, and that they were looking for donators. One of the charities was framed in promotion-related terms whereas the other charity was framed in prevention-related terms. The framing of the charities was randomized; half of the participants read the information about G.S.A.P. in a promotion framing (e.g., 'Our main aim is to make sure that children can go to school so they can learn how to read and thus realize their ambition and dreams') and the information about Nepal Pariwar in a prevention framing (e.g., '...to make sure that children don't have to go to school in an unhygienic and unsafe environment'). The other half of the participants read the information about G.S.A.P. in prevention-related terms (e.g., 'Our main aim is to make sure that children can go to school so we can prevent illiteracy and a lack of education and thus forestall unemployment'), and the information about Nepal Pariwar in promotion-related terms ("...to make sure that children can go to school in a hygienic and safe environment'). Both charities do exist and have the goal to stimulate educational programs in third world countries.

\section{Dependent Variable}

Charity donation. After reading the description of the charities participants were asked whether they wanted to donate any part of the money they earned from participating in the study to one or both charities. Participants were free to donate whatever amount they wanted (if at all). The amount of money donated to either charities served as the dependent measure.

\section{RESULTS AND DISCUSSION}

We tested two main hypotheses in this study. First, that participants would donate more money to a charity that was framed in terms that corresponded to their dispositional regulatory focus than a charity that was framed in a manner that mismatched their regulatory focus. Second, it was tested whether this effect would be moderated by situational private self-focus. Hence, a 2 (regulatory focus: promotion vs. prevention) x 2 (charity framing: promotion vs. 
prevention) $\times 2$ (private self-focus: high vs. low) ANOVA with repeated measures on the second factor was conducted. As expected, we found an interaction effect between regulatory focus and charity framing $(F(1,49)=$ 5.99, $p<.05)$. Participants with a predominant promotion focus donated 1.75 Euro $(S D=1.55)$ to the promotion framed charity and 1.12 Euro $(S D=1.24)$ to the charity framed in prevention related terms. Conversely, participants with a predominant prevention focus donated 1.52 Euro $(S D=1.64)$ to the charity when it was framed in preventionrelated terms and 1.08 Euro $(S D=1.24)$ to the promotion framed charity.

Moreover, a significant three-way interaction between regulatory focus, charity framing, and private self-focus qualified the two-way interaction in line with our predictions $(F(1,49)=6.20, p<.05)$. Simple main effect analyses revealed that among participants in the high self-focus condition, a predominant promotion focus elicited higher monetary donations to a promotion framed charity $(M=1.94, S D=1.81)$ than to a charity framed in preventionrelated terms $(M=.90, S D=1.17),(F(1,49)=5.49, p<.05)$. In contrast, in the high private self-focus condition, a predominant prevention focus produced higher monetary donations to the prevention framed charity $(M=1.87, S D=$ $1.90)$ in comparison to the promotion framed charity $(M=.80, S D=1.11),(F(1,49)=7.20, p<.01)$. In the low private self-focus condition regulatory fit did not affect charitable behavior, both $F_{S}<1$, (see figure 4.2).

Private Self-Focus: High

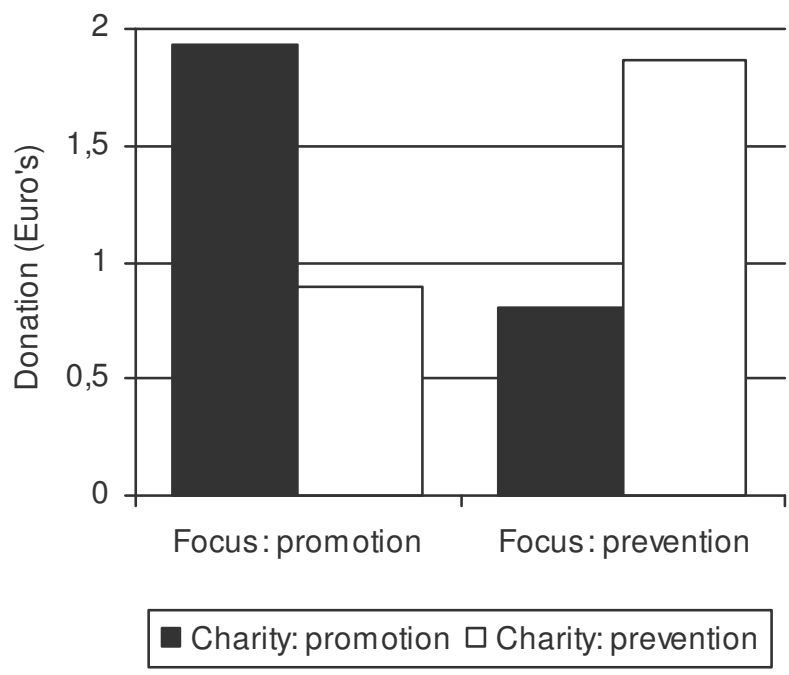

Private Self-Focus: Low

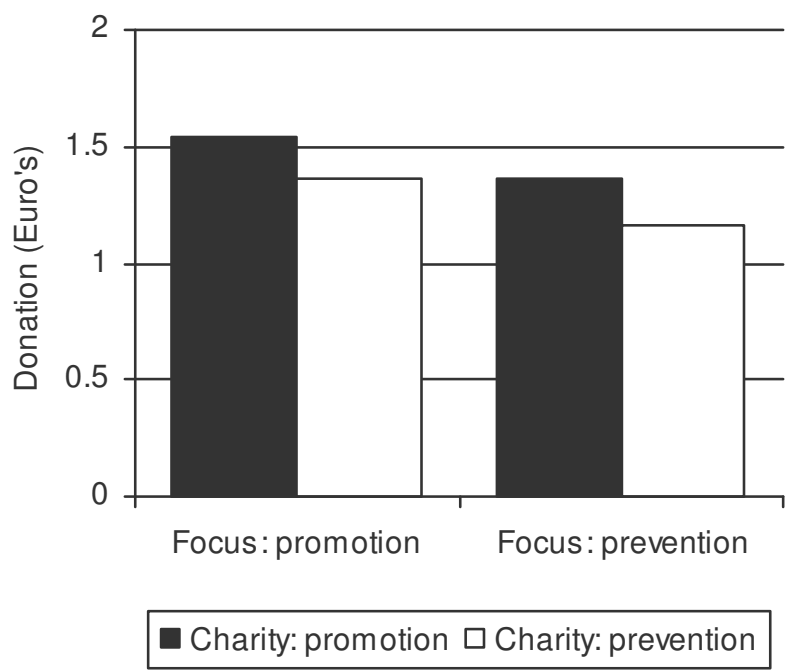

Figure 4.2. Charity donations as a function of regulatory focus, charity framing, and private self-focus. 
The findings of this study corroborate and extend the results of the first study by showing that people actually donate more money to a charity when its message is framed in terms that are congruent (versus incongruent) with their dispositional orientation focus, and that this effect is contingent on a private self-focus state. Moreover, the results generalized to a situation in which participants' private self-focus was manipulated instead of merely measured, which yields additional evidence for the notion that the effects of regulatory fit on charitable giving are stronger for people high in private self-focus, either as an individual difference characteristic or situational factor.

One could argue that the donations in this study may have been particularly easy to solicit given that participants were offered 6 Euros for attending the study insofar as participants may have viewed the participation payment as money that must be spent in the experiment. This effect is known in the literature as 'endowment' or the 'found money effect' (Cummings \& Taylor, 1999; Rutström, 1998) and it predicts that people will more easily give away money that they just received than money they have to pay out of their own pockets. From a practical standpoint, and to control for the endowment effect, it seems important to examine whether the results also will hold for a situation in which the initiative to donate money comes from within participants, insofar as the situation requires them to draw out their wallet and choose the amount they wanted to give (if so desired). Therefore, the next study assessed the moderated effects of regulatory fit on charitable giving, but in this case we rewarded participants with course credit rather than money. Moreover, Study 4.2b used another charity to establish that the effects observed thus far are not limited to the charities used in Studies 4.1 and 4.2 a.

\section{STUDY 4.2B}

The present study's goal was to replicate the results of Study 4.2a with some important changes. The first adaptation concerned the charity. The previous studies used the description of a charity that had the aim to support educational projects in third world countries. Because the participants in the previous studies were university students, this particular charity may have been especially relevant for them and thus may have facilitated their donations. To be sure, this does not disqualify the fact that we still found relative differences between conditions, but nonetheless a new context seemed desirable for the ensuing experiment. Therefore, we changed the subject of the charity from education to health care, thereby making it possible to generalize our results to different charities. A second key distinction in the current study is that participants were not paid for their attendance; rather, donations were participants' own money out of their own wallets. Third, we thought it prudent to measure and potentially control for unintended mood effects. Hence we adopted a mood measure with the aim to establish that regulatory fit has no effect on mood. Fourth, we opted to use a different private self-focus manipulation that has been validated in previous research (Webb, Marsch, Schneiderman, \& Davis, 1989; Silvia, 2001) so as to add converging evidence to our hypothesis that private self-focus moderates the effects of regulatory fit. 


\section{Design and Participants}

A 2 (regulatory fit: fit vs. non-fit) $\times 2$ (private self-focus: high vs. low) between-subjects design was used to test our hypotheses. A total of 62 undergraduate students (47 female) with a mean age of $19(S D=1.73)$ years participated. They received course credit for their attendance.

\section{Procedure}

Participants were told at the start of the experiment that they would take part in a series of unrelated studies. After answering demographic questions, participants responded to the Regulatory Focus Questionnaire in order to determine their predominant regulatory focus. Next, private self-focus was manipulated. Last, participants were asked to donate money to a charity that was described in a way that either or not fit their regulatory focus. The amount of money raised during this experiment was once again donated to the charity.

\section{Independent Variables}

Regulatory focus. Similar to Study 4.2a, regulatory focus was measured by the Regulatory Focus Questionnaire (Higgins et al., 2001). Predominant regulatory focus was calculated by subtracting the mean scores on the prevention items $(\alpha=.72)$ from the mean scores on the promotion items $(\alpha=.67)$. A median split (median $=.23)$ on the difference score was used to categorize participants as either predominantly promotion or prevention focused.

Private self-focus. High private self-focus was activated by asking participants to concentrate on their inner thoughts and feelings and write down what they were currently thinking and feeling (Webb, Marsch, Schneiderman, \& Davis, 1989). Moreover, we asked them to respond to several questions regarding themselves (e.g., What are your initials?; In what way are you different from your family? Silvia, 2001). The low private self-focus condition oriented participants to information unrelated to the self. Participants in this group engaged in a task that asked for conceptual similarities among various items. They were given four or five words and asked to indicate which word did not belong to the group (e.g., Pluto, Snoopy, Uranus, and Mars). We timed the tasks and found that both tasks lasted an equivalent amount of time.

Charity framing. Participants read information about the charity HealthNet Pro, which is concerned with health promoting programs in natural disaster areas. This real charity was unknown to our participants; an informal survey of our student participant population indicated that none had heard of the charity previously. Description of the charity was either promotion-framed (e.g., '...we also distribute medicines to promote people's health on the short term') or prevention-framed (e.g., '... we also distribute medicines to prevent people from getting ill on the short term'). 


\section{Dependent Variables}

Charity donation. As in Study 4.2a, participants were informed that a group of faculty researchers had decided to start supporting a charity and that they were looking for additional donors. Subsequently, participants read information about the charity (either promotion- or prevention- framed) and were told that they were free to donate any amount of money they desired. Note that participants in this study were not monetarily rewarded for their participation and hence their donations were drawn from their own private resources.

Mood. To determine whether regulatory fit led to unintended mood effects, we employed a six-item situational mood measure. Participants were asked to indicate on 5 -point scales ( $1=$ totally disagree, $5=$ totally agree) how negative, satisfied, angry, happy, positive, and sad they felt $(\alpha=.81)$. Item scores were averaged to create a situational mood index.

\section{RESULTS AND DISCUSSION}

Because of the relatively small sample size $(\mathrm{N}=62)$, we created separate fit and non-fit conditions before analyzing the data. Participants in the fit condition were exposed to information that was congruent with their predominant regulatory focus (promotion/promotion or prevention/prevention) whereas participants in the non-fit condition were exposed to information about the charity that was incongruent with their regulatory focus (promotion/prevention or prevention/promotion).

Mood. To establish whether there were any unintended mood effects we performed a full factorial ANOVA on the mood measure. The results revealed no significant effects (all $F_{S}<1$, except the interaction effect between regulatory fit and private self-focus $(F(1,58)=1.93, n s)$. Hence, mood states cannot account for the observed effects.

Charity donation. Data were submitted to a 2 (regulatory fit: fit vs. nonfit) $\times 2$ (private self-focus: high vs. low) full factorial ANOVA with monetary donations as the dependent variable. We found a main effect of private self-focus $(F(1,58)=7.081, p<.05)$, indicating that participants with a high private self-focus donated more money to charity $(M$ $=.56, S D=1.12)$ than participants with a low private self-focus $(M=.19, S D=.60)$. Moreover, we found a main effect of regulatory fit $(F(1,58)=7.58, p<.01)$, showing that participants donated more money to the charity when its description fit with their predominant regulatory focus $(M=.60, S D=1.18)$ than when there was no such fit $(M=.18$, $S D=.53$ ). Most germane to the current hypothesis, the predicted interaction effect between regulatory fit and private self-focus was also found $(F(1,58)=6.51, p<.05)$. Simple main effect analysis revealed that in the high self-focus condition, participants donated more money to charity when there was fit $(M=1.35, S D=1.60)$ than when the charity description did not fit their predominant regulatory focus $(M=.19, S D=.51),(F(1,58)=13.52, p<.01)$. In the low selffocus condition, this pattern was not found $(F<1$, see figure 4.3$)$. 


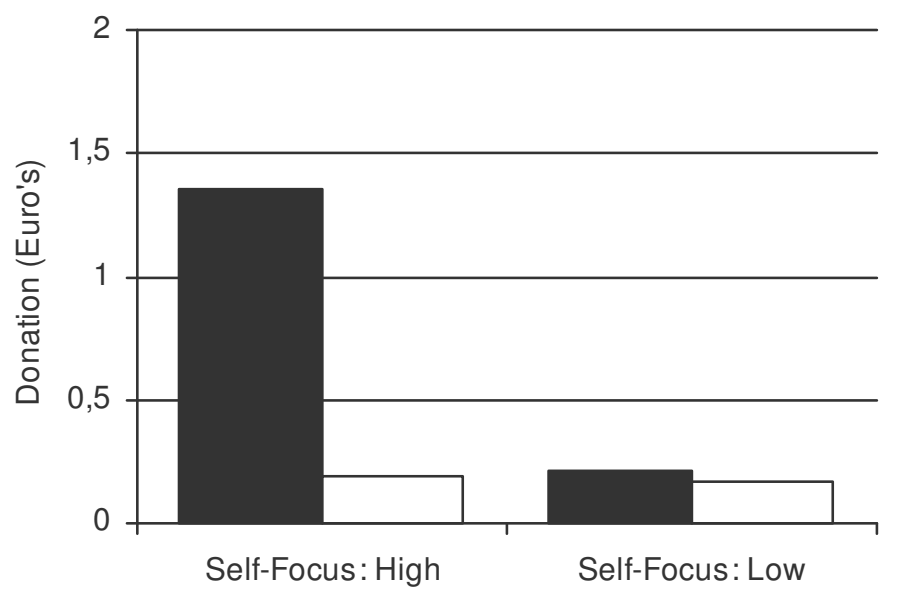

- Fit $\square$ Nonfit

Figure 4.3. Charity donations as a function of regulatory fit and private self-focus.

In extension of Study $4.2 \mathrm{a}$, the findings of Study $4.2 \mathrm{~b}$ showed that participants donate more money to a charity concerned with a cause framed in terms that are congruent (vs. incongruent) with individuals' predominant orientation focus. Moreover, the domain of the charity seems not to be an important variable, per se, in that we obtained the same pattern of effects on a different charity than had been used previously. Additionally, the use of a mood measure ruled out the alternate explanation that regulatory fit induces positive mood states, which could have affected donations.

We did find, as expected, that private self-focus - this time activated with a different procedure - moderated the regulatory fit effect. This finding contributes to our overarching idea that regulatory fit effects are stronger among people with a dispositional or situational high private self-focus. Furthermore, the results of the preceding study were replicated despite the fact that participants did not receive money for participating in the experiment and that the description of another charity was used. These extensions are of particular relevance in that they generalize the results to different situations and charities. Study 4.3 disentangled the underlying process that drives the interaction effect between regulatory fit and private self-focus by examining the role of processing fluency. 


\section{STUDY 4.3}

The results of Study $4.2 \mathrm{~b}$ suggested that the observed effects are not due to personal relevance or familiarity with the charity. We described a charity in Study $4.2 \mathrm{~b}$ with which our participants were unacquainted and the goal of the charity (to promote health programs in natural disaster areas) was not a goal to which our student participants felt strongly committed. Nonetheless, we did not have direct measures of personal involvement in Study 4.2b, which means that we cannot be certain that some personal relevance may have been lurking in our effects. Hence to provide an unequivocal test of this notion, the present study included a measure of involvement to rule out this alternate explanation.

However, the main objective of Study 4.3 was to test for the underlying mechanism that may explain the interaction between regulatory fit and private self-focus on charity support. We hypothesized that participants who possess a strong private self-focus process information that is relevant to their current regulatory orientation rather easily because the information fit with their activated self-knowledge. This experience of processing fluency is subsequently expected to be misattributed to the message objective. We hypothesized that this process does not occur within participants who possess a weak private self-focus because their self-knowledge is activated to a lesser extent, which makes for less of an impact when incoming information matches or mismatches their regulatory orientation. Hence, it was expected that people with a high private self-focus experience greater processing fluency when experiencing fit than do people low in private self-focus. Hence, based on earlier research (e.g., Whittlesea, 1993; Winkielman, Schwarz, Fazendeiro, \& Reber, 2003), heightened ease of processing is hypothesized to yield positive attitudes towards the charity by the process of misattribution.

METHOD

\section{Design and Participants}

The present study used a 2 (regulatory fit: fit vs. non-fit) $\times 2$ (private self-focus: high vs. low) design with ease of processing and charity attitude as dependent variables. Fifty-one undergraduate students (15 male, 36 females) participated for course credit or $€ 6,-$. Their mean age was $21(S D=2.36)$ years.

\section{Procedure}

The experimenter told the participants they would be taking part in a sequence of unrelated studies. Next, participants responded to some demographic questions after which regulatory focus and private self-focus were manipulated. Subsequently, participants read information about a charity (either promotion- or prevention-framed) and responded to both a processing fluency measure and an attitude measure. 


\section{Independent Variables}

Regulatory focus. Participants' regulatory focus was manipulated by a procedure developed by Freitas and Higgins (2002; Study 2) that has been found to induce temporarily states of promotion or prevention orientations. Participants in the promotion focus condition received a questionnaire entitled 'Hopes and Aspirations' and were asked to describe a current wish, dream, or ambition. Participants in the prevention focus condition were asked the complete a questionnaire entitled 'Duty and Obligation' and were asked to describe a current duty or obligation.

Private self-focus. We manipulated private self-focus by asking participants to concentrate on their internal feelings and answer questions regarding themselves (Silvia, 2001). During this task, participants saw their upper body and face (via a webcam) on one side of the computer screen, which is a procedure known to elicit a strong private selffocus (Govern \& Marsch, 1997). Participants in the control condition were instructed to solve some undemanding mathematical problems. They were presented with a series of numbers that they had to complete by filling in the answer (e.g., 1-3-6-?). Both tasks took the same amount of time.

Charity framing. As in Studies 4.1 and 4.2b, participants read information about the charity G.S.A.P, which was either framed in promotion-related terms or in prevention-related terms.

\section{Dependent Variables}

Participants were informed that a group of faculty researchers had decided to support a charity aimed at helping educational projects in third world countries, and that they would like to know what students think of this charity.

Processing fluency. After reading the information of the charity (either promotion- or prevention-framed), ease of processing was measured using the average of the following two items: 1) how difficult it was to process the information and 2) how difficult it was to understand the information (see Lee \& Aaker, 2004). Agreement with the statements was indicated using a seven point scale $(1=$ very difficult, $7=$ not difficult at all).

Attitude toward the charity. Participants' attitude toward the charity was measured by seven bipolar adjective scales on five-point scales. The scales assessed how positive vs. negative, bad vs. good, useless vs. useful, unreliable vs. reliable, unimportant vs. important, uninteresting vs. interesting, and ineffective vs. effective the charity seemed to participants. The average score on these seven items $(\alpha=.65)$ served as the dependent variable.

Involvement. To rule out involvement as an alternative account of the findings, we included a four-item measure using 7-point scales ( $1=$ not at all, 7 = very much so). Participants were asked to rate the following items: How involved were you while reading the information about the charity?; How interested were you while reading the information about the charity?; How carefully did you read the information about the charity?; and How much attention did you 
pay to the information about the charity? Scores on the items were averaged $(\alpha=.73)$ to arrive at an index of involvement.

\section{RESULTS AND DISCUSSION}

As in Study $2 b$ we created a fit and a nonfit condition, due to a small sample size $(\mathrm{N}=51)$, before analyzing our data.

Involvement. To determine whether participants in the fit condition were more involved in reading the charity information than participants in the non-fit condition, we conducted a full factorial ANOVA on the index of involvement. As anticipated, none of the effects were significant (all $F_{S}<1$ except the main effect of private self-focus $(F(1,47)=1.14, n s)$. Hence, involvement cannot account for the observed effects in our studies.

Processing fluency. To test the hypothesis that regulatory fit leads to greater ease of processing, especially for participants high in private self-focus, we performed a 2 (regulatory fit: fit vs. nonfit) $\times 2$ (private self-focus: high vs. low) ANOVA on the ease of processing measure. The results yielded the predicted interaction effect between regulatory fit and private self-focus $(F(1,47)=6.35, p<.05)$. No main effects of private self-focus and regulatory fit were found. Analysis of the simple main effects revealed a marginally significant effect $(F(1,47)=3.60, p=.06)$, demonstrating that participants high in private self-focus processed the charity information more easily under conditions of regulatory fit $(M=6.18, S D=.89)$ than when fit was absent $(M=5.54, S D=.66)$. In the low private selffocus condition no difference was found between the fit and the nonfit condition $(F(1,47)=2.79$, ns).

Attitude toward the charity. A 2 (regulatory fit: fit vs. nonfit) x 2 (private self-focus: high vs. low) factorial ANOVA tested the hypothesis that regulatory fit positively affects attitudes, particularly when private self-focus is high. The results demonstrated a marginally significant effect of regulatory fit $(F(1,47)=3.70, p=.06)$, indicating that participants evaluated the charity more positive in the fit condition $(M=4.01, S D=.46)$ compared to the nonfit situation $(M=3.77, S D=.43)$. No main effect of private self-focus was found.

More importantly, a significant interaction effect between regulatory fit and private self-focus was obtained $(F(1,47)=$ 3.93, $p=.05)$. Simple main effect analysis showed that participants with a high private self-focus evaluated the charity more positively in the fit condition $(M=4.12, S D=.31)$ compared to the nonfit condition $(M=3.64, S D=.35)$, $(F(1,47)=7.83, p<.01)$. This effect was not found among participants with a low private self-focus $(F<1)$.

Mediation analysis.To test whether ease of processing indeed mediated the interaction effect between regulatory fit and private self-focus on charity attitude, we followed the procedure outlined by Muller, Judd, and Yzerbyt (2005). Regression analyses confirmed the earlier reported significant interaction effects between regulatory fit (dummy coded) and self-focus (dummy coded) on both charity attitude ( $\beta=.48, t(47)=1.99, p=.05)$ and ease of processing $(B=.61, t(47)=2.52, p<.05)$. When processing fluency (the proposed mediator) and the interaction between private 
self-focus and processing fluency were added to the original regression model as predictors of charity attitude, the interaction between regulatory fit and private self-focus dropped to nonsignificance $(B=.28, t(47)=1.15, p>.20)$, whereas the effect of processing fluency remained significant $(B=.52, t(47)=2.87, p<.01)$. Hence processing fluency is confirmed as the mediator of the interaction effect between regulatory fit and private self-focus on charity attitude.

The present findings demonstrated that processing fluency underlies and explains the interaction between regulatory fit and private self-focus. Participants with dispositionally high private self-focus processed information that fit their currently activated regulatory focus (i.e., self-knowledge) more easily than information that did not fit their regulatory focus. This processing fluency subsequently yielded more positive attitudes toward the charity because this positive experience is misattributed to the charity. These results supported our predicted model, which states that outcomebased regulatory fit effects on charity behavior are stronger when people have a high private self-focus because this state activates self-knowledge which in turn makes it easier to process information that fits with this knowledge.

\section{GENERAL DISCUSSION}

The aim of the present studies was twofold. First, we hypothesized that consumers offer strong charity support when their regulatory focus fits with the framing of the charity. Hence, we examined the interplay between message framing and consumers' regulatory goals. Second, we hypothesized that these effects of outcome-based fit are stronger for consumers with high private self-focus as opposed to those with low private self-focus. In a series of four studies, we found support for these hypotheses. It was found that participants with a promotion focus were more willing to help a charity (Study 4.1), donate to charity (Studies $4.2 \mathrm{a}$ en $4.2 \mathrm{~b}$ ), and had a more positive attitude towards the charity (Study 4.3) when the charity described its goals in eager terms (aimed at attaining positive outcomes) than when the charity described its goals in vigilant terms (aimed at preventing negative outcomes). The opposite was found for people with a prevention focus. These participants were more positive about and willing to aid the charity when it was described in vigilant terms. Thus, the interplay between message framing and consumers' motivation goals accounts for the extent to which consumers are willing to contribute to charity. Moreover, as hypothesized, we found evidence for the moderating role of private self-focus. The four studies revealed that the aforementioned regulatory fit effects were stronger for participants with high (as opposed to low) private self-focus.

The regulatory fit effects found in these studies extend previous work on regulatory fit in the consumer behavior domain. For instance, Florack and Scarabis (2006) found that consumers favored products that were presented in an advertisement using a claim that matched rather than mismatched their current regulatory focus (see Aaker \& Lee, 2006; Avnet \& Higgins, 2006; Cesario, Grant, \& Higgins, 2004, Study 2 for similar findings). The present results extended these findings to another domain, namely charitable giving, and showed that the results generalize across various types of charity. Moreover, whereas previous research has shown effects of outcome-based regulatory fit on 
preferences, attitudes, persuasion, and memory the present studies are the first to show actual (donating) behavior as a function of outcome-based regulatory fit (cf. Baumeister, Vohs, \& Funder, 2007). Consumers donated more money to a charity that was framed in such a way that it fit their (current) regulatory focus than when the charity was framed in a nonfit manner. Additionally, similar results were obtained using a measure of dispositional regulatory focus and different manipulations of regulatory focus, which provides convergent evidence that further contributes to the generalizability of our results.

As far as we are aware, the present studies are the first to reveal the moderating role of private self-focus in regulatory fit effects. We found that the effects of regulatory fit on charity support were stronger among people with high private self-focus compared to people with low private self-focus. The effect of private self-focus was so powerful that we observed no effect of regulatory fit on charitable behavior among participants in a state of low private selffocus. Hence, when in a promotion orientation state, people with high private self-focus were more influenced by information that emphasized gaining positive outcomes than by information that stressed preventing negative outcomes. Conversely, people high in private self-focus with a prevention orientation state were more influenced by external information on preventing negative outcomes than by information on gaining positive outcomes. People with low private self-focus were equally affected by information that either fit or did not fit their momentary orientation focus. This pattern was found in all four studies, where private self-focus was either measured or manipulated. In fact, three different procedures were used to manipulate private self-focus and all resulted in similar effects, which too adds to the reliability of our results. Moreover, the moderating role of private self-focus was observed on a host of dependent variables including helping intentions, attitudes, and actual behavior.

These results are in line with the work by Hull and colleagues (Hull \& Levy, 1979; Hull, Treuren, Ashford, Propsom, \& Andrus, 1988; Hull, Slone, Meteyer, \& Matthews, 2002) in suggesting that people high in private self-focus are more influenced and affected by external information, which they render as self-relevant. Hull et al. (1988; 2002) argue that a state of high private self-focus activates self-knowledge, which instigates a process of self-relevant encoding. In line with this theorizing, we found that high self-focused people, as opposed to low self-focused people, were especially affected by external information that fit with their activated self-knowledge (in this case, their current orientation focus). Hence, when private self-focus is high, people are especially influenced by information that is congruent with their current orientation focus.

Moreover, the present results shed new light on the concept of private self-focus. Previous research on private selffocus mainly has emphasized the self-regulatory process instigated by a state of private self-focus. This line of reasoning states that high private self-focus activates a self-regulatory process aimed at reducing discrepancies between one's current state and an internal norm or standard. In accordance with Hull and colleagues, we showed that a state of high private self-focus is related not only to discrepancy-reducing self-regulation, but also entails a qualitatively different way of information processing aimed at rendering external information self-relevant. This 
viewpoint is also in line with the active-self account recently proposed by Wheeler, DeMarree, and Petty (2007). Wheeler and colleagues (2007) argue that the active self-concept plays a central role in priming effects. According to their model, moderators of general priming effects, such as private self-focus (Hull et al., 2002), operate by more than simply affecting construct accessibility. Rather their influence on active self-concepts is key given the role of the selfconcept to guide behavior. Hence, people who are prone to process external primes as self-relevant (i.e., high selffocused individuals) are more affected by this information; when external information is (actively) related to the self it exhibits larger effects on behavioral outcomes. As such, it is not merely the awareness of oneself but rather the selfrelevant information processing aspect of private self-focus that explains the effects of external information on behavior. A recent study by Wheeler, Morrison, DeMarree, \& Petty (2008) further argues that it is especially the selfreflective dimension, rather than the state awareness dimension, within the construct of private self-focus that accounts for the influence of external information on behavior under conditions of high private self-focus.

Yet we hypothesized in the present studies that not all information is easily processed as self-relevant. We proposed that external information that matches one's (active) self-regulation mechanism is more easily processed as selfrelevant than information that mismatches one's self-regulation focus. In line with results obtained by Lee and Aaker (2004), our findings confirmed this hypothesis by showing that processing fluency is the mechanism by which this moderating role occurs. People with a high private self-focus processed charity information that fit with their current orientation focus more easily than information that did not fit with their orientation focus. Subsequently, easy of processing led to a positive attitude towards the charity because the positive experience of processing fluency was misattributed to the charity. Hence, processing fluency mediated the interaction effect between regulatory fit and private self-focus on charity attitudes. Lee and Aaker (2004) already provided support for the processing fluency account in regulatory fit effects by showing that appeals presented in gain frames are more persuasive when the message is promotion focused whereas appeals in loss frames are more persuasive when the message is prevention focused (see also Labroo \& Lee, 2006). We add to the processing fluency account by demonstrating that high selffocused people experience particularly strong fluency when there is a situation of fit. Hence, the activation of selfknowledge, induced by high levels of private self-focus, seems to make it easier to process information that is in line with the self-concept.

As in previous studies on regulatory fit, we were able to rule out the alternative explanations of mood and involvement. The current studies found no effects of regulatory fit, private self-focus, or the interaction between these concepts on participants' mood states. This excludes the notion that positive mood states may underlie the observed effects on charitable giving. Moreover, our findings revealed no effects of the manipulations on involvement. Hence, not regulatory fit nor private self-focus enhances charity involvement. This helps to support our proposal that the misattribution of processing fluency, rather than mood or involvement, is the underlying mechanism for the interaction between private self-focus and regulatory fit on charitable behavior. 
The current work also adds to the literature on charitable behavior. Whereas previous research has focused largely on individual and demographic variables on the one hand, and message features on the other, we showed that considering the interplay between both aspects is profitable in predicting charity support. Consumers become more willing to engage in charitable behavior when a charity expresses goal pursuit strategies that are in line (versus not in line) with personal regulatory mechanisms.

In our studies we manipulated regulatory fit by focusing on promotion and prevention orientation states but other research has shown that consumers differ in other self-regulation mechanisms as well. For instance, consumers can have a locomotion or assessment orientation when perceiving a persuasive message (Kruglanski et. al., 2000). Consumers with a locomotion orientation tend to regulate their behavior from state to state and experience regulatory fit when they use a 'progressive elimination' strategy when making decisions. This strategy entails eliminating the worst alternative on successive attributes until the best alternative remains. Conversely, consumers with an assessment orientation tend to compare all alternatives and experience fit when they use a full evaluation strategy. This strategy consists of comparing all alternatives on all attributes before making a decision. Charities could take advantage of this knowledge by incorporating the interplay between message framing and consumer differences by framing their message in congruence with receivers' regulation mechanism in order to enhance fit. This state then could engender persuasion, positive attitudes, and generous donations.

\section{CONCLUSION}

It is perhaps paradoxical that the message of the studies in this chapter is that focusing consumers on themselves can lead to behavior aimed at helping others. One might think, a priori, that consumers who focus their attention on the environment would reliably show charitable behavior because in this state they are aware of the external world and its myriad problems. Instead, we found that the opposite occurs under some circumstances. It was high private self-focused consumers who responded strongly to opportunities to help a charity, as long as participants could easily relate the charity to the self. This notion contrasts with the impulsive, possibly even cynical, reaction that when people focus on themselves they become disinterested in aiding others, and that perhaps this would be especially true when those others are strangers and not family or friends. Yet the current work demonstrates that getting consumers to focus on themselves, in the right circumstances, just may pave the way to generosity. 
Chapter 5: General Discussion 
Brands, advertisements and persuasive messages have become part of our daily lives. It is almost impossible to spend a whole day without being exposed to a multitude of marketing expressions trying to inform, persuade, and seduce us into buying all kinds of products. The present dissertation examined if and how consumer responses might be unconsciously affected by external marketing communications. We argue and show that marketing communications such as brands, slogans, and persuasive messages can evoke automatic goal pursuit and unconsciously affect evaluation processes. We also find that these automatic processes are context dependent, such that they operate and manifest themselves in interplay with situational and individual variables. The effects of these automatic processes were subsequently demonstrated to affect consumer responses varying from consumer attitudes, choice, behavioral intentions, and actual behavior. In this chapter, we will first provide a summary of the main findings that will be discussed in light of the literature. We will then discuss how the current research relates to automaticity research and contributes to the field of unconscious consumer behavior. Finally, the practical implications of our findings, followed by some limitations and possible directions for future research, will be provided.

\section{SUMMARY AND DISCUSSION OF THE MAIN FINDINGS}

In Chapter 2, we examined whether the (un)conscious presence of brands in our environment can automatically elicit consumer goal pursuit. It was hypothesized that exposure to an insurance brand automatically activates mortalityrelated thoughts, eliciting the goal to reduce existential anxiety. Based on Terror Management Theory (Greenberg, Pyszczynski, \& Solomon, 1986) it was expected that consumers would use worldview defense strategies to deal with their brand-induced existential anxiety, subsequently guiding consumer behavior. These strategies are proposed to enhance self-esteem through the expression and defense of desirable cultural norms and values (see Greenberg, Koole, \& Pyszczynksi, 2004 for a recent overview). In Western countries, where consumerism and materialism are deeply interwoven with cultural beliefs and where money is a pervasive barometer of self-worth (Bauman, 1995), actions such as excessive spending and buying luxurious products can function as worldview defense strategies for dealing with existential anxiety (see also Arndt, Solomon, Kasser, \& Sheldon, 2004).

Study 2.1 showed that presenting participants with an insurance brand for five minutes increased the accessibility of mortality-related thoughts (measured with a word-fragment completion task). In comparison to participants in the control condition, this study also demonstrated that participants who were presented with the insurance brand intended to spend more money in the near future as a means of dealing with their existential anxiety. This effect was mediated by mortality salience, such that exposure to the insurance brand automatically activated mortality-related thoughts that, in turn, affected spending intentions. Study 2.2 used a more subtle brand manipulation procedure by printing the insurance brand logo (vs. a control brand) on a mouse pad that was used during the study. This study also focused on another worldview defense mechanism. As was proposed in previous research, donating to charitable causes (money, time, or effort) is regarded as desirable behavior in Western cultures, which makes charitable contributions a suitable strategy to reduce existential anxiety (see Jonas, Schimel, Greenberg, \& 
Pyszczynski, 2002). We therefore tested whether consumers intended to donate more money to charity as a function of brand exposure. The results demonstrated that using the mouse pad with the printed insurance brand resulted in more generous donations than using the mouse pad with the printed control brand (i.e., a cosmetic brand). Hence, brand-induced mortality salience positively affected intended charity donations, a variable germane to the consumer behavior domain. The final study of Chapter 2 (2.3), demonstrated that even the most implicit form of presentation, subliminal brand exposure, induced consumer-related worldview defense strategies. Participants who were subliminally exposed to the insurance brand (vs. soft-drink brand) were found to engage in yet another worldview defense strategy, in-group bolstering and out-group derogation (Greenberg, Pyszczynski, \& Solomon, 1986). In the consumer behavior domain, a worldview defense may translate itself into specific patterns of product preference, choice, or, conversely, avoidance. In particular, participants in the present study expressed more favorable attitudes towards national (Dutch) food products and less favorable attitudes towards foreign food products.

In summary, this chapter demonstrated how the mere (unconscious) presence of marketing communications in our environment can elicit automatic goal pursuit, subsequently affecting seemingly unrelated consumer responses in various, and sometimes heterogeneous, domains. The results of the studies presented in this chapter extend the literature in various ways. First, it was demonstrated that marketing communications (i.e., brands) can induce automatic goal pursuit. This result was obtained by using priming techniques varying from extensive and explicit to subtle and below the threshold of conscious perception. Previous research has already established that priming consumers can affect brand evaluation and brand choice (e.g., Strahan, Spencer, \& Zanna, 2002). The present studies add to this stream of research by demonstrating that brands themselves can also function as primes that subsequently affect (unrelated) consumer responses. In addition, brand exposure was found in our studies to enhance automatic goal pursuit (i.e., worldview defense strategies). One can imagine, however, that brand associations might also affect consumer behavior by processes such as automatic attitude activation, unconscious mimicry, and automatic trait and stereotype activation. Second, the findings contribute to the domain of Terror Management Theory by measuring four types of different goal-pursuit strategies aimed at reducing existential anxiety. Increased spending, increased charity donations, appreciation of domestic products, and aversion to foreign products all served as consumer-related strategies to reduce death-related anxiety. This clearly extends previous research on Terror Management Theory in the consumer behavior domain, which has remained on a conceptual level for a long time (e.g., Arndt, Solomon, Kasser, \& Sheldon, 2004; Maheswaran \& Agrawal, 2004). The present results are one of the first to provide empirical support pertaining to consumer-related outcomes.

While Chapter 2 focused primarily on the encoding context in which priming with marketing communication stimuli may occur, Chapter 3 extended our focus to the interplay between encoding and retrieval context. In particular, Chapter 3 investigated whether the interplay between the modality in which brands are communicated and encoded during the initial exposure (i.e., visual vs. aural) and the modality in which brands are communicated during evaluation and retrieval (i.e., visual vs. aural) positively affects brand evaluation by the experience of processing 
fluency. Based on previous research (see Roediger \& McDermott, 1993 for a review) showing that perceptual similarities/differences between exposure and retrieval enhance/decrease priming effects on memory tasks, it was argued that modality congruence would enhance processing fluency, which is automatically (mis)attributed to the brands concerned (see Bornstein \& D’Agostino, 1992). Moreover, we examined whether the effects of modality congruence on consumer responses were moderated by differences in processing style. It was suggested that the effects of modality congruence are stronger for individuals entertaining a data-driven processing style, i.e., when consumers focus on the perceptual elements of the brand rather than on the conceptual meaning (a conceptuallydriven processing style).

In Study 3.1, it was found that brands are processed more fluently when modalities between initial brand encoding and subsequent retrieval match versus mismatch. Hence, modality congruence seems to enhance processing fluency. Study 3.2 tested whether modality congruence also affects brand evaluation. The observed results agreed with our hypothesis by revealing that modality congruence between brand exposure and brand evaluation resulted in more positive brand evaluations than modality incongruence. In addition, this study demonstrated that this effect was stronger when participants were directed to focus on the perceptual features of the brand names rather than focusing on the meaning of the brands. Thus, processing style appears to be an important qualifying factor for the observed modality congruence effects. Given the critical role of processing style in the understanding of the interplay between encoding and retrieval context on consumer responses, Study 3.3 assessed whether context factors that can be found in the marketing communications domain can also fulfill this role. To examine a situation in which consumers automatically adopt a specific processing style, Study 3.3 used new and familiar brands as stimulus material. It was expected that the effects of modality congruence were stronger for new than for familiar brands because it is proposed that new brands are processed in a data-driven instead of a conceptually-driven manner. This was based on the notion that new brands have no related associations or schemata stored in memory that could facilitate a conceptually-driven processing style. The results of this study provided additional support for our hypotheses by showing that modality congruence (vs. incongruence) leads to more favorable brand evaluations when the brands are processed in a data-driven manner. Particularly new brands were therefore evaluated more favorably when modalities over situations were congruent vs. incongruent. Study 3.4 sought to replicate and extend the earlier findings to more ecologically valid settings. To do this, actual advertising slogans were used rather than mere brand names. Supplementing brand attitudes, we also included an actual brand choice measure. The results corroborated and extended the findings found in the previous studies by showing that modality congruence also has a positive effect on actual brand choice.

Together, the findings in this chapter demonstrate that the interplay between encoding and retrieval contexts, using marketing communications as stimuli, automatically affects consumer brand evaluation and choice behavior. This effect is due to a basic unconscious process of misattribution of positive affect brought about by processing fluency. Hence, a process that was not consciously recognized influenced consumers' evaluations in these studies. Moreover, 
a pivotal moderator qualifying the operation and manifestation of these automaticity effects was identified in the form of consumers' processing style. These findings contribute to previous research on modality congruence by showing that not only memory tasks (i.e., recognition and retrieval tasks) benefit from congruency between encoding and retrieval, but also that evaluation and actual choice benefit as well. The interplay between the way in which a brand is initially communicated and the way in which a brand is presented during evaluation and choice can automatically guide the evaluation processes through the experience of processing fluency. The focus in this chapter was on the modality in which brands were communicated, although other surface features that may influence processing fluency such as typography (e.g., font or case) or size can easily be applied to, for example, brands and brand slogans (e.g., Jacoby \& Hayman, 1987; Madigan, McDowd, \& Murphy, 1991; Roediger \& Blaxton, 1987). In addition, brand processing style was identified as a critical factor for modality congruence effects to occur. The positive effects of modality congruence unfold only when participants focus on the perceptual (vs. conceptual) brand features. This result was obtained by using both an explicit processing style manipulation and new versus familiar brand names. Identifying such moderators that pertain to a consumer context will lead to a greater understanding of the function of processing fluency effects in the consumer behavior domain.

In Chapter 4, our work was extended to yet another type of interplay, namely the interplay between the marketing communications' encoding context and consumer motivational states. More specifically, this chapter extends the results from Chapter 3 by addressing the role of a consumer focus on the self rather than merely on the stimulus, which was the object of Chapter 3. It was investigated how the interaction between the framing of a persuasive message and consumers' regulatory focus (i.e., regulatory fit) influences reactions towards the message objective. Furthermore, we tested the hypothesis that the effects of regulatory fit are stronger when consumers are focused on their private self. Previous research has shown that people with a high private self-focus (as compared to people with a low private self-focus) are especially affected by external information that is relevant to the self (Hull, Slone, Meteyer, \& Matthews, 2002). Private self-focus is assumed to increase the activation of self-knowledge, which enhances ease of information processing when such information fits with one's activated self-knowledge (i.e., regulatory focus). This type of matching is posited to act as another source of processing fluency, which is subsequently proposed to positively affect attitudes, behavioral intentions, and actual behavior.

In Study 4.1, we found initial evidence for our hypotheses. The results demonstrated that participants who read a persuasive message about a charity in terms that matched their situational regulatory focus showed a greater willingness to help the charity (e.g., by distributing flyers) than participants who read a persuasive message that mismatched their situational regulatory focus. Note that we used a similar type of dependent variable as in our previous work, although this was treated here as the consumer-related outcome of a misattribution process (see below) rather than as a worldview defense strategy (see Chapter 2). As expected, dispositional private self-focus moderated this effect. Participants predisposed to a high private self-focus were more willing to help the charity when it was framed in congruence with their regulatory focus than when it was framed in terms that were incongruent. For 
participants with a predisposition towards low private self-focus, this effect was not observed. Studies $4.2 \mathrm{a}$ and $4.2 \mathrm{~b}$ extended these results to actual charity donations and switched roles of regulatory focus and private self-focus. That is, we used a dispositional measure of regulatory focus to establish differences in orientation focus and adopted situational manipulations of private self-focus. Moreover, Study $4.2 \mathrm{~b}$ employed the description of another charity to determine whether or not the observed results were due to a particular effect of a specific type of charity. The results of both studies revealed that participants actually donated more money to charity when they read about this charity in a message that matched (vs. mismatched) their regulatory focus. In addition, these effects appeared stronger for participants with a high, as opposed to low, state private self-focus. Study 4.3 aimed to demonstrate the underlying mechanism explaining the observed moderating role of private self-focus in regulatory fit effects. It was expected and found that regulatory fit induces processing fluency, the mechanism underlying the automatic misattribution process of positive affect to the object of the present study (charity). This process is more articulate for high self-focus consumers than for low self-focus consumers. In particular, participants with a high private self-focus find it easier to process information that is congruent (compared to incongruent) with their regulatory focus. This positive experience of processing fluency is subsequently (misattributed) to the charity.

In sum, the results of this chapter demonstrated that the interplay between message framing and consumer regulatory goals can automatically affect attitudes, behavioral intentions, and actual behavior. Moreover, it revealed private self-focus as a boundary condition for these effects to occur. These findings have several implications for the literature on both regulatory fit and private self-focus. Whereas previous research demonstrated effects of regulatory fit on attitudes, persuasion, and memory, the studies presented in this chapter are the first to show actual (donating) behavior as a function of outcome-based regulatory fit. This was found when regulatory focus was measured as a state variable as well as when regulatory focus was manipulated as a trait variable. In addition, for regulatory fit effects to occur, it seems important that people focus on their private self. This is because it activates a way of processing that renders external information self-relevant. It was shown that the effects of marketing communications might even be stronger when consumers are focused on themselves rather that merely on the stimulus provided. The focus on their private selves made consumers more susceptible to marketing communications that could easily be related to their own consumer goals. We also contribute to the literature on private self-focused attention by focusing on information processing strategies under conditions of high private self-focus. Traditionally, theories on private selffocus argue that a state of high private self-focus results in self-regulation strategies to decrease any observed discrepancy between one's actual versus desired state (Duval \& Wicklund, 1972; Fenigstein, Scheier, \& Buss, 1975). In agreement with Hull and colleagues (Hull and Levy 1979; Hull, Treuren, Ashford, Propsom, \& Andrus, 1988; Hull, Slone, Meteyer, \& Matthews, 2002), the present results show that private self-focus also has an effect on behavior by activating qualitatively different ways of information processing under conditions of high and low private self-focus. 
Now that we have summarized and discussed the main results of the studies presented in this dissertation, we will discuss how the observed findings relate to automaticity research and contribute to our understanding of automatic processes in the field of consumer behavior.

\section{AUTOMATICITY IN CONSUMER BEHAVIOR}

Each of the empirical chapters provides evidence for the role of unconscious processes in explaining the effects of marketing communications on consumer behavior. All the studies revealed that marketing communications such as brands, advertising slogans, and persuasive messages can shape consumer behavior by eliciting automatic goals and unconsciously affecting the evaluation processes. These results are consistent with previous research on automatic behavior, showing that environmental cues can affect attitudes (Kunst-Wilson \& Zajonc, 1980), social judgments (Bargh \& Pietromonaco, 1982), and behavior (Bargh, Chen, \& Burrows, 1996). The present dissertation extends this work by 1) investigating automaticity in the domain of consumer behavior, 2) exploring the role of marketing communications and its specific features in unconscious consumer processes, and 3) highlighting the context dependency of automatic consumer responses.

The present research further explored the phenomenon of automaticity in the consumer behavior domain. As argued in Chapter 1, consumer decision making and behavior is traditionally regarded as a conscious and deliberate process. Consumers are seen as rational decision makers weighing all the pros and cons of products before deciding to buy (e.g., Von Neumann \& Morgenstern, 1947; for an overview, see for example Baron, 2004). Although rational and conscious decision making is still the dominant approach in consumer behavior (Simonson, 2005; Simonson, Carmon, Dhar, Drolet, \& Nowlis, 2001; Zaltman, 2000), this traditional view on consumer decision making has been questioned during the last two decades, particularly by researchers in the domain of social cognition (e.g., Bargh, 2002; Dijksterhuis, Smith, Van Baaren, \& Wigboldus, 2005; Fitzsimons et al., 2002; Liu, 2008). These researchers argue that not all consumer decisions are the outcome of such extensive elaboration, but rather that many consumer decisions are affected by automatic (unconscious) processes that are not always easily recognized by the consumer. The present studies fit within this burgeoning field of research by investigating automatic processes that play a role in consumer evaluation and decision making strategies.

Automatic processes and behavior were initially defined as actions that are 1) unaware, 2) uncontrollable, 3) effortless, and 4) unintentional (LaBerge \& Samuels, 1974; Posner \& Snyder, 1975). Bargh (1989; 1992; 1994; see also Moors \& De Houwer, 2006), however, stated that not all four components have to occur together for a process to be automatic. One usually regards a process to be automatic when the process or a behavior meets one of the features. For instance, when an experienced driver is driving a car, he is typically aware of driving the car, he usually intends to drive the car, and he is in control of driving the car (i.e., he can stop the car at any desired moment). The driver, however, most likely lacks conscious awareness of all the independent actions he is executing to arrive at the 
desired destination. Executing these actions is therefore rather efficient and cognitively effortless because it requires no attentional resources. Meeting the third criterion of efficiency in the use of resources defines the practice of driving in this instance as an automatic process (see also Bargh \& Chartrand, 1999). The studies we have presented in the current dissertation fit within this definition of automaticity by satisfying at least one of the dimensions required, as participants lacked awareness of the processes (i.e., automatic goal pursuit, misattribution) that accounted for their decisions and behavior. Chartrand (2005) specified the awareness component by arguing that a distinction can be made between different 'types' of awareness, proposing a model of 'automatic processes' that defines three steps that may or may not lack awareness. In general, the model states that environmental stimuli (e.g., events, objects, places, and other people) may instigate an automatic process (e.g., attitude activation, stereotype activation, unconscious goal pursuit, and evaluation) which, in turn, affects an outcome (e.g., judgments, decisions, and behavior). Chartrand argues that awareness or unawareness can play a role in each of the three steps.

In most of the studies we have reported, participants were aware of the external stimuli (i.e., marketing communications) in their environment. In fact participants were often explicitly instructed to concentrate on a particular marketing communication. An exception, however, can be found in Chapter 2. In Study 2.2, the particular marketing communication (i.e., insurance brand logo) was printed on a mouse pad, which may or may not have been consciously observed by the participants. We cannot, however, be entirely sure that our participants consciously detected the brand in their environment, as they might have overlooked its presence on a conscious level. In addition, Study 2.3 used a subliminal priming method making the brand exposure in this study unconscious. In the debriefing phase, participants in this study indicated that they were unaware of having been exposed to the brand logo. Hence, the studies in the present dissertation have demonstrated instances of both awareness and unawareness of environmental stimuli affecting subsequent processes and behavior. Interestingly, the results of Chapter 2 demonstrated similar behavioral effects for conscious and unconscious brand exposure contexts. This can also be found in studies on Terror Management Theory in which different priming methods were used (Arndt, Greenberg, Pyszczynski, \& Solomon, 1997). Moreover, Dijksterhuis, Aarts, and Smith (2005) argued that, in general, the context in which mental constructs are activated (i.e., either subliminal or supraliminal) does not change the way it affects subsequent behavior. They conclude that it is the activation of psychological processes, independent of the way they are activated, that is important and explains unconscious behavior (see also Bargh, 1992).

The marketing-induced processes observed in this dissertation were all unconscious. That is, participants were not aware of the processes that were instigated by (features of) marketing communications embedded in different contexts. In Chapter 2, we found that exposure to an insurance brand (varying from extensive and explicit to subtle and below the threshold of conscious perception) automatically activated mortality related thoughts, instigating the goal to reduce existential anxiety. Whether or not the presence of the brand (i.e., external stimuli) was a conscious experience, participants lacked awareness of the way the brand exposure context affected their subsequent intentions and behavior (i.e., outcome). The process of automatic goal pursuit (i.e., reducing one's existential anxiety) 
therefore appeared to occur completely outside of conscious awareness. Chapter 3 focused on modality congruence effects in brand evaluation and choice strategies. Participants were consciously aware of being presented with the brands in both exposure contexts (i.e., encoding and retrieval). In the initial brand exposure phase, they were explicitly instructed to pay attention to the brands (by either counting syllables or identifying the meaning of the branded product). In the brand evaluation phase, they were consciously presented with the brands and asked to evaluate them. The interplay between the encoding and retrieval context constitutes the environmental factor that affected consumer decisions (i.e., the outcome) through the misattribution of processing fluency (i.e., the process). The underlying misattribution process that accounted for their evaluation and choice occurred outside of conscious awareness. Participants therefore automatically attributed the positive feelings of processing fluency to the brand at hand. A similar process was observed in Chapter 4 where the interplay between marketing communications and consumer goals was the focus of attention. In these studies, participants consciously read a persuasive message. They reported, however, no awareness of the fact that the interplay between their (activated) consumer goals and the framing of the messages (i.e., environmental stimulus) affected their subsequent responses (i.e., outcomes) by the misattribution of processing fluency (i.e., process). Note that in Chapter 3, processing fluency was derived from the interplay between the stimulus (i.e., brands) presentations in both contexts, whereas, in Chapter 4, the observed processing fluency was derived from the interplay between the stimulus (i.e., persuasive message) and the consumer (i.e., regulatory focus). Both types of interplay affected consumer responses through the experience of processing fluency. Hence, processing fluency and the related process of misattribution appear to be important drivers for automaticity effects in the consumer behavior domain.

To extend the consumer behavior literature on automaticity, the role of marketing communication features and how they interact with contextual variables was highlighted in this dissertation. In our studies, we focused on different marketing communication features: brand associations (Chapter 2), communication modalities (Chapter 3), and message framing (Chapter 4). It is possible, however, that other characteristics of marketing communication techniques, such as interactivity (e.g., Bezjian- Avery, Calder, \& lacobucci, 1998; Rodgers \& Thorson, 2000) and humor (e.g., Alden, Hoyer, \& Lee, 1993; Chattopadhyay \& Basu, 1990; Weinberger, Spotts, Campbell, \& Parsons, 1995) may affect consumer processes in similar ways. In addition, we attested to the context dependent nature of automatic processes in consumer behavior. It was observed that different contexts and particularly the interplay between these contexts explicate the observed unconscious processes. Chapter 3 showed that the effects of different message communication strategies depend on the communication strategies of the purchase situation, while Chapter 4 demonstrated that the effects of message framing depend on the recipient's current orientation focus. We therefore demonstrated that automatic processes are not always instigated by mere environmental stimuli, but can also be instigated as a result of the interplay between environmental stimuli and their contexts. While previous research on context variables mainly focused on how different contexts affect memory and evaluations of marketing communications (e.g., Coulter, 1998; Moorman, Neijens, \& Smit, 2002; Murry, Lastovicka, \& Singh, 1992; Yi, 1990), the present studies emphasize how marketing communications, in conjunction with contextual variables, may affect 
(unrelated) consumer responses. By focusing on the context dependency of automatic effects, we also contribute to the literature on automatic behavior, which had hitherto mainly examined the autonomous effects of external stimuli (see also Bargh, 2006). Our findings also reveal that different marketing communication strategies can elicit different effects for different consumers. While, for instance, a promotion-framed message is more successful for consumers with a promotion focus (vs. prevention focus), a prevention-framed message is more successful for consumers with a prevention focus (vs. promotion focus). Similarly, Wheeler and Berger (2007) found that a primed construct could have different effects on different people depending on the associations one has with the prime. People can have dissimilar and sometimes even opposing associations with the same object, resulting in different behaviors for different groups of people. Consequently, segmentation procedures that are widely used for conscious behavior influence strategies could also be applied to enhance the more unconscious effects of external marketing stimuli. As such, it seems important not only to focus on the characteristics of marketing communications but also to incorporate the personal and situational characteristics of consumers and the situation. By also examining the interplay between these different factors, one may move beyond the establishment of isolated marketing communication effects.

As well as showing that the occurrence of automatic processes may depend on the interplay between marketing communications and different contextual variables, we also showed that these automatic processes are further moderated by differences in processing style and private self-awareness. In Chapter 3, it was shown that the type of processing style determines whether the interplay between encoding and retrieval modalities has a positive effect on brand evaluation and choice. The interplay between encoding and retrieval contexts seems to be significant only when consumers are focused on the perceptual features of the stimulus. Similarly, Chapter 4 demonstrated that the interplay between message framing and consumer goals was particularly successful when consumers were focused on their private selves. When private self-focus is high, consumers are especially influenced by information that is congruent with their current orientation focus. The interplay between message and consumer contexts is therefore of importance when consumers are merely focused on their private selves. These findings further contribute to our context dependency perspective by demonstrating that the interplay between marketing communications and different context variables may have a greater impact under certain conditions.

Taken together, the present results offer empirical support for automaticity in consumer decision making and point to the importance of considering automatic processes, instigated by marketing communications in conjunction with consumer and situational contexts, in the consumer behavior domain. Although the present research points to the prevalence of unconscious processes in the consumer behavior field, we do not want to claim that conscious and rational processes are irrelevant or unimportant in explaining consumer decision making. We suggest that future research integrates both consciousness and unconsciousness because it seems likely that many consumer decision processes include elements of both. By investigating, for instance, the conditions under which conscious or unconscious processes are dominant or operate together, a more comprehensive understanding of consumer 
behavior can be attained. Moreover, as argued by Zaltman (2000), neither unconscious nor conscious processes can be understood separately (see also Hobson, 1999); neither of these can exist or be recognized without the other.

\section{PRACTICAL IMPLICATIONS}

The central aim of the present dissertation was to further our understanding of automaticity in consumer behavior processes. The domain of marketing communication and consumer behavior proved to be an interesting playing field in which the proposed mechanisms could easily unfold. Understanding how marketing communications can automatically affect consumer responses clearly shows direct relevance for practitioners such as advertisers and marketers. The observed findings reveal that there are ample reasons why practitioners could fail by not paying attention to the unconscious processes that may underlie consumer evaluation and choice.

In Chapter 2, we focused on brand associations and their influence on consumer evaluation and behavioral intention. It was shown that exposing consumers to brands automatically activates a plethora of associations. These activated brand associations may activate an automatic process that affects subsequent consumer behavior. In general, marketers will be motivated to link their brands with positive associations because this may result in, for instance, a positive brand image (Keller, 1993). Strategies used to increase brand image may include associating brands with well-liked celebrities (Atkin \& Block, 1983; Freiden, 1984; McCracken, 1989; Tripp, Jensen, \& Carlson, 1994) or popular sports events (Gwinner \& Eaton, 1999; McDaniel, 1999). Unfortunately, using celebrities may not always be without risk because negative information (e.g., a scandal) about a celebrity may unintentionally be associated with the concerning brand, thereby affecting the brand image (e.g., Till \& Shimp, 1998). It became clear in Chapter 2 that brands may also contain associations that are not created and managed by intended marketing strategies. Instead, they are natural consequences of a product's meaning or features. These types of associations are often referred to as 'product attribute associations' (Keller, 1993) and entail associations such as physical composition, user imagery (i.e., who uses the product), and usage imagery (i.e., where and in which situations is the product used). Our findings suggest that it is also important to take these kinds of associations into consideration when designing marketing strategies. Before being able to account for product attribute associations, however, it is essential to get a clear picture of how consumers actually perceive a brand. A technique to map brand associations (BCM; Brand Concept Maps) was recently introduced (John, Loken, Kim, \& Monga, 2006). This methodology proved to be very helpful in establishing knowledge regarding how consumers observe a brand. This technique, however, focuses primarily on measuring explicit brand associations, whereas the associations in our studies may have only been activated on a more implicit unconscious level. In Study 2.1, participants were exposed to the insurance brand logo for five minutes and were instructed to write down all thoughts that came to mind. Analysis of these reported thoughts revealed that none of our participants explicitly linked the insurance brand with thoughts about mortality. However, mortality salience was observed on an implicit measure (i.e., the word-fragment completion task). It may therefore be beneficial to include an implicit brand association technique when mapping brand associations. A more complete 
brand concept map (including implicit and explicit brand associations) will then emerge. See also Krishnan and Chakravarti (1999) who developed a framework for testing advertising effectiveness including both implicit and explicit memory tests. Establishing a clear picture of a brand's associations is a first step in trying to manage the effects of brand associations on consumer responses. The next challenge is to gain a more inclusive understanding of the strategies that could be used to manage and/or change the way in which these associations automatically affect consumer responses. For now, it seems prudent for brand managers to bear in mind that brands may have a multitude of implicit or unknown (and possibly undesirable) associations that might unintentionally facilitate or interfere with their brand strategies. This is of particular relevance because these unintended brand associations can become activated by very subtle or even subliminal exposure.

Chapter 3 examined a different feature of brand communications by focusing on the modality (visual vs. aural) in which a brand is communicated. We emphasized the context in which a brand was communicated during the initial exposure (advertising phase) and the context in which consumers are subsequently confronted with the brand (purchase situation). Matching communication modalities between exposure and evaluation or choice seems profitable when aiming to influence consumer evaluations and decisions unconsciously. These results have important implications for the domain of media selection, which, to date, has mainly focused on communication criteria such as reach, frequency, and selectivity (De Pelsmacker, Geuens, Van den Bergh, 2004). These criteria are concerned with questions like 'how many people can be reached?', 'how many times do consumers have to be exposed to an advertisement?' and 'is a certain medium more effective during a particular period of the year?' Moreover, in the domain of media planning much research has emphasized the importance of media context, i.e., the characteristics of the content of the medium in which an advertisement is inserted (De Pelsmacker, Geuens, Anckaert, 2002; Moorman, 2003). Advertisements in magazines, for example, appear between articles, whereas advertisements on television are scheduled during and between television shows. These context features have been found to significantly influence advertising effects (see Moorman, 2003 for a review). Likewise, the circumstances in which a consumer is exposed to an advertisement (i.e., receiver context; Pieters \& Van Raaij, 1992) can affect advertising effectiveness. These features include, for example, the location where a consumer receives an advertisement (e.g., at home or on the street), with whom one watches the commercial (e.g., alone, or surrounded by friends), and the psychological state one is in while observing an advertisement (e.g., in a good or bad mood). Our studies, however, also included contextual circumstances during the purchase situation (i.e., during the evaluation and choice process). Previous studies have focused on aspects that pertain to the situation during the time of exposure (i.e., medium and receivers context), whereas our studies have incorporated the context of the situation in which consumers actually decide whether or not to buy a particular brand or product. This is important, because evaluation and decisions are often made during the purchase situation (rather than during advertising exposure). Consumers often just begin to think about a product during the process of making the actual choice (Novemsky, Dhar, Schwarz, Simonson, 2007). When developing advertising strategies, it therefore seems beneficial to also consider the contexts and circumstances in which consumers make their decisions. According to the findings observed in Chapter 3 , when 
choosing advertising strategies (for instance, deciding whether to invest in a radio commercial or in a billboard advertisement), it would seem profitable to consider the context (i.e., modality) in which consumers are most likely to encounter the advertised brand again. Based on our results, the most beneficial strategy would be to use visual advertisements for products sold in, for example, a supermarket where products are generally displayed visually. Aural commercial messages, on the other hand, seem best suited for products that are sold in interpersonal selling situations in which it is most likely for consumers to hear the brand name again.

By focusing on yet another type of interaction between marketing communication contexts, Chapter 4 investigated the interplay between marketing communication contexts and consumer motivational states. Rather than examining the interplay between stimulus encoding and retrieval context, the interplay between message framing and consumers' regulatory goal was explored. The findings showed that congruence between message framing (i.e., promotion vs. prevention) and current regulatory focus (i.e., promotion vs. prevention) enhanced responses towards the message objective. Participants had a more positive attitude towards the communicated charity, were more willing to help the charity, and donated greater amounts of money when a message regarding this charity was framed in congruence (vs. incongruence) with their current orientation focus. When designing a persuasive message, it therefore seems important to know about the consumers' regulatory focus. A message can thus be framed such that it matches with consumers' regulatory focus, subsequently enhancing their behavior. As reported in our studies, people tend to have a predominant chronic orientation focus (e.g., Higgins, 2001), and regulatory foci can be made temporarily more accessible by situational contexts (Idson, Liberman, \& Higgins, 2000). Advertisers and marketers could consider designing strategies that induce particular regulatory orientations, thereby providing a context in which specific regulatory goals become active and salient and could subsequently verify which types of appeals seem to fit best with that particular orientation state. Moreover, it is possible that certain target groups share a predominant focus orientation. Establishing these orientation goals in advance could be of help when developing persuasive messages. In our studies, we manipulated regulatory fit by focusing on promotion and prevention orientation states. Other research, however, has also shown that consumers differ in other self-regulation mechanisms. Besides promotion and prevention orientations, other regulatory orientations have been identified. For instance, message recipients can adopt a near vs. distal temporal construal (e.g., Trope \& Liberman, 2003) or a deliberative vs. implementative action (Gollwitzer, 1990) mindset to regulate their behavior. Communication messages that fit with these different regulatory orientations should be more persuasive and enhance consumer attitudes and behavior rather than when there is a mismatch between message and consumer orientations. Taken together, it is useful to consider situational and individual contexts before designing a persuasive message.

Although our studies were all set in a consumer behavior context, the findings of the present dissertation may not only bear relevance to the domain of marketing and advertising. One could easily imagine how this knowledge may also be fruitful for policy makers and practitioners in the domain of, for instance, health communication. As argued by Moorman (2002), the field of consumer behavior may have enormous potential to contribute to health research. On a 
yearly basis consumers spent large amounts of money on healthcare, making it a substantial part of consumer activity. Research on health communication is strongly influenced by social cognitive information processing frameworks such as the health belief model (Becker et al., 1977; Becker, Haefner, \& Maiman, 1977; Rosenstock, 1974), the protection motivation theory (Rogers, 1975, 1983) and the theory of planned behavior (Ajzen, 1988). These models have gathered extensive empirical support (e.g., Armitage \& Conner, 2001; Norman, Boer, \& Seydel, 2005; Conner \& Armitage, 1998; Harrison, Mullen, \& Green, 1992; Janz \& Becker, 1984; Milne, Sheeran, \& Orbell, 2000) and appear to be rather constructive for practitioners (Conner \& Norman, 2005). In marketing literature, these models are also used to explain how health messages could affect cognition and behavioral intentions (e.g., Pechmann, Zhao, Goldberg, \& Reibling, 2003). In a way, the traditional view on consumer decision making is comparable to models in health behavior. Both are based on the underlying assumption that people are rational beings and think consciously in the act of decision making. As demonstrated in this dissertation, however, automatic processes often influence consumer behavior and decision making. Given the overlap between the underlying mechanisms predicting consumer and health behavior (Moorman, 2002), it would be interesting to examine whether similar unconscious processes could also influence health behavior.

In fact, Pechmann (2001) has already proposed a theoretical model on health behavior that was termed 'the stereotype priming model', in which the role of (automatic) stereotype activation is discussed. Based on work by Bargh and colleagues (Bargh, 1989; Bargh, Chen, \& Burrows. 1996; Bargh, Raymond, Pryor, \& Strack, 1995), Pechmann states that health behavior is often guided by the social stereotypes one holds about particular groups of people (e.g., drugs users, smokers, and drinkers). Exposing people to (personality traits of) these stereotypes may automatically promote healthy or discourage unhealthy behavior by activating an example of how (not) to become. For health messages to be effective, they might focus on activating the positive stereotypes of people who behave as desired as well as the negative stereotypes of people who fail to do so. This would then automatically elicit the goal to perform healthy behavior or to prevent unhealthy behavior. This theoretical framework is particularly related to the findings described in Chapter 2, which empirically demonstrate that consumer responses can be affected by an automatically activated goal. Moreover, the findings observed in Chapters 3 and 4 could easily be applied to health communication messages. In the domain of regulatory fit, for instance, it has already been demonstrated that messages regarding healthy eating habits are more effective in influencing the consumption of fruits and vegetables when they are framed in a congruent versus incongruent way (e.g., Aaker \& Lee, 2001; Spiegel, Grant-Pillow, \& Higgins, 2004). This is of relevance because one of the most important challenges for policy makers and health care professionals is to overcome targets' self-positivity biases, such as denying vulnerability (Das \& Fennis, in press; Menon, Block, Rahmanathan, 2002; Perloff \& Fetzer, 1986). Any strategy that could help reach targets more effectively may result in greater compliance to the advocated health message. Hence, combining the well-established knowledge on social cognitive models with knowledge regarding automatic processes seems to be a productive way to stimulate healthy behavior. 
So far, we have looked at the possible ways practitioners in the fields of marketing, advertising, and health communication could improve their strategies by incorporating the knowledge on automatic processes reported in this dissertation. The findings presented in this dissertation may also be of importance to consumers and message recipients. As rational beings, people are likely to believe that they are in full control of their actions and make conscious decisions. The outcomes described in the present dissertation, however, contribute to the growing body of literature demonstrating that much of human behavior is actually driven by unconscious processes. Nevertheless, are we completely defenseless when targeted with stimuli that evoke automatic processes, subsequently affecting our decisions and behavior? The answer is probably a qualified no. As discussed in the first chapter of this dissertation, consumers are less susceptible to automatic effects when they become aware of the actual source of their feelings and behavior (Higgins, 1998). When consumers know why they are experiencing, for example, processing fluency, they are able to attribute this feeling to the correct source. In the domain of regulatory fit, this was demonstrated in a study conducted by Cesario, Grant, and Higgins (2004). They showed that drawing participants' attention to the correct source of their experience (i.e., regulatory fit) eliminated the effect on persuasion because it reduced source confusion (see also Higgins, 1998; Schwarz \& Clore, 1983; Whittlesea \& Williams, 1998; 2001a, b). Thus, knowledge regarding the source of one's experience blocks the misattribution process.

Informing consumers about the reasons for one's feelings and behavior seems to help them exercise control and to possibly alter their behavior. Hence, understanding what is going on during, for instance, attempts at persuasion might help consumers to regain their power and improve their decisions.

\section{LIMITIATIONS AND DIRECTIONS FOR FUTURE RESEARCH}

In the present dissertation, we investigated how automaticity can play a role in consumer behavior. Moreover, we examined the functions of marketing communications in affecting automatic consumer responses. We conducted experimental studies in which we used various forms of marketing communications (i.e., brands, slogans, and persuasive messages) and focused on different marketing communication features (i.e., brand associations, communication modalities, and message framing). We demonstrated the context dependency of automatic consumer processes by showing that automatic effects may operate in interplay with situational and individual factors. Moreover, we shed new light on automatic consumer goal pursuit and automatic (mis)attribution processes. Although the present findings incorporated various marketing communications and their features, addressed a range of consumer responses and emphasized underlying mechanisms, some of our results could be limited due to methodological or theoretical reasons. Below we will consider some of these limitations and propose suggestions for future research.

Even though experimental research is not conducted primarily to gain external validity (e.g., Mook, 1983), questions regarding external validity often arise when reporting experimental studies, particularly in the domain of consumer 
behavior. This might be explained by the notion that many people believe that the artificial nature of laboratory settings is an accidental error rather than a deliberate choice of the experimenter (Kardes, 1996). Artificial settings and conditions are, however, purposely designed to enable us to learn about specific cause-effect relationships. Although we intentionally chose to conduct experimental studies (because we primarily sought to identify causal relationships and underlying mechanisms explaining consumer behavior), we do think it might be interesting to study the phenomena of automaticity in real world settings. In everyday life, consumers are overwhelmed with external stimuli like marketing communications (Peter \& Olson, 2005), whereas a carefully controlled laboratory study usually investigates the effects of one particular stimulus. It would be interesting to see how these different stimuli combine and guide our decisions and behavior in the real world. Moreover, there are many other potential factors outside the laboratory, such as consumers' conscious goals, product prices, and other product characteristics that could influence, interact, and interfere with the effects of a particular marketing stimulus on attitudes, choice, or behavior. Bargh (2006) has pointed out that one of the major remaining questions in the literature on automaticity refers to how automatic effects unfold in the real world. In addition, Simonson (2005) states that the significance of automatic processes in the consumer behavior domain will not be easily recognized until researchers are able to demonstrate these effects in real-world settings. Hence, a possible road for future research lies in examining if and under what conditions the effects of external stimuli on consumer behavior hold up in a real-world environment that is full of cues ready to influence our behavior. These various cues potentially interact with each other as well as various other contextual factors. Investigating these relationships may help to establish a detailed and comprehensive understanding of automatic environmental effects. Berger and Fitzsimons (2008) recently started to test the effects of external cues on evaluation and choice in field experiments, finding promising evidence for the presence of automaticity in everyday life. The demonstrated, for instance, that during Halloween season when there are substantial orange cues present in the environment, orange-related products, such as Reese's and orange sodas become more accessible. Although, in our studies, we often used actual existing brands and advertisements as stimulus material and measured actual choice and behavior, we are of the opinion that extending research on automatic processes outside the laboratory would strengthen the relevance and practicality of automaticity research.

Another methodological limitation can be found in the time durations used in our studies. In all of our studies, the time duration between the stage of exposure and the observed consumer response was rather short. It would be interesting to investigate if, and under what conditions, the effects of marketing communications hold when the measurement does not take place shortly after the manipulation. Research on automatic goal pursuit often builds in a time delay (of five minutes) to provide evidence for the underlying processes of goal pursuit and to control for effects of trait priming (e.g., Bargh, Gollwitzer, Lee-Chai, Barndollar, \& Trötschel). It is assumed that once activated, goals increase in strength, whereas non-motivational activated constructs decrease in strength. Activated goals seem to remain active until the goal can be achieved. Thus, by adopting a time delay manipulation, one can quite easily distinguish between the two possible processes. When consumers are exposed to marketing communications that elicit automatic goal pursuit, the effects should therefore increase over time. In these studies, however, we still 
describe a difference between a measure that directly follows the manipulation and a measure that takes place five minutes later. What will happen when consumer responses are measured the next day or the next week? Are goals still active at that point? In addition, it would be interesting to examine similar time constraints when experiencing processing fluency derived from regulatory fit or modality congruence. How long do these experiences last? Do they remain active until one has the possibility to attribute the experience to an object or event or do they decrease in time such as non-motivational constructs?

As alluded to before, we argue in the present dissertation that consumers are often not aware of the marketinginduced processes that drive their consumer choices and behavior. In Chapters 3 and 4, it was observed that consumers automatically misattribute the positive feelings of processing fluency to the stimulus at hand. Our studies, however, are not conclusive about the consciousness or unconsciousness of the experience of processing fluency in itself. Participants could have been consciously experiencing the positive feelings of processing fluency. As argued by Kelley and Rhodes (2002), people unconsciously engage in the process of attributing fluency, yet consciousness might be found in people's awareness in a way that 'something seems familiar'. In future research, it would be interesting to examine whether consumers are indeed conscious about this experience, and if so, where they think this feeling comes from and when they do or do not rely on these feelings as a basis of their evaluations and decisions. Are there conditions under which consumers do rely more or less on their (affective) experiences? One answer may be found in research on thought confidence and self-validation (e.g., Feldman \& Lynch, 1988; Kruglanski, 1980; Petty, Brinol, \& Tormala, 2002). According to the self-validation hypothesis, the more confidence one has in one's thoughts, the greater the impact of those thoughts on evaluation and behavior (Brinol, Petty, Tormala, 2004). Hence, being confident about, for instance, the experience of processing fluency (e.g., evoked by modality congruence or regulatory fit) should then enhance the positive effects on evaluation and behavior. Interestingly, this theory would also predict that experiences of modality incongruence and regulatory non-fit would decrease the effectiveness of marketing communications under conditions of high thought confidence. Identifying moderators like this would help us gain a more complete understanding of the circumstances under which automatic processes may thrive best.

\section{CONCLUDING REMARKS}

The aim of the present dissertation was to examine the role of marketing communications in unconscious consumer behavior. In doing so, we attested to a range of possible automatic processes in consumer behavior, particularly emphasizing the role of marketing communications as instigators of these unconscious processes. We explored the effects of marketing communications such as brands, slogans, and persuasive messages on consumer responses varying form attitudes, behavioral intentions, and actual behavior. One of the most important findings is that we have demonstrated that automatic effects of marketing communications on consumer responses are often times context dependent. That is, the occurrence of automatic marketing communication effects depends on the interplay between 
marketing communications and context variables that may pertain to both the situation and the consumers themselves. From this finding, one may conclude that, to fully understand the effects that marketing communications may have on unconscious consumer processes and behavior, it is important to incorporate situational and individual differences between consumers and the circumstances in which they are exposed to these marketing communications. Marketing communications do not always seem to evoke the same responses in all situations for all consumers at all times. By considering the context dependent nature of automatic consumer processes, we aim to have provided the next step towards the understanding of automaticity in consumer behavior contexts. 
References 
Aaker, D. A. (1991). Managing brand equity. New York: Free Press.

Aaker, J. L., \& Lee, A. Y. (2001). 'I' seek pleasures and 'we' avoid pains: The role of self-regulatory goals in information. Journal of Consumer Research, 28, 33-49.

Aaker, J. L., \& Lee, A. Y. (2006). Understanding regulatory fit. Journal of Marketing Research, 43, 15-19

Aarts, H., \& Dijksterhuis, A. (2000). Habits as knowledge structures: Automaticity in goal-directed behavior. Journal of Personality \& Social Psychology, 78, 53-63.

Aiken, L. S., \& West, S. G. (1991). Multiple regression: Testing and interpreting interactions: Sage Publications, Inc.

Ajzen, I. (1988). Attitudes, personality, and behavior. Milton Keynes: Open University Press.

Alden, D. L., Hoyer, W. D., \& Chol, L. (1993). Identifying global and culture-specific dimensions of humor in advertising: A multinational. Journal of Marketing, 57, 64-75.

Anderson, J. R. (1993). The architecture of cognition. Cambridge, MA: Harvard University Press.

Armitage, C. J., \& Conner, M. (2001). Efficacy of the theory of planned behaviour: a meta-analytic review. British Journal of Social Psychology, 40, 471-499.

Arndt, J., Greenberg, J., Solomon, S., \& Pyszczynski, T. (1997). Suppression, accessibility of death-related thoughts, and cultural worldview defense: Exploring the psychodynamics of terror management. Journal of Personality and Social Psychology, 73, 5-18.

Arndt, J., Solomon, S., Kasser, T., \& Sheldon, K. M. (2004). The urge to splurge: A terror management account of materialism and consumer behavior. Journal of Consumer Psychology, 14, 198-212.

Atkin, C., \& Block, M. (1983). Effectiveness of celebrity endorsers. Journal of Advertising Research, 23, 57-61.

Avnet, T., \& Higgins, E. T. (2006). How regulatory fit affects value in consumer choices and opinions. Journal of Marketing Research, 43, 1-10.

Bagozzi, R. P., \& Dholakia, U. (1999). Goal setting and goal striving in consumer behavior. Journal of Marketing, 63, 19-32.

Baker, W. E. (1999). When can affective conditioning and mere exposure directly influence brand choice? Journal of Advertising, 28, 31-46.

Bargh, J. A. (1989). Conditional automaticity: Varieties of automatic influence in social perception and cognition. In J. S. Uleman \& J. A. Bargh (Eds.), Unintended thought (pp. 3-51). New York: GuilfordPress.

Bargh, J. A. (1990). Auto-motives: Preconscious determinants of social interaction. In E. T. Higgins \& R. M. Sorrentino (Eds.), Handbook of motivation and cognition (Vol. 2, pp. 93-130). New York: Guilford Press.

Bargh, J. A. (1992). The ecology of automaticity: Toward establishing the conditions needed to produce automatic processing effects. The American Journal of Psychology, 105, 181-199.

Bargh, J. A. (1994). The four horsemen of automaticity: Awareness, efficiency, intention, and control in social cognition. In R. S. Wyer, Jr., \& T. K. Srull (Eds.), Handbook of social cognition (2nd ed., pp. 1-40). Hillsdale, NJ: Erlbaum.

Bargh, J. A. (1999). The cognitive monster: The case against controllability of automatic stereotype effects. In S. Chaiken \& Y. Trope (Eds.), Dual process theories in social psychology (pp. 361-382). New York: Guilford. 
Bargh, J. A. (2002). Losing consciousness: Automatic influences on consumer judgment, behavior, and motivation. Journal of Consumer Research, 29, 280-285.

Bargh, J. A. (2006). What have we been priming all these years? On the development, mechanisms, and ecology of nonconscious social behavior. European Journal of Social Psychology, 36, 147-168.

Bargh, J. A., \& Chartrand, T. L. (1999). The unbearable automaticity of being. American Psychologist, 54, 462-479.

Bargh, J. A., \& Chartrand, T. L. (2000). The mind in the middle: A practical guide to priming and automaticity research. In H. T. Reisand \& C. M. Judd (Eds.), Handbook of research methods in social and personality psychology (pp. 253-285). Cambridge: University Press.

Bargh, J. A., Chaiken, S., Raymond, P., \& Hymes, C. (1996). The automatic evaluation effect: Unconditional automatic attitude activation with a pronunciation task. Journal of Experimental Social Psychology, 32, 104128.

Bargh, J. A., Chen, M., \& Burrows, L. (1996). Automaticity of social behavior: Direct effects of trait construct and stereotype activation on action. Journal of Personality \& Social Psychology, 71, 230-244.

Bargh, J. A., Gollwitzer, P. M., Lee-Chai, A., Barndollar, K., \& Trötschel, R. (2001). The automated will: Nonconscious activation and pursuit of behavioral goals. Journal of Personality and Social Psychology, 81, 1014-1027.

Bargh, J. A., \& Pietromonaco, P. (1982). Automatic information processing and social perception: The influence of trait information presented outside of conscious awareness on impression formation. Journal of Personality and Social Psychology, 43, 437-449.

Bargh, J. A., Raymond, P., Pryor, J. B., \& Strack, F. (1995). Attractiveness of the underling: An automatic power-sex association and its consequences for sexual harassment and aggression. Journal of Personality \& Social Psychology, 68, 768-781.

Baron, J. (2004). Normative models of judgment and decision making. In D. J. Koehler \& N. Harvey (Eds.), Blackwell Handbook of judgment and decision making (pp. 19-36). Malden, USA: Blackwell Publishing.

Baron, R. M., \& Kenny D. A. (1986). The moderator-mediator variable distinction in social psychological research: Conceptual, strategic, and statistical considerations. Journal of Personality and Social Psychology, 51, 11731182.

Basil, D. Z., Ridgway, N. M., \& Basil. M. D. (2008). Guilt and giving: A process model of empathy and efficacy. Psychology \& Marketing, 25, 1-23.

Bassili, J. N., Smith, M. C., \& MacLeod, C. M. (1989). Presentation modality and type of processing effects on priming in auditory and visual word-stem completion. The Quarterly Journal of Experimental Psychology: Human Experimental Psychology, 41, 439-453.

Batra, R., \& Ray, M. L. (1986). Situational effects of advertising repetition: The moderating influence of motivation, ability, and opportunity to respond. Journal of Consumer Research, 12, 432-445.

Bauman, Z. (1995). Life in fragments: Essays in postmodern morality. Oxford: Blackwell.

Baumeister, R. F., Bratslavsky, E., Muraven, M., \& Tice, D. M. (1998). Ego depletion: Is the active self a limited resource? Journal of Personality and Social Psychology, 74, 1252-1265. 
Baumeister, R. F., Vohs, K. D., \& Funder, D. C. (2007). Psychology as the science of self-reports and finger movements: whatever happened to actual behavior? Perspectives on Psychological Science, 2, 396-403.

Becker, M. H., Haefner, D. P., Kasl, S. V., Kirscht, J. P., Maiman, L. A., \& Rosenstock, I. M. (1977). Selected psychosocial models and correlates of individual health-related behaviors. Medical Care, 15, 27-46

Becker, M. H., Haefner, D. P., \& Maiman, L. A. (1977). The health belief model in the prediction of dietary compliance: a field experiment. Journal of Health and Social Behaviour, 18, 348-366.

Belén del Río, A., Vázques, R., Iglesias, V. (2001). The effects of brand associations on consumer response. Journal of Consumer Marketing, 18, 410-425.

Bemmaor, A. C., \& Mouchoux, D. (1991). Measuring the short-term effect of in-store promotion and retail advertising on brand sales: A factorial experiment. Journal of Marketing Research, 28, 202-214.

Berger, J., \& Fitzsimons, G. (2008). Dogs on the street, Pumas on your feet: How cues in the environment influence product evaluation and choice. Journal of Marketing Research, 45, 1-14.

Bettman, J. R. (1979). Memory factors in consumer choice: A review. Journal of Marketing, 43, 37-53.

Bettman, J. R., Luce, M. F., \& Payne, J. W. (1998). Constructive consumer choice processes. Journal of Consumer Research, 25, 187-217.

Bezjian-Avery, A., Calder, B., \& lacobucci, D. (1998). New media interactive advertising vs. traditional advertising. Journal of Advertising Research, 38, 23-32.

Blaxton, T. A. (1989). Investigating dissociations among memory measures: Support for a transfer-appropriate processing framework. Journal of Experimental Psychology: Learning, Memory, and Cognition, 15, 657-668.

Bless, H., Bohner, G., Schwarz, N., \& Strack, F. (1990). Mood and persuasion: A cognitive response analysis. Personality and Social Psychology Bulletin, 16, 331-345.

Bornstein, R. F. (1989). Exposure and affect: Overview and meta-analysis of research, 1968-1987. Psychological Bulletin, 106, 265-289.

Bornstein, R. F., \& D'Agostino, P. R. (1992). Stimulus recognition and the mere exposure effect. Journal of Personality and Social Psychology, 63, 545-552.

Bransford, J. D., Franks, J. J., Morris, C.D., \& Stein, B.S. (1979). Some general constraints on learning and memory research. In L. S. Cermak, \& F. I. Craik, (Eds), Levels of processing in human memory (pp. 226-243). Hillsdale, NJ: Lawrence Erlbaum Associated, INC.

Brewer, M. B. (1988). A dual process model of impression formation. In T. K. Srull \& R. S. Wyer, Jr. (Eds.), Advances in social cognition (Vol. 1, pp. 1-36). Hillsdale, NJ: Erlbaum.

Brinol, P., Petty, R. E., \& Tormala, Z. L. (2004). Self-validation of cognitive responses to advertisements. Journal of Consumer Research, 30, 559-573.

Brooks, A. C. (2005). Does social capital make you generous? Social Science Quarterly, 86, 1-15.

Brosius, H., Donsbach, W., \& Birk, M. (1996). How do text-picture relations affect the informational effectiveness of television newscasts? Journal of Broadcasting and Electronic Media, 40, 180-195. 
Brown, T. J., \& Dacin, P. A. (1997). The company and the product: Corporate associations and consumer product responses. Journal of Marketing, 61, 68-84.

Burgoyne, C. B., Young, B., \& Walker, C. (2005). Deciding to give to charity: A focus group study in the context of the household economy. Journal of Community \& Applied Social Psychology, 15, 383-405.

Butler, L. T., \& Berry, D. C. (2001). Transfer effects in implicit memory and consumer choice. Applied Cognitive Psychology, 15, 587-601.

Calder, B., \& Sternthal, B. (1980). Television commercial wearout: An information processing view. Journal of Marketing Research, 17, 173-186.

Cesario, J., Grant, H., \& Higgins, E. T. (2004). Regulatory fit and persuasion: transfer from 'feeling right'. Journal of Personality and Social Psychology, 86, 388-404.

Chaiken, S. (1980), Heuristic versus systematic information processing and the use of source versus message cues in persuasion. Journal of Personality and Social Psychology, 39, 752-756.

Chaiken, S., \& Trope, Y. (Eds.). (1999). Dual-process theories in social psychology. New York: Guilford Press.

Chandy, R. K., Tellis, G. J., Maclnnis, D. J., \& Thaivanich, P. (2001). What to say when: Advertising appeals in evolving markets. Journal of Marketing Research, 38, 399-414.

Chang, C. (2002). Self-congruency as a cue in different advertising-processing contexts. Communication Research, 29, 503-536.

Chartrand, T. L. (2005). The role of conscious awareness in consumer behavior. Journal of Consumer Psychology, $15,203-210$.

Chartrand, T. L., \& Bargh, J. A. (1996). Automatic activation of impression formation and memorization goals: Nonconscious goal priming reproduces effects of explicit task instructions. Journal of Personality \& Social Psychology, 71, 464-478.

Chartrand, T. L., Huber, J., Siv, B., \& Tanner, J. (2008). Nonconscious goals and consumer choice. Journal of Consumer Research, 35, 189-201.

Chattopadhyay, A., \& Basu, K. (1990). Humor in advertising: The moderating role of prior brand evaluation. Journal of Marketing Research, 27, 466-476.

Chen, S., \& Chaiken, S. (1999). The heuristic-systematic model in its broader context. In S. Chaiken \& Y. Trope (Eds.), Dual process theories in social psychology (pp. 73-96). New York: Guilford Press.

Chung, S. W., \& Szymanski, K. (1997). Effects of brand name exposure on brand choices: An implicit memory perspective. Advances in Consumer Research, 24, 288-294.

Cialdini, R. B., \& Goldstein, N. J. (2004). Social influence: Compliance and conformity. Annual Review of Psychology, $55,591-621$.

Coates, S. L., Butler, L., \& Berry, D. C. (2006). Implicit memory and consumer choice: The mediating role of brand familiarity. Applied Cognitive Psychology, 20, 1101-1116.

Cobb-Walgren, C. J., Ruble, C. A., \& Donthu, N. (1995). Brand equity, brand preference, and purchase intent. Journal of Advertising, 24, 25-40. 
Conner, M., \& Armitage, C. J. (1998). Extending the theory of planned behavior: A review and avenues for further research. Journal of Applied Social Psychology, 28, 1429-1464.

Conner, M., \& Norman, P. (2005). Predicting health behaviour. New York: Open University Press.

Coulter, K. S. (1998). The effects of affective responses to media context on advertising evaluations. Journal of Advertising, 27, 41-51.

Craik, F. I. M., Moscovitch, M., \& McDowd, J. M. (1994). Contributions of surface and conceptual information to performance on implicit and explicit memory tasks. Journal of Experimental Psychology: Learning, Memory, and Cognition, 20, 864-875.

Cummings, R. G., \& Taylor, L. O. (1999). Unbiased value estimates for environmental goods: A cheap talk design for the contingent valuation method. The American Economic Review, 89, 649-665.

Das, E., \& Fennis, B. M., (in press). In the mood to face the facts: When a positive mood promotes systematic processing of self-threatening information. Motivation and Emotion.

Davis, B. P., \& Knowles, E. (1999). A disrupt-then-reframe technique of social influence. Journal of Personality and Social Psychology, 76, 192-199.

Pelsmacker, P. D., Geuens, M., \& Anckaert, P. (2002). Media context and advertising effectiveness: The role of context appreciation and context/ad similarity. Journal of Advertising, 31, 49-61.

De Pelsmacker, P. D., Geuens, M., \& Van den Bergh, J. (2004). Marketing communications: A European perspective. Prentice Hall.

Deaton, A., \& Muellbauer, J. (1980). Economics and consumer behavior. Cambrigde: University Press.

Devine, P. G. (1989). Stereotypes and prejudice: Their automatic and controlled components. Journal of Personality and Social Psychology, 56, 5-18.

Dijksterhuis, A., Aarts, H., \& Smith, P. K. (2005). The power of the subliminal: On subliminal persuasion and other potential applications. In R. R. Hassin, J. S. Uleman, \& J. A. Bargh (Eds.), The new unconscious (pp. 77106). Oxford University Press.

Dijksterhuis, A., \& Bargh, J. A. (2001). The perception-behavior expressway: Automatic effects of social perception on social behavior. Advances in experimental social psychology, 33, 1-40.

Dijksterhuis, A., Smith, P. K., Van Baaren, R. B., \& Wigboldus, D. H. J. (2005). The unconscious consumer: Effects of environment on consumer behavior. Journal of Consumer Psychology, 15, 193-202.

Dijksterhuis, A., \& Van Knippenberg, A. (1998). The Relation between perception and behavior, or how to win a game of trivial pursuit. Journal of Personality and Social Psychology, 74, 865-877.

Duval, S. \& Wicklund, R. A. (1972). A theory of objective self-awareness. New York: Academic Press.

Fazio, R. H., Sanbonmatsu, D. M., Powell, M. C., \& Kardes, F. R. (1986). On the automatic activation of attitudes. Journal of Personality and Social Psychology, 50, 229-238.

Feldman, J. M., \& Lynch, Jr J. G. (1988). Self-generated validity and other effects of measurement on belief, attitude, intention, and behaviour. Journal of Applied Psychology, 73, 421-435. 
Fenigstein, A., \& Levine, M. P. (1984). Self-attention, concept activation, and the causal self. Journal of Experimental Social Psychology, 20, 231-245.

Fenigstein, A., Scheier, M. F., \& Buss, A. H. (1975). Public and private self-consciousness: Assessment and theory. Journal of Consulting and Clinical Psychology, 43, 522-527.

Fennis, B. M., \& Bakker, A. B. (2001). 'Stay tuned-we will be back right after these messages': Need to evaluate moderates the transfer of irritation in advertising. Journal of Advertising, 30, 15-25.

Ferguson, M., \& Bargh, J. A. (2002). Sensitivity and flexibility: Exploring the knowledge function of automatic attitudes. In L. F. Barret, \& P. Salovey (Eds.), The wisdom of feelings: Processes underlying emotional intelligence (pp. 383-405). New York: Guilford.

Ferraro, R., Shiv, B., \& Bettman, J. R. (2005). Let us eat and drink, for tomorrow we shall die: Effects of mortality salience and self-esteem on self-regulation in consumer choice. Journal of Consumer Research, 32, 65-75.

Fisher, R. P., \& Craik, F. I. (1977). Interaction between encoding and retrieval operations in cued recall. Journal of Experimental Psychology: Human Learning \& Memory, 3, 701-711.

Fisher, R. J., Vandenbosch, M., \& Antia, K. D. (2008). An empathy-helping perspective on consumers' responses to fund-raising appeals. Journal of Consumer Research, 35, 519-531.

Fitzsimons, G. M., \& Bargh, J. A. (2003). Thinking of you: Nonconscious pursuit of interpersonal goals associated with relationship partners. Journal of Personality \& Social Psychology, 84, 148-163.

Fitzsimons, G. M., Chartrand, T. L., \& Fitzsimons, G. J. (2008). Automatic effects of brand exposure on motivated behavior: How Apple makes you 'think different'. Journal of Consumer Research, 35, 21-35.

Fitzsimons, G. J., Hutchinson, W., Williams, P., Alba, J. W., Chartrand, T. L., Huber, J., Kardes, F., Menon, G., Raghubir, P., Russo, J. E., Shiv, B., \& Tavassoli, N. (2002). Non-conscious Influences on Consumer Choice. Marketing Letters, 13, 269-279.

Florack, A., \& Scarabis, M. (2006). How advertising claims affect brand preferences and category-brand associations: The role of regulatory fit. Psychology and Marketing, 23, 741-755

Forster, J., Higgins, E. T., \& Idson, L (1998). Approach and avoidance strength during goal attainment: Regulatory focus and the 'goal looms larger' effect. Journal of Personality and Social Psychology, 75, 1115-1131.

Fox, J. R. (2004). A signal detection analysis of audio/video redundancy effects on television news video. Communication Research 31, 524-536

Franks, J. J., Bilbrey, C. W., Lien, K. G., \& McNamara, T. P. (2000). Transfer-appropriate processing (TAP) and repetition priming. Memory \& Cognition, 1140-1151.

Fransen, M. L., Fennis, B. M., \& Pruyn, A. Th. H. (2007). Be all you can be: The influence of advertising slogans on regulatory focus and consumer spending behavior. In G. V. Fitzsimons \& V. G. Motwitz (Eds), Advances in Consumer Research (Vol. 34, pp. 206-207). Duluth, MN: Association for Consumer Research.

Fransen, M. L., Fennis, B. M., \& Pruyn, A. Th. H. Matching communication modalities: The influence of modality congruence and processing style on brand evaluation and brand choice (under review). 
Fransen, M. L., Fennis, B. M., \& Pruyn, A. Th. H. \& Das, E. (2008). Rest in Peace? Brand-induced mortality salience and consumer behavior. Journal of Business Research, 60, 1053-1061.

Fransen, M. L., Fennis, B. M., Vohs, K. D., \& Pruyn, A. Th. H. Fit for charity: The role of private self-focus in the effectiveness of regulatory fit (invited for revision).

Franzoi S. L., \& Brewer, L. C. (1984). The experience of self-awareness and its relation to level of selfconsciousness: An experiential sampling study. Journal of Research in Personality, 18, 522-540.

Freiden, J. B. (1984). Advertising spokesperson effects: An examination of endorser type and gender on two audiences. Journal of Advertising Research, 24, 33-41.

Freitas, A. L., \& Higgins, E. T. (2002). Enjoying goal-directed action: The role of regulatory fit. Psychological Science, 13, 1-6.

Geller, V., \& Shaver, P. (1976). Cognitive consequences of self-awareness. Journal of Experimental Social Psychology, 12, 99-108.

Giving USA Foundation (2007). www.givingusa.org

Gollwitzer, P. M. (1990). Action phases and mind-sets. In E. T. Higgins \& R. M. Sorrentino (Eds.), Handbook of motivation and cognition (Vol. 2, pp. 53-92). New York: Guilford.

Govern J. M., \& Marsch, L. A. (1997). Development and validation of the situational self-awareness scale. Consciousness and Cognition: An International Journal, 10, 366-378.

Greenberg, J., Koole, S. L., Pyszczynski, T. (2004). Handbook of experimental existential psychology. Guilford Press.

Greenberg, J., Porteus, J., Simon, L., Pyszczynski, T., Solomon, S. (1995). Evidence of a terror management function of cultural icons: The effects of mortality salience on the inappropriate use of cherished cultural symbols. Personality \& Social Psychology Bulletin, 21, 1221-1228.

Greenberg, J., Pyszczynski, T., \& Solomon, S. (1986). The causes and consequences of a need for self-esteem: A terror management theory. In R. F. Baumeister (Ed.), Public self and private self (pp. 189-192). New York/Berlin: Springer-Verlag.

Greenberg, J., Pyszczynski, T., Solomon, S., \& Rosenblatt, A. (1990). Evidence for terror management theory II: The effects of mortality salience on reactions to those who threaten or bolster the cultural worldview. Journal of Personality and Social Psychology, 58, 308-18.

Greenberg, J., Pyszczynski, T., Solomon, S., \& Simon, L. (1994). Role of consciousness and accessibility of deathrelated thoughts in mortality salience effects. Journal of Personality \& Social Psychology, 67, $627-37$.

Gwinner, K. P., \& Eaton, J. (1999). Building brand image through event sponsorship: The role of image transfer. Journal of Advertising, 28, 47-57.

Harrison, J. A., Mullen, P. D., \& Green, L. W. (1992). A meta-analysis of studies of the health belief model with adults. Health Education Research, 7, 107-116.

Haugtvedt, C. P., Petty, R. E., \& Cacioppo, J. T. (1992). Need for cognition and advertising: understanding the role of personality variables in consumer behavior. Journal of Consumer Psychology, 1, 239-260. 
Heine, S. J., Harihara, M., \& Niiya, Y. (2002). Terror management in Japan. Asian Journal of Social Psychology, 5, 187-196.

Hibbert, S., Smith, A. \& Davies, A. (2007). Guilt appeals: Persuasion knowledge and charitable giving. Psychology \& Marketing, 24, 723-742.

Higgins, E. T. (1996). Knowledge activation: Accessibility, applicability, and salience. In E. T. Higgins \& A. W. Kruglanski (Eds.), Social psychology: Handbook of basic principles (pp. 133-168). New York:Guilford Press.

Higgins, E. T. (1997). Beyond pleasure and pain. American Psychologist, 52, 1280-1300.

Higgins, E. T. (1998). Promotion and prevention: Regulatory focus as a motivational principle. In M. P. Zanna (Ed.), Advances in Experimental Social Psychology (Vol. 30, pp 1-46). New York: Academic Press.

Higgins, E. T. (2000). Making a good decision: Value from fit. American Psychologist, 11, 1217-1230.

Higgins, E. T. (2001). Promotion and prevention experiences: Relating emotions to nonemotional motivational states. In J. P. Forgas (Ed.), Handbook of affect and social cognition (pp. 186-211). Mahwah, NJ: Erlbaum.

Higgins, E. T. (2002). How self-regulation creates distinct values: The case of promotion and prevention decision making. Journal of Consumer Psychology, 12, 177-191.

Higgins, E. T. (2005). Value from regulatory fit. Current directions in Psychological Science, 14, $209-213$.

Higgins, E. T., Bargh, J. A., \& Lombardi, W. J. (1985). Nature of priming effects on categorization. Journal of Experimental Psychology: Learning, Memory, \& Cognition, 11, 59-69.

Higgins, E. T., Friedman, R. S., Harlow, R. E., Idson, L., Ayduk, O. N., \& Taylor, A. (2001). Achievement orientations from subjective histories of success: Promotion pride versus prevention pride. European Journal of Social Psychology, 31, 3-23.

Higgins, E. T. \& Tykocinski, O. (1992). Self-discrepancies and biographical memory: Personality and cognition at the level of psychological situation. Personality and Social Psychology Bulletin, 18, 527-535

Hobson, J. A. (1999). Consciousness, New York: ScientificAmerican Library.

Hollender, D. (1986). Semantic activation without conscious identification in dichotic listening, parafoveal vision, and visual masking: A survey and appraisal. Behavioral and Brain Sciences, 9, 1-66.

Huber, J., Payne, J. W., \& Puto, C. (1982). Adding asymmetrically dominated alternatives: Violations of regularity and the similarity hypothesis. Journal of Consumer Research, 9, 90-98.

Hull, J. G. \& Levy, A. S. (1979). The organizational functions of the self: An alternative to the Duval and Wicklund model of self-awareness. Journal of Personality and Social Psychology, 37, 756-768.

Hull, J. G., Slone, L. B., Meteyer, K. B., \& Matthews, A. R. (2002). The nonconsciousness of self-consciousness. Journal of Personality and Social Psychology, 83, 406-424.

Hull, J. G., Treuren, R. R., Ashford, S. J., Propsom, P., \& Andrus, B. W. (1988). Self-consciousness and the processing of self-relevant information. Journal of Personality and Social Psychology, 54, 452-465.

Hullett, C. R., (2005). The impact of mood on persuasion: A meta-analysis. Communication Research, 32, $432-442$.

Idson, L. C., Liberman, N., \& Higgins, E. T. (2000). Distinguishing gains from nonlosses and losses from nongains: A regulatory focus perspective on hedonic intensity. Journal of Experimental Social Psychology, 36, $252-274$. 
Jacoby, L. L. (1983). Remembering the data: Analyzing interactive processes in reading. Journal of Verbal Learning \& Verbal Behavior, 22, 485-508.

Jacoby, L. L., \& Dallas, M. (1981). On the relationship between autobiographical memory and perceptual learning. Journal of Experimental Psychology: General, 110, 306-340.

Jacoby, L. L., \& Hayman, L.L. (1987). Specific visual transfer in word identification. Journal of Experimental Psychology: Learning, Memory, and Cognition, 13, 456-463.

James, R. N. \& Sharpe, D. I. (2007). The nature and causes of the U-shaped charitable giving profile. Nonprofit and Voluntary Sector Quarterly, 36, 217-238.

Janiszewski, C. (1993). Preattentive mere exposure effects. Journal of Consumer Research, 20, 376-392.

Janiszewski, C., \& Chandon, E. (2007). Transfer-appropriate processing, response fluency, and the mere measurement effect. Journal of Marketing Research, 44, 309-323.

Janiszewski, C. \& Meyvis, T. (2001). Effects of brand logo complexity, Repetition, and spacing on processing fluency and judgment. Journal of Consumer Research, 28, 18-32.

Janz, N. K., \& Becker, M. H. (1984). The health belief model: A decade later. Health Education Quarterly, 11, 1-47.

John, D. R., Loken, B., Kim, K., \& Monga, A. B. (2006). Brand concept maps: A methodology for identifying brand association networks. Journal of Marketing Research, 43, 549-563.

Jonas, E., Fritsche, I., \& Greenberg, J. (2005). Currencies as cultural symbols -an existential psychological perspective on reactions of Germans toward the Euro. Journal of Economic Psychology, 26, 129-146.

Jonas, E., Schimel, J., Greenberg, J., \& Pyszczynski, T. (2002). The Scrooge effect: Evidence that mortality salience increases prosocial attitudes and behavior. Personality and Social Psychology Bulletin, 28, 1342-1352.

Kardes, F. R. (1996). In defense of experimental consumer psychology. Journal of Consumer Psychology, 5, 279296.

Kardes, F. R. (2001). Consumer behavior and mangerial decision making. New Jersey; Prentice Hall.

Karremans, J. C., \& Stroebe, W. C. J. (2006). Beyond Vicary's fantasies: The impact of subliminal priming and brand choice. Journal of Experimental Social Psychology, 42, 792-798.

Kasser, T., \& Sheldon, K. M. (2000). Of wealth and death: Materialism, mortality salience, and consumption behavior. Psychological Science, 11, 348-351.

Kay, A. C., Wheeler, S. C., Bargh, J. A., \& Ross, L. (2004). Material priming: The influence of mundane physical objects on situational construal and competitive behavioral choice. Organizational Behavior and Human Decision Processes, 95, 83-96.

Keller, K. L. (1993). Conceptualizing, measuring, and managing customer-based brand equity. Journal of Marketing, $57,1-22$.

Keller, K. L. (2003). Brand synthesis: The multidimensionality of brand knowledge. Journal of Consumer Research, 29, 596-600.

Kelley, C. M., Jacoby, L.L., \& Hollingshead, A. (1989). Directs versus indirect tests of memory for source: Judgments of modality. Journal of Experimental Psychology: Learning, Memory, and Cognition, 15, 1101-1108. 
Kelley, C. M., \& Rhodes, M. G. (2002). Making sense and nonsense of experience: Attributions in memory and judgment. In B. H. Ross (Ed.), The psychology of learning and motivation: Advances in research and theory (pp. 295-316). Academic Press.

Key, W. B. (1980). The clam-plate orgy: And other subliminals the media use to manipulate your behavior. Englewood Cliffs, NJ: Prentice Hall.

Khalil E. L. (2004). What is altruism. Journal of Economic Psychology, 25, 97-123.

Kohli, C. S., Harich, K. R., \&Leuthesser, L. (2005). Creating brand identity: A study of evaluation of new brand names. Journal of Business Research, 58, 1506-1515.

Kotler, P., \& Keller, K. L. (2005), Marketing management: New Jersey: Prentice Hall.

Krishnan, H. S. (1996). Characteristics of memory associations: A consumer-based brand equity perspective. International Journal of Research in Marketing, 13, 389-405.

Krishnan, H. S., \& Chakravarti, D. (1999). Memory measures for pretesting advertisements: An integrative conceptual framework and a diagnostic template. Journal of Consumer Psychology, 8, 1-37.

Kruglanski, A. W. (1980). Lay epistemo-logic-process and contents: Another look at attribution theory. Psychological Review, 87, 70-87.

Kruglanski, A. W., Thompson, E. P., Higgins, E. T., Atash, M. N., Pierro, A., Shah, J. Y. \& Spiegel, S. (2000). To do the right thing! or to just do it!: Locomotion and assessment as distinct self-regulatory imperatives. Journal of Personality and Social Psychology, 79, 793-815.

Kunst-Wilson, W. R., \& Zajonc, R. B. (1980). Affective discrimination of stimuli that cannot be recognized. Science, 207, 557-558.

LaBerge, D., \& Samuels, S. J. (1974). Toward a theory of automatic information processing in reading. Cognitive Psychology, 6, 293-323.

Labroo, A. A., \& Lee, A. Y. (2006). Between two brands: A goal fluency account of brand evaluation. Journal of Marketing Research, 43, 374-385.

Lang, A. (1995). Defining audio/video redundancy from a limited capacity information processing perspective. Communication Research, 22, 86-115.

Lee, A. Y. (2001). The mere exposure effect: An uncertainty reduction explanation revisited. Personality and Social Psychology Bulletin, 27, 1255-1266.

Lee, A. Y., \& Aaker, J. L. (2004). Bringing the frame into focus: The influence of regulatory fit on processing fluency and persuasion. Journal of Personality \& Social Psychology, 86, 205-218.

Lee, A. Y., \& Labroo, A. A. (2004). The effect of conceptual and perceptual fluency on brand evaluation. Journal of Marketing Research, 41, 151-165.

Leshner, G., \& Coyle, J. R. (2000). Memory for television news: Match and mismatch between processing and testing. Journal of Broadcasting \& Electronic Media, 44, 599-613.

Liedtke, M. (2007). Google skims on its own advertising. Report on Business. http://www.reportonbusiness.com/

Liu, J. (2008). Brand and automaticity. Doctoral Dissertation. University of Tilburg, The Netherlands. 
Liu, W., \& Aaker, J. (2008). The happiness of giving: The time-ask effect. Journal of Consumer Research, 35, 543557.

Lockwood, P., Jordan, C. H., \& Kunda, Z. (2002). Motivation by positive or negative role models: Regulatory focus determines who will best inspire us. Journal of Personality \& Social Psychology, 83, 854-864.

MacKenzie, S. B., \& Lutz, R. J. (1989). An empirical examination of the structural antecedents of attitude toward the ad in an advertising pretesting context. Journal of Marketing, 53, 48-65.

Macrae, C. N., \& Johnston, L. (1998). Help I need somebody: Automatic action and inaction. Social Cognition, 16, 400-417.

Macrae, C. N., Stangor, C., \& Milne, A. B. (1994). Activating social stereotypes: A functional analysis. Journal of Experimental Social Psychology, 30, 370-389.

Madigan, S., McDowd, J., \& Murphy, D. (1991). Facilitating word-fragment completion with hidden primes. Bulletin of the Psychonomic Society, 29, 189-191.

Maheswaran, D., \& Agrawal, N. (2004). Motivational and cultural variations in mortality salience effects: Contemplations on terror management theory and consumer behavior. Journal of Consumer Psychology, 14, 213-218.

Mandel, N., \& Heine, S. J. (1999). Terror management and marketing: He who dies with the most toys wins. Advances in Consumer Research, 26, 527-532.

Mandel, N., \& Smeesters D. (2008). The sweet escape: Effects of mortality salience on consumption quantities for high and low self-esteem consumers. Journal of Consumer Research, 35, 309- 323.

Matsuba, M. K., Hart, D., \& Atkins, R. (2007). Psychological and social-structural influences on commitment to volunteering. Journal of Research in Personality, 41, 889-907.

McCracken, G. (1989). Who is the celebrity endorser? Cultural foundations of the endorsement process. Journal of Consumer Research, 16, 310-321.

McDaniel, S. R. (1999). An investigation of match-up effects in sport sponsorship advertising: The implications of consumer advertising schemas. Psychology \& Marketing, 16, 163-184.

McMillan, S., Hwang, J. S., \& Lee, G. (2003). Effects of structural and perceptual factors on attitudes toward the website. Journal of Advertising Research, 43, 400-409.

Menon, G., Block, L. G., \& Ramanathan, S. (2002). We're at as much risk as we are led to believe: effects of message cues on judgments of health risk. Journal of Consumer Research, 28, 533-549.

Meyer, D. E., \& Schvaneveldt, R.W. (1971). Facilitation in recognizing pairs of words: Evidence of a dependence between retrieval operations. Journal of Experimental Psychology, 90, 227-234.

Milne, S., Sheeran, P., \& Orbell, S. (2000). Prediction and intervention in health-related behavior: A meta-analytic review of protection motivation theory. Journal of Applied Social Psychology, 30, 106-143.

Mook, D. G. (1983). In defense of external invalidity. American Psychologist, 38, 379-387.

Moore, T. E. (1982). Subliminal advertising: What you see is what you get. Journal of Marketing, 46, 38-37.

Moorman, C. (2002). Consumer health under the scope. Journal of Consumer Research, 29, 152-158. 
Moorman, M. (2003). Context considered: The relationship between media environments and advertising effects. Doctoral Dissertation. University of Amsterdam, The Netherlands.

Moorman, M., Neijens, P. C., \& Smit, E. G. (2002). The effects of magazine-induced psychological responses and thematic congruence on memory and attitude toward the ad in a real-life setting. Journal of Advertising, 31, 27-40.

Moors, A., \& De Houwer, J. (2006). Automaticity: A theoretical and conceptual analysis. Psychological Bulletin, 132, 297-326.

Mueller, J. H. (1982). Self-awareness and access to material rated as self-descriptive or non-descriptive. Bulletin of the Psychonomic Society, 19, 323-326.

Mulder, J., Poort, J., Marlet, G., \& Van Woerkens, C. (2006). Het economische belang van reclame. SEO Economisch Onderzoek/Stichting Atlas voor gemeenten. http://www.seo.nl/assets/binaries/publicaties/rapporten/2006/853.pdf

Muller, D., Judd, C. M., \& Yzerbyt, V. Y. (2005). When moderation is mediated and mediation is moderated. Journal of Personality and Social Psychology, 89, 852-863.

Murphy, S. T., \& Zajonc, R. B. (1993). Affect, cognition, and awareness: Affective priming with optimal and suboptimal stimulus exposures. Journal of Personality and Social Psychology, 64, 723-739.

Murphy, S. T., Monahan, J. L., \& Zajonc, R. B. (1995). Additivity of nonconscious affect: Combined effects of priming and exposure. Journal of Personality and Social Psychology, 69, 589-602.

Murry Jr, J. P., Lastovicka, J. L., \& Singh, S. N. (1992). Feeling and liking responses to television programs: An examination of two explanations for media-context effects. Journal of Consumer Research, 18, 441-451.

National and Community Service (2007), http://www.nationalservice.org/about/volunteering/states.asp

Nebenzahl, I., \& Hornik, J. (1985). An experimental study of the effectiveness of commercial billboards in televised sports arenas. International Journal of Advertising, 4, 27-36.

Neely, J. H. (1977). Semantic priming and retrieval from lexical memory: Roles of inhibitionless spreading activation and limited-capacity attention. Journal of Experimental Psychology: General, 106, 226-254.

Nelson, L. J., Moore, D. L., Olivetti, J., \& Scott, T. (1997). General and personal mortality salience and nationalistic bias. Personality and Social Psychology Bulletin, 23, 884-892.

Nelson, M. R., Brunel, F. F., Supphellen, M., \& Manchande R. V. (2006). Effects of culture, gender, and moral obligations on responses to charity advertising across masculine and feminine cultures. Journal of Consumer Psychology, 16, 45-56.

Norman, P., Boer, H., \& Seydel, E. R. (2005). Protection motivation theory. In M. Conner, \& P. Norman (Eds), Predicting health behaviour (pp. 81-126). New York: Open University Press.

Novemsky, N., Dhar, R., \& Schwarz, N, \& Simonson, I. (2007). Preference fluency in choice. Journal of Marketing Research, 44, 347-356.

Packard, V. (1957). The hidden persuaders. New York: David McKay 
Pechmann, C. (2001). A Comparison of Health Communication Models: Risk Learning Versus Stereotype Priming. Media Psychology, 3, 189-210.

Pechmann, C., Zhao, G., Goldberg, M. E., \& Reibling, E. T. (2003). What to convey in antismoking advertisements for adolescents: The use of protection motivation theory to identify effective message themes. Journal of Marketing, 67, 1-18.

Perloff, L. S., \& Fetzer, B. K. (1986). Self-other judgments and perceived vulnerability to victimization. Journal of Personality and Social Psychology, 50, 502-510.

Perloff, R. M. (1999). The third-person effect: A critical review and synthesis. Media Psychology, 1, 353-378.

Perrine, R. M. (2000). Effects of a picture and even-a-penny-will-help appeals on anonymous donations to charity. Psychological Reports, 86, 551-559.

Peter, J. P., \& Olson, J. C. (2005). Consumer behavior and marketing strategy. McGraw-Hill.

Petty, R. E., Brinol, P., \& Tormala, Z. L. (2002). Thought confidence as a determinant of persuasion: The selfvalidation hypothesis. Journal of Personality and Social Psychology, 82, 722-741.

Petty, R. E., \& Cacioppo, J. T. (1986). Communication and persuasion: Central and peripheral routes to attitude change. New York: Springer-Verlag.

Petty, R. E., Cacioppo, J. T., \& Schumann, D. (1983). Central and peripheral routes to advertising effectiveness: The moderating role of involvement. Journal of Consumer Research, 10, 135-146.

Pham, M. T. (1992). Effects of involvement, arousal, and pleasure on the recognition of sponsoring stimuli. Advances in Consumer Research, 19, 85-93.

Pham, M. T., \& Avnet, T. (2004). Ideals and oughts and the reliance on affect versus substance in persuasion. Journal of Consumer Research, 30, 503-518.

Pieters, R. G. M., Wedel, E., \& Rosbergen, M. (1999). Visual attention to repeated print advertising: A test of scanpath theory. Journal of Marketing Research, 36, 424-438.

Pieters, R. G. M., \& Van Raaij, W. F. (1992): De werking van reclame. Leiden: Stenfert Kroese.

Posner M. I., \& Snyder C. R. R. (1975). Attention and cognitive control. In R. L. Solso (Ed.), Information Processing and Cognition. Hillsdale, NJ:Erlbaum.

Preacher, K. J., \& Hayes, A. F. (2004). Spss and Sas procedures for estimating indirect effects in simple mediation models. Behavior Research Methods, Instruments \& Computers, 36, 717-731.

Punj, G., \& Moon, J. (2002). Positioning options for achieving brand association: A psychological categorization framework. Journal of Business Research, 55, 275-283.

Pyszczynski, T., Greenberg, J., Solomon, S., Arndt, J., \& Schimel, J. (2004). Why do people need self-esteem? A theoretical and empirical review. Psychological Bulletin, 130, 435-68.

Pyszczynski, T., Wicklund, R. A., Floresku, S., Koch, H., Gauch, G., Solomon, S., \& Greenberg, J. (1996). Whistling in the dark: Exaggerated consensus estimates in response to incidental reminders of mortality. Psychological Science, 7, 332-336. 
Rajaram, S., \& Roediger, H. L. (1993). Direct comparison of four implicit memory tests. Journal of Experimental Psychology: Learning, Memory, and Cognition, 19, 765-776.

Reber, R., Meier, B., Ruch-Monachon, M. A., \& Tiberini, M. (2006). Effects of processing fluency on comparative performance judgments. Acta Psychologica, 123, 337-354.

Reber, R., Winkielman, P., \& Schwarz, N. (1998). Effects of perceptual fluency on affective judgments. Psychological Science, 9, 45-48.

Rindfleisch, A., \& Burroughs, J. E. (2004). Terrifying thoughts, terrible materialism? Contemplations on a terror management account of materialism and consumer behavior. Journal of Consumer Psychology, 14, 219224.

Rodgers, S., \& Thorson, E. (2000). The interactive advertising model: How users perceive and process online ads. Journal of Interactive Advertising, 1, 15-20.

Roediger, H. L, \& Blaxton, T. A. (1987). Effects of varying modality, surface features, and retention interval on priming in word-fragment completion. Memory \& Cognition, 15, 379-388.

Roediger, H. L., \& McDermott, K. B. (1993). Implicit memory in normal human subjects. Handbook of Neuropsychology (Vol. 8, pp. 63-131). Amsterdam: Elsevier.

Rogers, R. W. (1975). A protection motivation theory of fear appeals and attitude change. Journal of Psychology, 91, 93-114.

Rogers, R. W. (1983). Cognitive and physiological processes in fear appeals and attitude change: a revised theory of protection motivation. In J. T. Cacioppo, \& R. E. Petty (Eds.), Social Psychophysiology: A source book (pp. 153-176). New York: Guilford Press.

Rosenblatt, A., Greenberg, J., Solomon, S., Pyszczynski, T., \& Lyon, D. (1989). Evidence for terror management theory I: The effects of mortality salience on reactions to those who violate or uphold cultural values. Journal of Personality and Social Psychology, 57, 681-690.

Rosenstock, I. M. (1974). Historical origins of the health belief model. Health Education Monographs, 2, 1-8.

Rutström, E. E. (1998). Home-grown values and incentive compatible auction design. International Journal of Game Theory, 27, 427-441.

Scheier, M. F., Carver, C. S., \& Gibbons, F. X. (1979). Self-directed attention, awareness of bodily states, and suggestibility. Journal of Personality and Social Psychology, 37, 1576-1588.

Schwarz, N. (2004) Metacognitive experiences in consumer judgment and decision making. Journal of Consumer Psychology, 14, 332-348.

Seamon, J. G., Brody, N., \& Kauff, D. M. (1983). Affective discrimination of stimuli that are not recognized: Effects of shadowing, masking, and cerebral laterality. Journal of Experimental Psychology: Learning, Memory, and Cognition, 9, 544-555.

Schwarz, N., \& Clore, G. L. (1983). Mood, misattribution, and judgments of well-being: Informative and directive functions of affective states. Journal of Personality and Social Psychology, 45, 513-523. 
Schwarz, N. Clore, G. L. (1996). Feelings and phenomenal experiences. In E. T. Higgins \& A. W. Kruglanski (Eds), Social psychology: Handbook of basic principles (pp. 433-65). New York: Guilford.

Shah, J. (2003). Automatic for the people: How representations of significant others implicitly affect goal pursuit. Journal of Personality and Social Psychology, 84, 661-681.

Shah, J., Higgins, E. T., \& Friedman, R. S. (1998). Performance incentives and means: How regulatory focus influences goal attainment. Journal of Personality and Social Psychology, 74, 285-293.

Shah, J. \& Kruglanski, A. W. (2003). When opportunity knocks: Bottom-up priming of goals by means and its effects on self-regulation. Journal of Personality and Social Psychology, 84, 1109-1122.

Shen, L., \& Dillard, J. P. (2007). The Influence of behavioral inhibition/approach systems and message framing on the processing of persuasive health messages. Communication Research, 34, 433-467.

Silvia, P. J. (2001). Nothing or the opposite: Intersecting terror management and objective self-awareness. European Journal of Personality, 15, 73-82.

Simonson, I. (2005). In defense of consciousness: The role of conscious and unconscious inputs in consumer choice. Journal of Consumer Psychology, 15, 211-217.

Simonson, I., Carmon, Z., Dhar, R., Drolet, A., \& Nowlis, S. M. (2001). Consumer research: In search of identity. Annual Review of Psychology, 52, 249-275.

Solomon, S., Greenberg, J., \& Pyszczynski, T. (2004). Lethal consumption: death-denying materialism. In T. Kasser \& A. D. Kanner (Eds), Psychology and consumer culture: The struggle for a good life in a materialistic world (pp. 127-146). American Psychological Association.

Spencer, S. J., Fein, S., Wolfe, C. T., Fong, C., \& Dunn, M. A. (1998). Automatic activation of stereotypes: The role of self-image threat. Personality and Social Psychology Bulletin, 24, 139-1152.

Spiegel, S., Grant-Pillow, H., \& Higgins, E. T. (2004). How regulatory fit enhances motivational strength during goal pursuit. European Journal of Social Psychology, 34(1), 39-54.

Strahan, E. J., Spencer, S. J., \& Zanna, M. P. (2002). Subliminal priming and persuasion: Striking while the iron is hot. Journal of Experimental Social Psychology, 38, 556-568.

Till, B. D., \& Shimp, T. A. (1998). Endorsers in Advertising: The Case of Negative Celebrity Information. Journal of Advertising, 27, 67-82.

Trappey, C. (1996). A Meta-analysis of consumer choice and subliminal advertising. Psychology and Marketing, 13, 517-530.

Tripp, C., Jensen, T. D., \& Carlson, L. (1994). The effects of multiple product endorsements by celebrities on consumers' attitudes and intentions. Journal of Consumer Research, 20, 535-547.

Trope, Y., \& Liberman, N. (2003). Temporal construal. Psychological Review, 110, 403-421.

Tulving, E., \& Osler, S. (1968). Effectiveness of retrieval cues in memory for words. Journal of Experimental Psychology, 77, 593-601.

Tulving, E., \& Thomson, D. M. (1973). Encoding specificity and retrieval processes in episodic memory. Psychological Review, 80, 352-373. 
Vaidya, C., Gabrieli, J. D. E., Keane, M. M. K., Monti, L. A., Gutiérrez-Rivas, H., \& Zarella, M. M. (1997). Evidence for multiple mechanisms of conceptual priming on implicit memory tests. Journal of Experimental Psychology: Learning, Memory, and Cognition, 23, 1324-1343.

Vakratsas, D., \& Ambler, T. (1999). How advertising works: What do we really know? Journal of Marketing, 63, 26-43.

Van Osselaer, S. M. J., \& Janiszewski, C. (2001). Two ways of learning brand associations. Journal of Consumer Research, 28, 202-223.

Vleeming, R. G. \& Engelse, J. A. (1981). Assessment of private and public self-consciousness: A Dutch replication. Journal of Personality Assessment, 45, 385-389.

Vokey, J. R., \& Read, J. D. (1985). Subliminal messages: Between the devil and the media. American Psychologist, 40, 1231-1239.

Von Neumann, J., \& Morgenstern, O. (1947). Theory of games and economic behavior, 2nd ed. Princeton, NJ: Princeton University Press.

Walker, C. (2004). A Charitable view of altruism; Commentary on 'What is altruism?' by Elias Khalil. Journal of Economic Psychology, 25, 129-134.

Walker, C., Pharoah, C., Jas, P., Passey, A., \& Romney-Alexander, D. (2002). A lot of give: Trends in charitable giving for the 21st century. London: Hodder \& Stoughton

Warren, P. E., \& Walker, I. (1991). Empathy, effectiveness, and donations to charity: Social psychology's contribution. British Journal of Social Psychology, 30, 325-337.

Watson, D., Clark, L. A., \& Tellegen, A. (1988). Development and validation of brief measures of positive and negative affect: The PANAS scales. Journal of Personality \& Social Psychology, 54, 1063-1070.

Webb, W. M., Marsh, K. L., Schneiderman, W., \& Davis, B. (1989). Interaction between self-monitoring and manipulated states of self-awareness. Journal of Personality and Social Psychology, 56, 70-80.

Weinberger, M. G., Spotts, H., Campbell, L., \& Parsons, A. L. (1995). The use and effect of humor in different advertising media. Journal of Advertising Research, 35, 44-56.

Weldon, M. S., \& Roediger, H. L. (1987). Altering retrieval demands reverses the picture superiority effect. Memory \& Cognition, 15, 269-280.

Wheeler, S. C., \& Berger, J. (2007). When the same prime leads to different effects. Journal of Consumer Research, 34, 357-368.

Wheeler, S. C., DeMarree, K. G., \& Petty, R. E. (2007). Understanding the role of the self in prime-to-behavior effects: The Active-Self account. Personality and Social Psychology Review, 11, 234-261.

Wheeler, S. C., Morrison, K. R., DeMarree, K. G., \& Petty, R. E. (2008). Does self-consciousness increase or decrease priming effects? It depends. Journal of Experimental Social Psychology, 3, 882-889.

Wheeler, S. C., \& Petty R. E. (2001). The effects of stereotype activation on behavior: A review of possible mechanisms. Psychological Bulletin, 127, 797-826.

Whittlesea, B. W. A. (1993). Illusions of familiarity. Journal of Experimental Psychology: Learning, Memory, and Cognition, 19, 1235-1253. 
Whittlesea, B. W. A., \& Williams, L. D. (1998). Why do strangers feel familiar, but friends don't? A discrepancyattribution account of feelings of familiarity. Acta Psychologica, 98, 141-165.

Whittlesea, B. W. A., \& Williams, L. D. (2001a). The discrepancy-attribution hypothesis: I. The heuristic basis of feelings and familiarity. Journal of Experimental Psychology: Learning, Memory, and Cognition, 27, 3-13.

Whittlesea, B. W. A., \& Williams, L. D. (2001b). The discrepancy-attribution hypothesis: II. Expectation, uncertainty, surprise, and feelings of familiarity. Journal of Experimental Psychology: Learning, Memory, and Cognition, 27, 14-33.

Wilson, T. D., \& Brekke, N. (1994). Mental contamination and mental correction: Unwanted influences on judgments and evaluations. Psychological Bulletin, 116, 117-142.

Wilson, T. D., Gilbert, D. T., \& Wheatley, T. P. (1998). Protecting our minds: The role of lay beliefs. In V. Y. Yzzerbyt, G. Lories, \& B. Dardenne (Eds.), Metacognition: Cognitive and social dimensions (pp. 171-201). Thousand Oaks, CA: Sage.

Winkielman, P., Schwarz, N., Fazendeiro, T. A., \& Reber, R. (2003). The hedonic marking of processing fluency: Implications for evaluative judgment. In J. Musch \& K. C. Klauer (Eds), The psychology of evaluation: Affective processes in cognition and emotion (pp. 189-217). Lawrence Erlbaum Associates Publishers.

Winkielman, P., \& Cacioppo, J. T. (2001). Mind at ease puts a smile on the face: Psychophysiological evidence that processing facilitation elicits positive affect. Journal of Personality and Social Psychology, 81, 989-1000.

Winkielman, P., Berridge, K. C., \& Wilbarger, J. (2005). Unconscious affective reactions to masked happy versus angry faces influence consumption behavior and judgments of value. Personality and Social Psychology Bulletin, 31, 121-135.

Wyer, R. S., Jr., \& Srull, T. K. (1989). Memory and cognition in its social context. Hillsdale, NJ: Erlbaum.

Yates, R., \& Noyes, J. M. (2007). Web site design, self-monitoring style, and consumer preferences. Journal of Applied Social Psychology, 37, 1341-1362.

Yi, Y. (1990). Cognitive and affective priming effects of the context for print advertisements. Journal of Advertising, $19,40-48$.

Yi, Y. (1990). The effects of contextual priming in print advertisements. Journal of Consumer Research, 17, $215-222$.

Yoo, B., Donthu, N., \& Lee, S. (2000). An examination of selected marketing mix elements and brand equity. Journal of the Academy of Marketing Science, 28, 195-211.

Zajonc, R. B. (1968). Attitudinal effects of mere exposure. Journal of Personality and Social Psychology, 9, 1-27

Zajonc, R. B. (1980). Feeling and thinking: Preferences need no inferences. American Psychologist, 35, $151-175$.

Zaltman, G. (2000). Consumer researchers: Take a hike! Journal of Consumer Research, 26, 423-428. 
Summary in Dutch (samenvatting) 
In onze huidige samenleving kun je de aanwezigheid van allerlei vormen van marketingcommunicatie bijna niet meer wegdenken. We worden praktisch overal omgeven door merken, advertenties en persuasieve boodschappen. Dagelijkse activiteiten zoals het lezen van de krant, het bekijken van een film en het wachten op de bus zijn onlosmakelijk verbonden met blootstelling aan allerlei marketingcreaties. In dit proefschrift onderzoeken we hoe blootstelling aan verschillende marketinguitingen van invloed is op onze consumentenbeslissingen en bestedingen. Als je mensen vraagt of ze denken dat hun dagelijkse consumentenbeslissingen beïnvloed worden door de aanwezigheid van marketinguitingen, antwoorden de meesten met een welgemeend 'nee'. Hoewel veel mensen wel erkennen dat anderen beïnvloed worden door de aanwezigheid van externe marketingcommunicaties, geloven ze dat hun eigen beslissingen en gedrag niet afhankelijk zijn van de aanwezigheid van merken en advertenties in hun omgeving. Toch investeren veel bedrijven elk jaar miljoenen in reclame en merkmanagement er vanuit gaande dat ze uiteindelijk zullen profiteren van het promoten van hun producten door marketingactiviteiten. Deze ogenschijnlijke tegenstrijdigheid lijkt te suggereren dat veel effecten van reclame automatisch zijn en onopgemerkt blijven. Consumenten lijken zich vaak niet bewust te zijn van de invloed die dagelijkse blootstelling aan marketingcommunicaties op hen kan hebben. In dit proefschrift onderzoeken we hoe consumentengedrag onbewust beïnvloed wordt door externe marketinguitingen zoals merken, advertenties en persuasieve boodschappen. We verwachten dat blootstelling aan marketingcommunicaties ongemerkt en onbewust doelen kan activeren en evaluatieprocessen kan beïnvloeden wat vervolgens effect heeft op consumentenattitudes, beslissingen en gedrag zonder dat de consument zich hiervan bewust is. Bovendien stellen we dat automatische effecten van marketingcommunicaties vaak afhankelijk zijn van de persoonlijke en situationele context waarin consumenten blootgesteld worden aan die marketinguitingen. In hoofdstuk 2 zal onderzocht worden of de aanwezigheid van merken in verschillende consumentencontexten van invloed is op consumentengedrag. Hoofdstuk 3 richt zich op de overeenkomst tussen de context waarin consumenten worden blootgesteld aan een merk en de context waarin consumenten vervolgens een merk evalueren of kiezen. In het laatste empirische hoofdstuk (4) ligt de nadruk op de samenhang tussen de context van de marketinguiting en de individuele context van de consument.

\section{HOOFDSTUK 2}

In hoofdstuk 2 onderzochten we of de bewuste of onbewuste aanwezigheid van merken in de omgeving automatisch gerelateerde merkassociaties activeert. Vervolgens gingen we na of deze merkassociaties onopgemerkt consumentengedrag beïnvloeden door de activatie van een doel. In het algemeen hebben consumenten de neiging om merken te associëren met gerelateerde constructen zoals productkenmerken, gebruiksituaties en de persoon die het product aanprijst in een reclame. Als je het merk 'Nike' ziet zullen er waarschijnlijk automatisch beelden van sportkleding en bekende tennisspelers in je opkomen. Het kan echter ook gebeuren dat het merk 'Nike' onbedoelde associaties bij je oproept zoals de 'sweatshops' waar kinderarbeid plaatsvindt. Gebaseerd op de literatuur naar automatisch gedrag verwachtten we dat de subtiele aanwezigheid van merken in de omgeving genoeg is om zulke gerelateerde associaties te activeren. Met het ultieme doel om productverkoop te stimuleren zullen marketeers er 
alles aan doen om positieve merkassociaties te creëren. Echter, soms zullen merken ook onbedoelde associaties oproepen door oncontroleerbare invloeden zoals negatieve publiciteit of bepaalde productkenmerken. Wij veronderstelden dat verzekeringsmerken, door associaties met rampen, ongelukken en ziekten, mensen automatisch (en ongemerkt) herinnert aan hun sterfelijkheid. We verwachtten dan ook dat de (on)bewuste aanwezigheid van verzekeringsmerken automatisch gedachten aan de dood activeert. Uit eerder onderzoek is gebleken dat wanneer mensen herinnerd worden aan hun sterfelijkheid, zij gemotiveerd zijn om de angst die hiermee gepaard gaat te reduceren. Dit is mogelijk door gebruik te maken van strategieën die gericht zijn op het naleven en beschermen van normen en waarden die belangrijk zijn in een bepaalde cultuur. Zo zullen mensen, die herinnerd zijn aan hun sterfelijkheid, geneigd zijn om een positievere attitude te uiten ten opzichte van mensen die dezelfde normen en waarden naleven dan zijzelf. Het gebruik van dit soort strategieën leidt vervolgens tot een verhoogde mate van eigenwaarde wat kan dienen als een buffer tegen sterfelijkheidsgerelateerde angst. In onze Westerse samenleving, waarin consumeren en materialisme verweven zijn met culturele overtuigingen, en geld een barometer van eigenwaarde is, kunnen excessief spenderen en het kopen van luxe producten functioneren als strategieën die eigenwaarde verhogen en zodoende doodsgerelateerde angst reduceren.

In Studie 2.1 lieten we zien dat sterfelijkheidsgerelateerde gedachten automatisch geactiveerd werden wanneer mensen voor een periode van 5 minuten werden blootgesteld aan een verzekeringsmerk. Bovendien bleek uit de resultaten dat deelnemers die blootgesteld werden aan het verzekeringsmerk (vergeleken met deelnemers in de controlegroep die niet blootgesteld werden aan een merk) de intentie hadden om meer geld uit te geven in de nabije toekomst als een manier om om te gaan met de geactiveerde doodsangst. Studie 2.2 maakte gebruik van een subtielere merkblootstelling door het logo van het verzekeringsmerk (versus een controlemerk) af te beelden op een muismat, die gedurende het hele onderzoek werd gebruikt. Deze studie richtte zich ook op een andere angstreducerende strategie, namelijk donatie aan goede doelen. Liefdadigheid kan gezien worden als normatief wenselijk gedrag in onze cultuur. Hierdoor is doneren aan goede doelen een passende strategie om doodsgerelateerde angst te reduceren. De resultaten demonstreerden dat deelnemers die gewerkt hadden met de muismat waarop het logo van het verzekeringmerk was gedrukt meer geld wilden doneren aan een goed doel dan deelnemers die gewerkt hadden met de muismat waarop het logo van een controlemerk was gedrukt. De laatste studie van dit hoofdstuk (2.3) liet zien dat zelfs wanneer mensen het verzekeringsmerk zo kort te zien kregen dat het niet bewust waarneembaar is (subliminale blootstelling), angstreducerende strategieën in werking worden gezet. In deze studie werd gevonden dat subliminale blootstelling aan het verzekeringsmerk (versus een frisdrankmerk) er toe leidt dat mensen hun eigen cultuur beschermen door het positief evalueren van producten die geproduceerd worden in hun eigen land (bijv. Gouda kaas en Grolsch bier) en het negatief evalueren van producten die geproduceerd worden in het buitenland (Carbonell Olijven en Corona bier).

De resultaten in dit hoofdstuk laten zien dat de (onbewuste) aanwezigheid van merken in de omgeving automatisch het doel om angst te reduceren kan activeren. Dit doel had vervolgens invloed op ongerelateerde 
consumentenreacties op verschillende heterogene domeinen. Consumenten zijn zich niet bewust van de effecten die merkblootstelling op hen kan hebben ongeacht of de blootstelling bewust of onbewust plaatsvond. Geen van de deelnemers in de studies legde een relatie tussen de merkblootstelling en hun spendeerintenties en evaluaties. De huidige studies bieden ondersteuning voor ons algemene idee dat evaluatieprocessen en gedrag beïnvloed kunnen worden door marketingcommunicaties zonder dat consumenten (en marketeers) zich hiervan bewust zijn.

HOOFDSTUK 3

In hoofdstuk 2 werd onderzocht hoe blootstelling aan merken in verschillende contexten automatisch doelen activeert en daaropvolgend gedrag beïnvloedt. In hoofdstuk 3 werd de nadruk gelegd op de interactie tussen de context waarin consumenten worden blootgesteld aan een merk en de context waarin ze vervolgens een merk evalueren of kiezen. Bovendien werd er in dit hoofdstuk gekeken naar de modaliteit (visueel of auditief) waarin een merk gecommuniceerd wordt. We hebben onderzocht hoe de overeenkomst tussen de modaliteit waarin een merk aanvankelijk gepresenteerd wordt (tijdens een reclame) en de modaliteit waarin een merk vervolgens geëvalueerd of gekozen wordt (tijdens de aankoopsituatie) ongemerkt merkattitudes en keuzes beïnvloedt. Samengevat, in dit hoofdstuk onderzochten we de manier waarop perceptuele kenmerken van marketingcommunicaties in interactie met perceptuele kenmerken van de situatie automatisch consumentenreacties beïnvloedt. Eerder onderzoek heeft laten zien dat herhaalde blootstelling aan een neutrale stimulus er voor zorgt dat de stimulus positiever beoordeeld wordt. Dit komt omdat de stimulus makkelijker verwerkt wordt wat leidt tot een positief gevoel van vloeiendheid. Dit gevoel wordt vervolgens toegeschreven aan de stimulus die op dat moment geëvalueerd wordt. Op basis van deze bevindingen veronderstelden we in dit hoofdstuk dat de effecten van voorafgaande merkblootstelling afhankelijk zijn van de congruentie tussen de communicatie modaliteit waarin de initiële merkblootstelling plaatsvindt en de modaliteit waarin merkevaluatie plaatsvindt. Er werd verwacht dat congruentie tussen modaliteiten een positief effect heeft op merkevaluaties en merkkeuzes vergeleken met incongruentie tussen modaliteiten. De vloeiendheid waarmee een merk verwerkt wordt, werd verondersteld als het onderliggende mechanisme. Er werd verwacht dat het gevoel van vloeiendheid geattribueerd werd aan het merk. Bovendien hebben we onderzocht of de effecten van communicatie congruentie sterker zijn wanneer consumenten zich expliciet of impliciet richten op de perceptuele kenmerken (bijv. modaliteit) van een merk in plaats van op de betekenis van het merk.

In Studie 3.1 werd gevonden dat merken makkelijker verwerkt worden wanneer de communicatie modaliteiten tussen de initiële merkblootstelling en de daaropvolgende herkenningsfase overeenkomen dan wanneer de communicatie modaliteiten van elkaar verschillen. Het lijkt er dus op dat congruentie tussen modaliteiten tot vloeiende verwerking leidt. Studie 3.2 toetste of congruentie tussen modaliteiten ook invloed heeft op merkevaluaties. De gevonden resultaten zijn in overeenstemming met onze hypotheses en laten zien dat congruentie tussen modaliteiten resulteerde in positievere evaluaties dan incongruentie tussen modaliteiten. Daarnaast liet deze studie zien dat dit effect sterker is wanneer deelnemers expliciet geïnstrueerd werden om zich te richten op de perceptuele kenmerken 
van het merk in plaats van op de betekenis van het merk. De stijl die consumenten gebruiken om het merk te verwerken speelt dus een belangrijke rol in congruentie effecten. Gegeven deze belangrijke rol van verwerkingsstijl werd in Studie 3.3 onderzocht of de resultaten zich laten vertalen naar marketingcontexten waar deze effecten op een meer 'natuurlijke' wijze worden opgeroepen. Om dit te onderzoeken hebben we gebruik gemaakt van bestaande en nieuwe merken. Van nieuwe merken hebben we nog geen kennis en associaties opgeslagen in ons geheugen waardoor we ons niet kunnen richten op de reeds opgeslagen betekenis van het merk. Hierdoor zullen consumenten zich bij het zien van nieuwe merken sterker richten op de perceptuele kenmerken van een merk. In Studie 3.3 werd dus verwacht dat congruentie effecten sterker zijn voor nieuwe dan voor bestaande merken. De resultaten van deze studie bieden ondersteuning voor onze hypotheses door te laten zien dat congruentie (vs. incongruentie) tussen modaliteiten resulteert in positievere merkevaluaties als consumenten zich richten op de perceptuele kenmerken. Er werd namelijk gevonden dat vooral nieuwe merken positiever geëvalueerd werden wanneer er sprake was van congruentie tussen communicatie modaliteiten. Studie 3.4 had tot doel de voorgaande resultaten te repliceren en te laten zien dat congruentie tussen modaliteiten ook effect heeft op feitelijk gedrag. In deze studie hebben we gebruik gemaakt van bestaande advertentieslogans waarin een merknaam genoemd werd en lieten we zien dat congruentie ook van invloed is op werkelijk gedrag.

De bevindingen in dit hoofdstuk laten zien dat de interactie tussen de context van blootstelling en de context van evaluatie automatisch effect heeft op merkevaluaties en keuzegedrag. Dit effect kan toegeschreven worden aan een onbewust proces van misattributie. Evaluaties en keuzes bleken beïnvloed te worden door een proces dat niet bewust herkend werd door de consument. Daarnaast hebben we een belangrijke moderator geïdentificeerd, namelijk verwerkingsstijl. De effecten van congruentie werden met name blootgelegd wanneer consumenten gericht waren op de perceptuele kenmerken van het merk. Hiermee dragen de huidige studies bij aan het idee dat de effecten van marketingcommunicaties op consumentenreacties automatisch kunnen zijn en afhankelijk zijn van verschillende contexten.

\section{HOOFDSTUK 4}

Het doel van hoofdstuk 4 was te onderzoeken of automatische effecten van marketingcommunicaties op consumentengedrag afhankelijk zijn van individuele verschillen tussen consumenten. Waar hoofdstuk 3 zich richtte op verschillende situationele contexten (modaliteit tijdens initiële blootstelling en modaliteit tijdens het evaluatieproces), lag de nadruk in hoofdstuk 4 op verschillen tussen consumenten met betrekking tot de focus op zichzelf in plaats van op de marketingstimulus. We hebben onderzocht hoe de interactie tussen de manier waarop een persuasieve boodschap geframed wordt en de (tijdelijk geactiveerde) regulatieve focus van de consument reacties ten opzichte van het onderwerp van de boodschap beïnvloedt. Uit eerder onderzoek weten we dat er twee verschillende regulatiemechanismen zijn. Als een consument gericht is op het bereiken van de persoon die hij idealiter zouden willen zijn dan neemt hij een promotie focus aan (nastreven van winst), en als een consument 
gericht is op het bereiken van de persoon die hij denkt te moeten zijn dan nemen hij een preventie focus aan (voorkomen van verlies). Consumenten kunnen 'regulatieve fit' ervaren wanneer (bijvoorbeeld) persuasieve boodschappen zo geframed worden dat ze in overeenstemming zijn met hun regulatieve focus. We verwachtten dan ook dat consumenten positiever reageren op een goed doel wanneer dit goede doel gepresenteerd wordt in een boodschap die aansluit bij hun regulatieve focus (fit) dan wanneer dit niet het geval is (non-fit). Daarnaast hebben we de hypothese getoetst dat regulatieve fit effecten sterker zijn voor consumenten met een hoog (versus) laag privaat zelfbewustzijn. Dit is gebaseerd op eerder onderzoek wat heeft laten zien dat vooral mensen met een hoog privaat zelfbewustzijn beïnvloed worden door externe informatie die potentieel relevant is voor het zelf. Er wordt verondersteld dat privaat zelfbewustzijn zelfkennis activeert waardoor het makkelijker wordt om informatie die aansluit bij deze kennis te verwerken. Net als in hoofdstuk 3 verwachtten we in hoofdstuk 4 dat deze ervaren vloeiendheid geattribueerd wordt aan het onderwerp van de boodschap die op dat moment gelezen wordt.

In Studie 4.1 vonden we bewijs voor onze hypotheses. De resultaten demonstreerden dat deelnemers die een persuasieve boodschap lazen die aansloot bij hun geactiveerde regulatieve focus meer bereidheid toonden om het goede doel te helpen dan deelnemers die een boodschap lazen die afweek van hun geactiveerde regulatieve focus. Zoals verwacht bleek dit effect sterker voor consumenten met een hoog privaat zelfbewustzijn dan voor consumenten met een laag privaat zelfbewustzijn. Studies $4.2 \mathrm{a}$ en $4.2 \mathrm{~b}$ lieten zien dat regulatieve fit en privaat zelfbewustzijn ook van invloed waren op feitelijke donaties. Beide studies lieten zien dat deelnemers meer geld doneerden aan een goed doel wanneer het beschreven werd in termen die congruent (vs. niet incongruent) waren aan hun regulatieve focus. Ook hier werd gevonden dat deze effecten sterker zijn voor consumenten met een hoog (versus laag) privaat zelfbewustzijn. Studie 4.3 had tot doel het onderliggende mechanisme van de rol van privaat zelfbewustzijn in regulatieve fit effecten te onderzoeken. We verwachtten en vonden dat regulatieve fit (versus non-fit) er toe leidt dat een boodschap makkelijker verwerkt wordt en vervolgens positiever geëvalueerd wordt. Dit proces bleek sterker te zijn voor consumenten met een hoog (versus) laag zelfbewustzijn. Dus consumenten met een hoog zelfbewustzijn vinden het makkelijker om informatie te verwerken die congruent (versus incongruent) is met hun regulatieve focus. Deze positieve ervaring van vloeiendheid wordt vervolgens geattribueerd aan het goede doel.

De resultaten die gerapporteerd zijn in dit hoofdstuk demonstreren dat de interactie tussen boodschap framing en de regulatieve focus van consumenten effect kan hebben op attitudes, gedragsintenties, en feitelijk gedrag zonder dat consumenten zich bewust zijn van de redenen hiervoor. Daarnaast vonden we dat deze effecten vooral optreden wanneer consumenten gericht zijn op hun privaat zelf. Deze bevindingen dragen bij aan de notie dat veel effecten van marketingcommunicaties zich manifesteren zonder dat consumenten zich bewust zijn van deze effecten. Bovendien laat dit hoofdstuk zien dat onbewuste effecten van marketinguitingen afhankelijk kunnen zijn van individuele verschillen tussen consumenten. 
In dit proefschrift is de rol van marketingcommunicatie in automatisch consumentengedrag onderzocht. We hebben dit gedaan door ons in het bijzonder te richten op de wijze waarop marketinguitingen onbewuste processen kunnen activeren. We hebben onderzoek gedaan naar de effecten van marketingcommunicaties zoals merken, slogans, en persuasieve boodschappen op consumentenreacties variërend van attitudes, gedragsintenties en feitelijk gedrag. Een van de meest belangrijke bevindingen is dat automatische effecten van marketingcommunicaties op consumentenreacties vaak contextafhankelijk zijn. Dit betekent dat het optreden van automatische marketingcommunicatie effecten afhankelijk is van contextuele factoren die betrekking kunnen hebben op de situatie en op de consument zelf zoals de omstandigheden waarin consumenten blootgesteld worden aan een marketinguiting en individuele verschillen in regulatiemechanismen. Hieruit kan geconcludeerd worden dat het belangrijk is om rekening te houden met situationele en individuele verschillen tussen consumenten en de omstandigheden waarin ze geconfronteerd worden met marketinguitingen. Alleen dan is het mogelijk om een volledig beeld te krijgen van de manier waarop marketingcommunicaties consumentenprocessen en gedrag beïnvloeden. Het lijkt erop dat marketinguitingen niet altijd tot dezelfde reacties leiden onder alle omstandigheden bij alle consumenten. Door de contextafhankelijkheid van automatische consumentenreacties te onderzoeken hopen we de volgende stap te hebben gezet in het verwerven van meer kennis over automaticiteit in consumenten contexten. 
Acknowledgments (dankwoord) 
Het waren 4 fantastische jaren!

Al waren er natuurlijk ook momenten waarop ik het even niet meer zag zitten. Echter, deze momenten zijn, dankzij de mensen in mijn omgeving, op één hand te tellen. Zij hebben er voor gezorgd dat ik het plezier in 'promoveren' geen moment verloren ben. Een aantal van deze mensen wil ik hier graag persoonlijk bedanken.

Allereerst wil ik mijn promotor, Ad Pruyn, bedanken. Ad, ook al kon je soms erg kritisch zijn, je hebt me altijd het gevoel gegeven dat je vertrouwen in mij had. Daarnaast heb je er voor gezorgd dat ik me niet te veel liet afleiden door onderwijstaken, projecten buiten mijn proefschrift en andere activiteiten. Nu pas zie ik hoe belangrijk dat was. Ook wil ik mijn co-promotor/dagelijks begeleider, Bob Fennis, bedanken. Bob, jij neemt je taak als dagelijks begeleider heel letterlijk. Ik kan me geen dag herinneren dat jouw deur niet openstond voor al mijn vragen, opmerkingen en het delen van de nieuwste roddels. Naast alle gesprekken die we over mijn onderzoek en statistiek hebben gehad, heb je me veel geleerd over het vak van wetenschapper. Het is moeilijk om niet meegevoerd te worden in jouw enthousiasme; je hebt me zelfs weer aan het sporten gekregen! lk denk met heel veel plezier terug aan al die uren die we discussiërend in het zwembad, op de fiets en hardlopend hebben doorgebracht.

I am very grateful to my committee members. Thank you for your time and effort in reading my dissertation!

Promoveren aan de vakgroep Marketingcommunicatie en Consumentenpsychologie is een waar genoegen. Thomas, Peter, Mirjam, Jos, Monique en Vanessa, hartelijk dank voor de goede sfeer, betrokkenheid en alle leuke momenten in de 'vrijhof'. Karin, Joost, en Loes, jullie waren de beste collega-aio's die ik me maar kon wensen. Niet alleen waren jullie altijd bereid om mijn papers van feedback te voorzien, jullie boden ook altijd een luisterend oor wanneer ik even stoom af moest blazen over zeurende reviewers, niet significante data en andere onderzoeksperikelen.

Ook alle andere aio's van de voormalige afdeling CW wil ik bedanken voor hun bijdrage aan de 'promovendi-club'. Het was erg leerzaam om te discussiëren met onderzoekers uit zoveel verschillende richtingen. Daarnaast wil ik het NESCoR bedanken voor het aanbieden van inspirerende cursussen en workshops.

Kathleen, thank you very much for your all your supportive comments and inspiring feedback, it is great working with you!

Enny, het is altijd weer leuk om met jou over onderzoek (en andere dingen) te praten. Ik hoop dat, nu ik ook in Amsterdam woon, we onze samenwerking weer kunnen oppakken.

Claartje, het is een raar idee dat we elkaar nog geen 4 jaar geleden ontmoet hebben. Eerst als collega's maar al snel als vriendinnen. Jij kunt als geen ander meeleven met de leuke en ook minder leuke momenten in mijn leven. Het is ongelooflijk hoeveel we de afgelopen jaren samen hebben beleefd; van leuke vakanties, tot aan gekmakende all- 
inclusive schrijfweken en afzien tijdens de marathon (dat nooit meer!). Ik hoop dat we in de toekomst nog veel zullen delen en dat we blijven samenwerken zodat de hele collectie van Warholl uiteindelijk op een congresposter verschijnt. Wist je trouwens dat de afstand tussen onze huisjes nu in Amsterdam en toen in Enschede precies gelijk is (3,3 km; www.routenet.nl)?

'La Familia' (Clara, Henrik, Joris, Kell, Maarten en Marc), wat heerlijk dat jullie een deel van mijn leven zijn! 'Gracias' voor alle gezelligheid tijdens de vele vakanties, concertjes, etentjes, cava's en biertjes. Het is echt 'mejor para todos' om hier nog lang mee door te gaan.

Annemarie, sinds onze productieve samenwerking tijdens 'informatiekunde II' zijn we elkaar nooit meer uit het oog verloren. We hebben allebei voor sociale psychologie, promoveren, en (uiteindelijk) de Randstad gekozen. Het is fijn om met jou in de buurt deze 'zelfde' weg te bewandelen. Dankjewel voor alle leuke momenten!

Rachel, ook al was je gedurende mijn hele promotietijd ver weg en was het moeilijk om elkaar te zien, het is goed om te weten dat we altijd vriendjes zullen blijven, waar op de wereld we ons ook bevinden.

Jiska, Lotje, Joyce, Martijn \& Angela, Ivo en Michiel, dank jullie wel voor jullie interesse in mijn onderzoek en voor de ontspannende momenten die ik met jullie beleefd heb.

Ben \& Tineke, Bas \& Jana, Jorrit \& Femke, het is fijn om jullie als (schoon)familie te hebben. Op jullie eigen manier hebben jullie allemaal bijgedragen aan de totstandkoming van dit proefschrift. Bedankt hiervoor.

Papa \& mama, het geeft een goed gevoel te weten dat jullie achter mij staan wat ik ook doe of wil. Na veel te hebben geïnvesteerd in mijn 'danscarrière' was het voor jullie een hele verassing dat ik na het afronden van de dansacademie besloot om 'echt' te gaan studeren en geen baan te zoeken als danseres. Ik kan me nog herinneren dat jullie vroegen 'is dat nou nodig?'. Mijn korte 'ja' als antwoord was genoeg om direct jullie volledige steun te krijgen. Dank jullie wel voor alles!

Lieve Maarten, natuurlijk heel erg bedankt voor al je praktische hulp bij de totstandkoming van mijn experimenten. Logo's ontwerpen, merknamen verzinnen, merknamen inspreken, niets was je te gek. Maar ik ben vooral blij dat je er altijd voor me was, zonder jou was het allemaal een stuk minder leuk geweest! lk hoop dat ik nog lang van jouw humor mag genieten, jouw originaliteit verbaast me elke keer weer! 